\title{
Role and Therapeutic Potential of Melatonin in Various Type of Cancers
}

This article was published in the following Dove Press journal: OncoTargets and Therapy

\author{
Sangiliyandi Gurunathan' \\ Muhammad Qasim (1D) \\ Min-Hee Kang (D' \\ Jin-Hoi Kim (D) \\ 'Department of Stem Cell and \\ Regenerative Biotechnology, Konkuk \\ University, Seoul, 05029, Korea; ${ }^{2}$ Center \\ of Bioengineering and Nanomedicine, \\ Department of Food Science, University \\ of Otago, Dunedin, 9054, New Zealand
}

Correspondence: Jin-Hoi Kim Department of Stem Cell and Regenerative Biotechnology, Konkuk University, Seoul, 05029, Korea

Tel +82 24503687

Fax +82 25444645

Email jhkim54I@konkuk.ac.kr

\begin{abstract}
Cancer is a large group of diseases and the second leading cause of death worldwide. Lung, prostate, colorectal, stomach, and liver cancers are the most common types of cancer in men, whereas breast, colorectal, lung, cervical, and thyroid cancers are the most common among women. Presently, various treatment strategies, including surgical resection combined with chemotherapy, radiotherapy, nanotherapy, and immunotherapy, have been used as conventional treatments for patients with cancer. However, the clinical outcomes of advanced-stage disease remain relatively unfavorable owing to the emergence of chemoresistance, toxicity, and other undesired detrimental side effects. Therefore, new therapies to overcome these limitations are indispensable. Recently, there has been considerable evidence from experimental and clinical studies suggesting that melatonin can be used to prevent and treat cancer. Studies have confirmed that melatonin mitigates the pathogenesis of cancer by directly affecting carcinogenesis and indirectly disrupting the circadian cycle. Melatonin (MLT) is nontoxic and exhibits a range of beneficial effects against cancer via apoptotic, antiangiogenic, antiproliferative, and metastasisinhibitory pathways. The combination of melatonin with conventional drugs improves the drug sensitivity of cancers, including solid and liquid tumors. In this manuscript, we will comprehensively review some of the cellular, animal, and human studies from the literature that provide evidence that melatonin has oncostatic and anticancer properties. Further, this comprehensive review compiles the available experimental and clinical data analyzing the history, epidemiology, risk factors, therapeutic effect, clinical significance, of melatonin alone or in combination with chemotherapeutic agents or radiotherapy, as well as the underlying molecular mechanisms of its anticancer effect against lung, breast, prostate, colorectal, skin, liver, cervical, and ovarian cancers. Nonetheless, in the interest of readership clarity and ease of reading, we have discussed the overall mechanism of the anticancer activity of melatonin against different types of cancer. We have ended this report with general conclusions and future perspectives.
\end{abstract}

Keywords: melatonin receptors, antioxidant, antiangiogenic, anticancer, apoptosis, angiogenesis, metastasis, chemotherapy, combination therapy, molecular mechanisms

\section{Introduction}

The International Agency for Research on Cancer predicted that there were 18.1 million new cancer cases and 9.6 million cancer deaths in 2018. ${ }^{1}$ Lung cancer is the most commonly diagnosed cancer and the leading cause of cancer death in both sexes, closely followed by female breast cancer. However, the degree of mortality depends on the degree of economic development and the associated social and lifestyle factors of individual countries. ${ }^{2}$ Cancer is a major killer disease in both developing and developed countries. According to the American Cancer Society, in 2019, $1,762,450$ new cancer cases and 606,880 cancer deaths were predicted to occur in the 
United States. ${ }^{3}$ Among various types of cancer, lung cancer is the most commonly diagnosed in both men and women, followed by breast cancer in women, prostate cancer, and colorectal cancer. Women are afflicted with breast cancer, which is the most commonly diagnosed cancer and the leading cause of cancer death, followed by colorectal and lung cancer. ${ }^{2}$ Childhood cancer is the second leading cause of death among children aged 1-14 years, and its rates have increased by $0.6 \%$ per year on average since 1975 . There are several types of cancer, and several therapies are available, such as radiation, stem cell, chemo-, immuno-, hormone-, and targeted drug therapies. Currently, patients with cancer depend on clinical treatment, such as surgery, radiotherapy, and chemotherapy. In addition, some natural products have shown potential for the prevention and treatment of cancer. ${ }^{4}$ Therefore, studies on cancer and anticancer therapies have attracted immense interest and attention in the clinical field.

Cancer cells have the following seven specific properties: 1) self-sufficiency in growth signals, 2) insensitivity to anti-growth signals, 3) evasion of apoptosis, 4) limitless replicative potential (the telomerase and telomere pathway), 5) sustained angiogenesis, 6) tissue invasion and metastasis, and 7) genome instability. ${ }^{5,6}$ Generally, tumors are classified according to the differentiated part. However, few neuroendocrine tumor cells are found among dedifferentiated and anaplastic tumor cells; such cases are classified based on the origin of cells. These neuroendocrine cells are believed to be redifferentiated exocrine-derived tumor cells. ${ }^{7}$ The features distinguishing malignant from benign (nonmalignant) tumors are well established, including rapid growth, increased cell turnover, invasive growth, metastases, and vascular or lymphatic channel invasion. Benign tumors show chromosome aberrations. ${ }^{8}$ In many tumors classified as adenocarcinomas based on glandular growth pattern and/or tumor cell positivity for PAS or Alcian blue, which are believed to contain mucin, there are tumor cells with neuroendocrine properties. ${ }^{9}$ Classification of tumors based on the cell of origin of carcinomas seems to be the best system to help understand the biological significance of carcinogenesis, gain insight on new possibilities for prevention and early treatment, and possibly develop new drugs for the treatment of tumors. ${ }^{9}$

Melatonin (MLT), a neuroendocrine active substance chemically composed of $N$-acetyl-5-methoxytryptamine, is synthesized and secreted by the pineal gland and is highly conserved from prokaryotes to eukaryotes (Figure 1). MLT regulates various biological functions, including circadian rhythm, and exerts free radical-scavenging, immunemodulating, anti-inflammatory, antitumor, antiaging, and endocrine-regulatory effects, thus affecting the occurrence, development, and treatment of cancer ${ }^{10,11}$ (Figure 2).

The production of MLT is strongly affected by physiological conditions; MLT levels are higher at night and lower at noon. ${ }^{12,13}$ Loss of circadian rhythm eventually leads to MLT abnormalities in patients with cancer. ${ }^{14}$ MLT plays a crucial role in human physiology and pathology by acting as a cell protector in immunomodulation, antioxidant processes, and hematopoiesis. ${ }^{15-17}$ Furthermore, MLT exhibits oncogenic

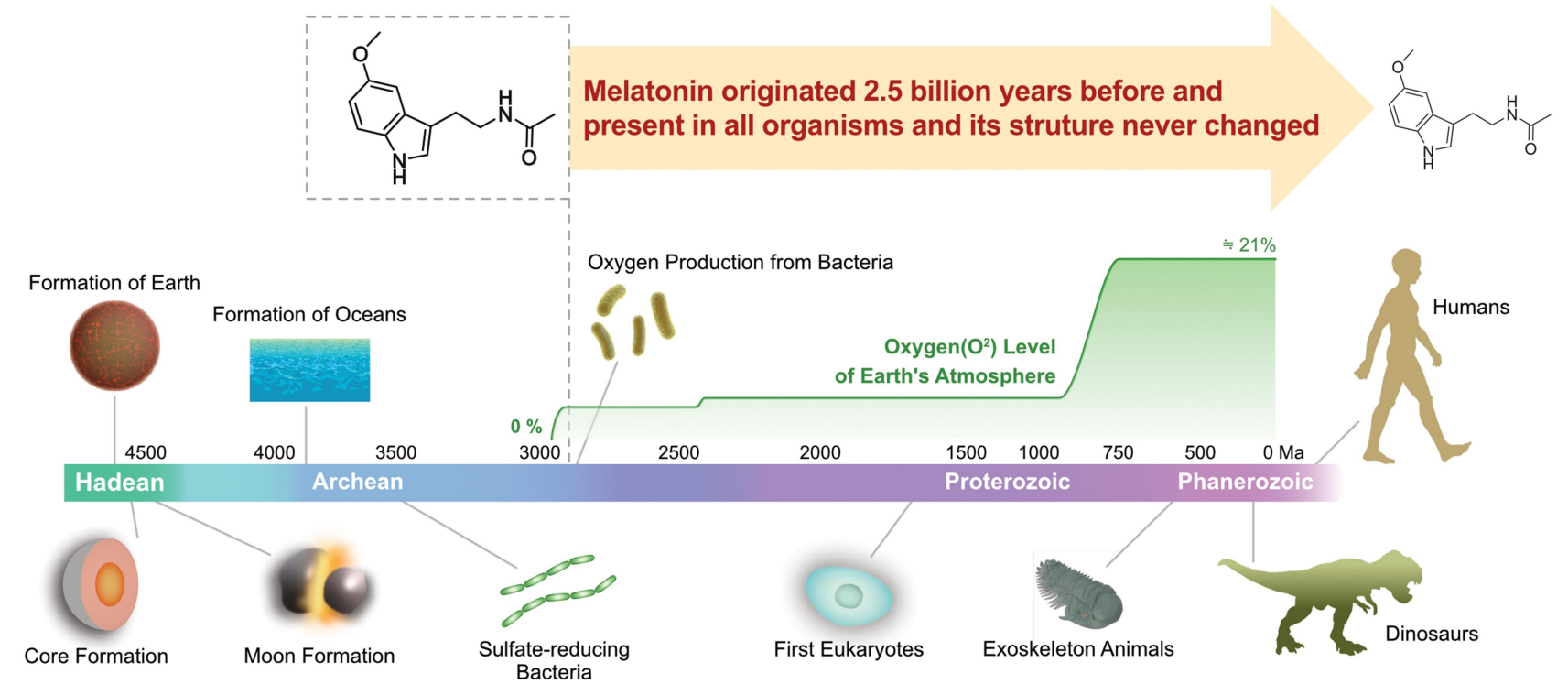

Figure I Conserved nature of MLT from prokaryotes to eukaryotes. 


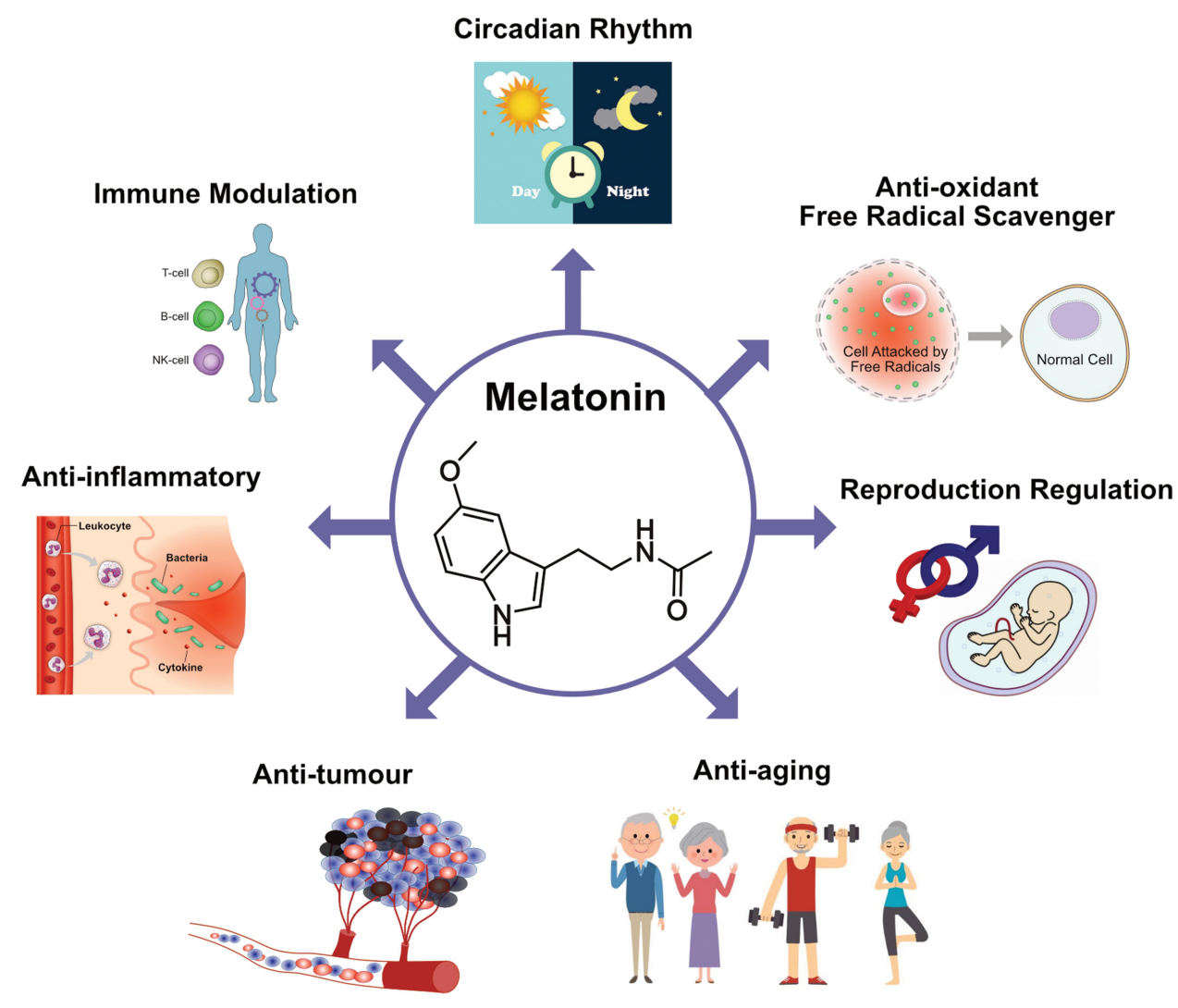

Figure 2 Multifunctional aspects of MLT.

properties through receptor-dependent and -independent mechanisms. ${ }^{18}$ It also regulates antioxidant activity, apoptosis, tumor metabolism and cancer immunity, inhibition of angiogenesis and migration, and prevention of circadian disruption through receptor-independent mechanisms. ${ }^{18-20}$ Studies have reported that MLT levels are critical for cancer development; however, a low level of nocturnal MLT increases tumor growth. Interestingly, patients with metastatic lung and colorectal tumors treated with MLT showed stabilization of cancer and exhibited improved quality of life. ${ }^{21}$ Preclinical and in vitro studies revealed that MLT can delay tumor development via membrane receptor-dependent and -independent mechanisms at the initiation, promotion, progression, and malignant metastasis phases. ${ }^{11,22}$ Pinealectomy stimulates, whereas MLT inhibits the growth and metastasis of various cancers, including lung, liver, ovary, pituitary, and prostate cancers as well as melanoma and leukemia. ${ }^{23}$ The association between MLT and cancer has been documented, and several epidemiological studies substantiate the involvement of MLT in cancer. ${ }^{24,25}$ MLT is considered to be a multifunctional compound that controls various functions, such as circadian rhythm, and exerts free radical-scavenging, reproduction-regulatory, antiaging, anticancer, anti-inflammatory, and immune-modulatory effects (Figure 2). The goal of this review is to summarize the recent literature on the history, epidemiology, risk factors, therapeutic effect, and clinical significance of MLT alone or in combination with chemotherapeutic agents or radiotherapy, as well as its anticancer mechanism in lung, breast, prostate, colorectal, skin, liver, cervical, and ovarian cancers.

\section{Role and Therapeutic Potential of MLT in Lung Cancer}

According to Global Cancer Statistics 2018, 2.1 million new lung cancer cases and 1.8 million deaths were predicted in 2018, representing approximately 1 in $5(18.4 \%)$ cancer deaths. Lung cancer remains the leading cause of cancer incidence and mortality. In both sexes, lung cancer is the most commonly diagnosed cancer $(11.6 \%$ of the total cases) followed by breast cancer in women $(11.6 \%)$, prostate cancer $(7.1 \%)$, and colorectal cancer $(9.2 \%)$, stomach cancer $(8.2 \%)$, and liver cancer $(8.2 \%)$ in terms of mortality. Lung cancer is the leading cause of cancer death among men and women in 93 and 28 countries, respectively. Several studies have reported the involvement of MLT in lung cancer. To evaluate the relationship between 
MLT levels and T lymphocyte subsets in patients with metastatic solid neoplasm, the study was performed in 28 patients, comprising 10 and 18 patients with breast cancer and non-small cell lung cancer (NSCLC), respectively. The patients were not treated with any medications for metastasis. The analyses from this study revealed unusually high MLT levels and a low $\mathrm{T}$ helper/suppressor ratio (CD4/CD8) in $10 / 28$ and in $11 / 28$ patients, respectively. ${ }^{26}$ To investigate the effect of immunomodulation of interleukin (IL)-2 in solid neoplasms, authors designed with low-dose IL-2 subcutaneous therapy plus MLT for advanced solid neoplasms other than renal cancer and melanoma, which are generally resistant to IL-2 alone. The results showed that objective tumor regression was achieved in 17/82 (21\%) patients. Stabilization of disease was observed in 30 patients, whereas disease progression was observed in 35 patients. The lack of progression was associated with a significantly higher increase in mean lymphocyte and eosinophil counts as well as a significantly lower increase in mean neopterin levels. ${ }^{27}$ To elucidate the effect of MLT on chemotherapy toxicity, a study involving 80 patients with metastatic solid tumors. Patients with lung cancer were treated with cisplatin and etoposide, those with breast cancer were treated with mitoxantrone, whereas those with gastrointestinal tract tumor received 5-fluorouracil (5-FU) plus folates (FA). Patients were randomized to receive chemotherapy alone or chemotherapy plus MLT showed significantly low presentations of thrombocytopenia, malaise, and asthenia. ${ }^{28}$

In a study, the in vivo immunoinflammatory effects of IL-12 were investigated by analyzing the secretions of neopterin, soluble IL-2 receptor (SIL-2R), tumor necrosis factor (TNF)- $\alpha$, IL-2, and IL-6. IL-12 at $1.25 \mu \mathrm{g} / \mathrm{kg}$ body weight was subcutaneously administered to patients with renal cell cancer in the morning once a week for three consecutive weeks. The results revealed that the mean serum levels of neopterin, SIL-2R, and TNF significantly increased in response to IL-12, but there was no significant change in IL-6 and IL-2 mean concentrations. ${ }^{29}$ A study was conducted to evaluate the daily secretion of dehydroepiandrosterone-sulfate (DHEAS) in a group of patients with early and advanced cancer. The study group consisted of 70 patients with solid tumors. The findings suggested that there was no significant difference in the mean serum levels of DHEAS between controls and non-metastatic patients. Conversely, patients with metastases in visceral locations showed significantly lower mean levels of DHEAS, irrespective of the tumor histotype, compared to either the controls or non-metastatic patients. ${ }^{30}$ To evaluate the combined effects of MLT and chemotherapeutic agents in patients with advanced cancer and poor clinical status, 250 patients with metastatic solid tumors received MLT plus chemotherapy, or chemotherapy alone. The chemotherapy consisted of cisplatin plus etoposide or gemcitabine alone for lung cancer; doxorubicin alone, mitoxantrone alone, or paclitaxel alone for breast cancer; 5-FU plus folinic acid for gastrointestinal tumors; and 5-FU plus cisplatin for head and neck cancers. The results showed that the objective tumor regression rate was significantly higher in patients treated with MLT and chemotherapeutic agents, as mentioned above, than in those who received chemotherapy alone.

A study was conducted involving patients with metastatic lung cancer treated with a combination therapeutic approaches containing cisplatin and etoposide, the study included 20 patients treated with cisplatin plus etoposide. The results of this study revealed that the concentrations of hemoglobin in the blood significantly decreased in both groups of patients. However, the decrease in hemoglobin levels observed in patients treated with chemotherapy alone was significantly higher than that in patients concomitantly treated with 5-MTT. These preliminary results indicated that the concomitant administration of 5-MTT may reduce cisplatin-induced anemia in patients with cancer. ${ }^{31}$ The study was conducted to assess the effect of MLT on the 5-year survival of patients with metastatic NSCLC, the patients were subjected to a chemotherapeutic regimen consisting of cisplatin and etoposide, with or without the concomitant administration of MLT. The results showed that both the overall tumor regression rate and 5-year survival were significantly higher in patients concomitantly treated with MLT. $^{32}$ In another study, the effect of various regimens of MLT treatment on the development of mammary tumors in HER2/neu transgenic mice was investigated. Female HER-2/neu mice were exposed to interrupted treatments or constant MLT treatment $(20 \mathrm{mg} / \mathrm{L})$. MLT treatment slowed down age-related disturbances in estrous function and promotion of mammary carcinogenesis, with the group exposed to interrupted treatment with the hormone showing the highest degree of improvement. Constant treatment with MLT decreased the incidence and size of mammary adenocarcinomas as well as the incidence of lung metastases, compared with controls. ${ }^{33}$ The study consisted of 370 patients who were randomized to receive chemotherapy alone or chemotherapy plus MLT. Patients 
with colorectal cancer were treated with oxaliplatin plus 5-FU, or weekly CPT-11 or 5-FU and FA. Patients with NSCLC received cisplatin plus etoposide or cisplatin plus gemcitabine, whereas those with gastric cancer received cisplatin, epirubicin, 5-FU, and FA or weekly 5-FU plus FA. The results showed that tumor regression was significantly higher in patients concomitantly treated with MLT than in those treated with chemotherapy alone. ${ }^{34}$ Another study was conducted to determine the efficacy of MLT or 5-MTT with chemotherapy; 100 patients receiving randomized chemotherapy with MLT or 5-MTT exhibited better response and significant reduction of chemotherapyrelated toxicities, namely thrombocytopenia and neurotoxicity. ${ }^{35}$ MLT not only potentiates anticancer activity but also protects cells from adverse conditions caused by anticancer drugs. For example, MLT inhibited doxorubicin (DOX)-induced senescence in a dose-dependent manner by blocking the DOX-induced G2/M phase cell cycle arrest and decreased cyclin $\mathrm{B}$ and cdc2 expression in A549 and IMR90 cells. Furthermore, MLT decreased DOX-induced reactive oxygen species (ROS) levels, mitochondrial respiration, and loss of mitochondrial membrane potential in an MLT receptor-independent manner. ${ }^{36}$ Zhou et $\mathrm{al}^{37}$ designed a study to investigate the effect of MLT on the migration of human lung adenocarcinoma A549 cells and its mechanism. The cells treated with MLT showed significant inhibition of cell viability and migration. The expression levels of OPN and MLCK, as well as the phosphorylation of MLC in A549 cells were reduced, whereas the expression of occludin was conversely elevated. The combination of MLT and cisplatin increased cytotoxicity, apoptosis, and cell cycle arrest induced by the chemotherapeutic agent cisplatin in human lung adenocarcinoma cisplatin-sensitive cell line (SK-LU-1). Combined treatment increased apoptosis by elevating mitochondrial membrane depolarization, activating caspases-3/7, and inducing cell cycle arrest in the S phase, compared with treatment with cisplatin alone. ${ }^{38}$ MLT suppresses lung cancer metastasis by inhibiting epithelial-mesenchymal transition by targeting twisting family transcription factors (Figure 3). Furthermore, this effect was mediated by the MT1 receptor, PLC, p38/extracellular signal-regulated protein kinase (ERK), and $\beta$-catenin signaling cascades. ${ }^{39}$ The effect of MLT receptors MT1 and MT2 was investigated in NSCLC and nonmalignant lung tissue using tissue microarrays. The expression of both receptors was higher in NSCLC than in nonmalignant lung tissue. Higher levels of MT1 and MT2 expression were observed in squamous cell carcinomas than in adenocarcinomas. ${ }^{40}$ A study was conducted to elucidate whether histone deacetylase is

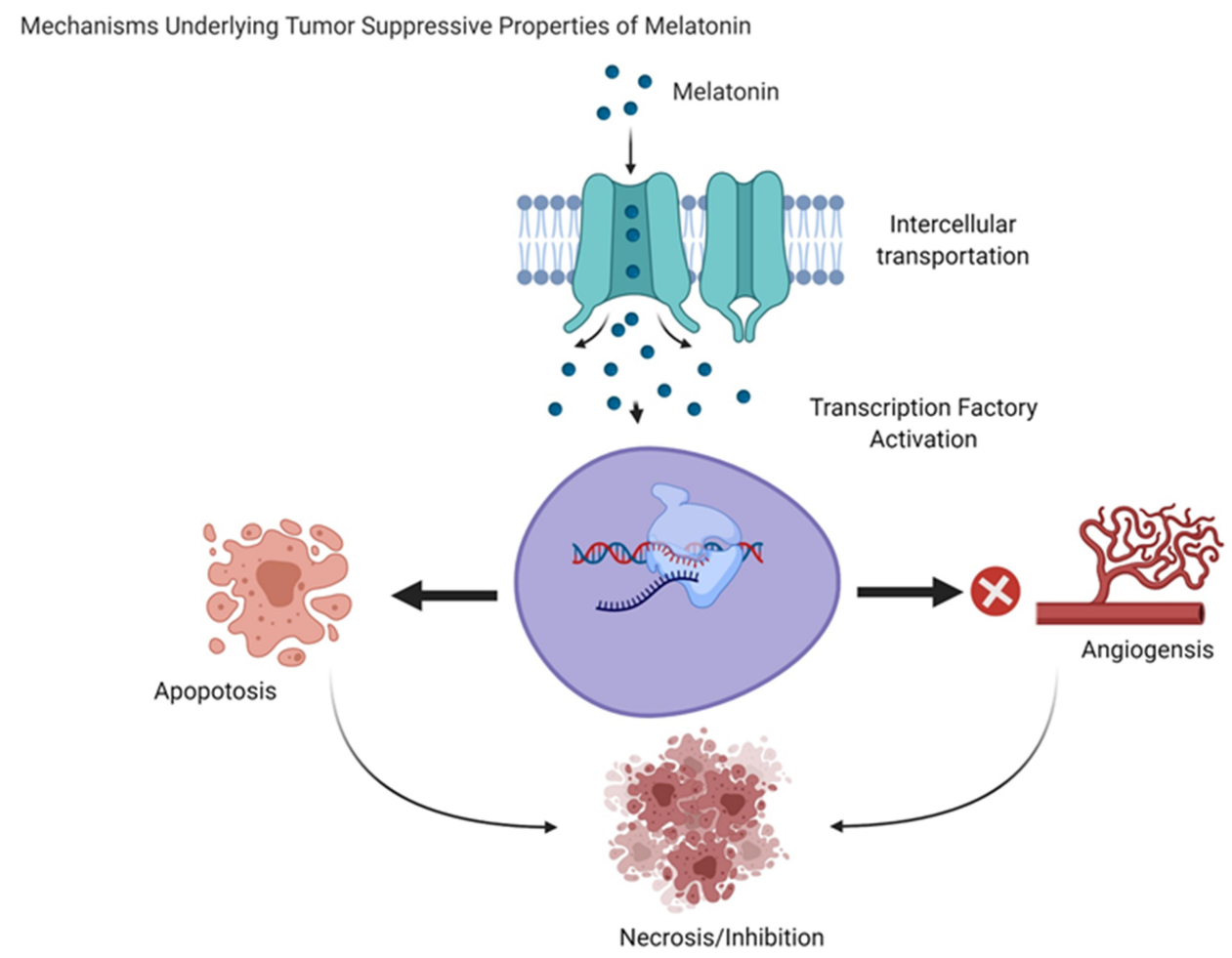

Figure 3 Tumor suppressive properties of MLT on lung cancer by targeting family of transcription factors. 
involved in tumor suppression and enhanced apoptosis in NSCLC after MLT treatment. To verify this hypothesis, 337 patients who underwent NSCLC surgery were recruited in this study. The findings revealed that patients with NSCLC having high HDAC9 expression showed worse overall survival and poor prognosis. HDAC9 knockdown significantly reduced NSCLC cell growth and induced apoptosis both in vivo and in vitro. Interestingly, MLT administration markedly inhibited NSCLC cell proliferation, metastasis, and invasion, as well as promoted apoptosis and decreased the HDAC9 level of NSCLC cells. HDAC9 knockdown increases the anticancer activities of MLT treatment. Additionally, an in vivo study showed that HDAC9 knockdown increased anticancer activity in xenograft tumors. ${ }^{41}$ Recently, we reported the combination effect of palladium nanoparticles and MLT in A549 lung epithelial adenocarcinoma cells. These findings suggest that the combination of palladium nanoparticles and MLT increases cytotoxicity by decreasing cell viability and cell proliferation. Furthermore, these combinations increase the levels of various oxidative stress markers, including leakage of lactate dehydrogenase, increased intracellular protease, decreased membrane integrity, and increased levels of ROS, malondialdehyde (MDA), nitric oxide, protein carbonyl content, lipid hydroperoxide, and 8-isoprostane, as well as increased mitochondrial dysfunctions. In addition, palladium nanoparticles and MLT induced apoptosis and oxidative DNA damage due to the accumulation of 4-hydroxynonenal (HNE), 8-oxo-2'deoxyguanosine (8-OhdG), and 8-hydroxyguanosine (8-OHG). The combination effect increased mitochondriamediated stress and apoptosis, which was confirmed by the increased expression levels of apoptotic genes. ${ }^{42}$ The antiproliferative and antitumor effects of MLT were investigated in B16-F10 cell murine melanoma models. MLT reduced the growth rate and migration of B16-F10 cells, induced G2/M cell cycle arrest, and altered cytoskeletal organization. The in vitro data are in accordance with the in vivo findings. ${ }^{43}$ Pourhanifeh et al reviewed the impact of MLT on non-small cell lung cancer and reported that prevents tumor metastasis via inducing apoptosis and restraining the autonomous cell proliferation due to its multifunctional aspects such as oncostatic, pro-oxidant and anti-inflammatory effects. ${ }^{44}$ Combination of chemotherapy and MLT increases survival and improved quality of life in patients with NSCLC. The administration of $1 \mathrm{mM}$ of MLT $1 \mathrm{~h}$ before irradiation of A549 cells suppresses cell viability without activating apoptotic pathway. ${ }^{45}$ MLT directly reduces osteoclast differentiation, bone resorption activity and promotes apoptosis of mature osteoclasts and also MLT inhibits RANKL production in lung and prostate cancer cells by downregulating the p38 MAPK pathway ${ }^{46}$ Recently, we have shown that combination of MLT and retinoic acid induced cytotoxicity and apoptosis in human lung epithelial adenocarcinoma cells A549 and H1229 by enhancing oxidative stress and decreasing mitochondrial dysfunctions. ${ }^{42}$

\section{Role and Therapeutic Potential of MLT in Breast Cancer}

Breast cancer is the most commonly diagnosed cancer and rate of breast cancer is extremely high compared with other cancers in women of both developing and developed countries. $^{2}$ The primary risk factors for breast cancer are prolonged endogenous hormonal exposures, and the best prevention method is the long-term duration of breastfeeding. MLT enhanced chemotherapy irrespective of the type of tumor and chemotherapeutic regimen in various patients with cancer, as shown by a study involving 10 patients with breast cancer in both sexes. ${ }^{47}$ MLT combined with the synthetic progestin norethisterone suppressed the pituitaryovarian axis. Administration of $300 \mathrm{mg}$ MLT caused significantly decreased mean LH levels compared with those in eight non-medicated controls. Patients with breast cancer in India had a low level of MLT in urine. ${ }^{48}$ Tamarkin et $\mathrm{al}^{49}$ found that the increased nocturnal MLT concentration in plasma was significantly decreased in women with estrogen receptor (ER)-positive breast tumors, indicating that an inverse correlation existed between ER levels and peak MLT values. Physiological concentrations of MLT not only alter the morphology of estrogen-responsive MCF-7 human breast cancer but also inhibit the growth of cancer cells. The physiological concentration of MLT potentially inhibits the growth of MCF-7 cells than supraor subphysiological levels of MLT, which are completely ineffective in impeding breast cancer cell proliferation. Interestingly, precursors and metabolites of MLT, such as serotonin, $\mathrm{N}$-acetylserotonin, and 6-hydroxyMLT, do not inhibit MCF-7 cell growth. ${ }^{50,51}$ MLT exhibited antitumor effects in MCF-7 cells through a cell-cycle-specific mechanism by delaying the entry of MCF-7 cells into mitosis and eventually leading to differentiation. ${ }^{52}$ MLT inhibits tumor-promoter prolactin-induced mitogenic activity in MCF-7 and ZR75-1 human breast cancer cells by blocking PRLR-mediated growth signal. ${ }^{53}$ Sequential 
administration of MLT and retinoic acid on the ERpositive MCF-7 human breast tumor cell line resulted in the complete cessation of cell growth and a reduction in the number of cells through activation of apoptotic pathways, which leads to apoptosis by decreasing $\mathrm{Bcl}-2$ expression, increasing Bax expression, and altering growth factor-beta 1 (TGF- $\beta 1$ ) expression. Sequential treatment had no apoptotic effect in ER-negative MDA-MB-231 and BT-20 breast tumor cells. ${ }^{54}$ MLT reduces the invasiveness of MCF-7 cells, causing a decrease in cell attachment and cell motility. Culture of tumor cells in the presence of MLT (1 $\mathrm{nM}$ ) increased the membrane staining for E-cadherin and $\beta 1$ integrin. To corroborate the in vitro study, in vivo experiments were conducted in ovariectomized athymic nude mice implanted with $17 \beta$-estradiol pellets and inoculated with $5 \times 10^{6} \mathrm{MCF}-7$ cells in the inguinal mammary fat pad, and the results suggested that MLT decreased the tumorigenicity of these tumor cells. ${ }^{55}$ MLT inhibits the proliferation of MCF-7 cells through inhibition of estrogen-elicited cyclin D1 induction. ${ }^{56}$ The nanomolar concentration of MLT inhibits cell proliferation, increases the expression of p53 and p21WAF1 proteins, modulates the length of the cell cycle, decreases the metastatic capacity of these cells, and counteracts the stimulatory effect of estradiol on cell invasiveness. ${ }^{55,57,58}$ MLT at the lowest concentration of $1 \mathrm{nM}$ and overexpression of MLT G protein-coupled receptor significantly inhibited the growth of MCF-7 and vt-MCF 7 cells. ${ }^{59}$ MLT exerted significant growth-inhibitory effects on MCF-7 cells in a biphasic manner, such as at the early time of incubation in a TGF- $\beta 1$-dependent manner, in which programmed cell death is associated with a significant increase in the $\mathrm{p} 53 / \mathrm{MDM} 2$ ratio and in AIF release, without modifications in caspase activity or cleaved-PARP levels. In contrast, in the latter period, the long incubation time of MLT activates caspases-9 and -7 and cleaved-PARP, parallel with the downregulation of the Bcl-2/Bax ratio. The study concluded that two different types of apoptotic processes are triggered by MLT in MCF-7 cells: an early, TGF- $\beta 1$ and caspase-independent response, and a late apoptotic TGF- $\beta 1$-dependent process where activated-caspase-7 is likely to be the terminal effector. ${ }^{60}$ MLT inhibits breast cancer growth by modulating miRNA and expression of miRNA-related genes. ${ }^{61}$ Several studies have reported that the combination of MLT and chemotherapeutic agents potentiates anticancer activity. The combination of MLT with all-trans retinoic acid and somatostatin inhibits cell viability through alteration of $\mathrm{Ca}^{+}$and voltage-activated $\mathrm{K}^{+}(\mathrm{BK})$ channels, and impairments of Notch-1 and epidermal growth factor (EGF)-mediated signaling. In addition, the combined treatment caused a decrease in the mitochondrial membrane potential and intracellular ATP production as well as the induction of necrotic cell death. Taken together, these results suggest that the administration of MLT with alltrans retinoic acid and somatostatin exhibited significant therapeutic potential in breast cancer. ${ }^{62}$ The antiangiogenic effect and regulation of vascular endothelial growth factor (VEGF) in breast cancer cells was investigated using MLT. MLT inhibits angiogenic processes by decreasing production of VEGF in co-culture of human breast cancer cells (MCF-7) with human umbilical vein endothelial cells (HUVECs). This study suggests that MLT may play a role in the paracrine interactions between malignant epithelial cells and proximal endothelial cells through a down regulatory action on VEGF expression in human breast cancer cells. ${ }^{63}$ MLT inhibits the viability and invasiveness of breast cancer mammospheres as well as in modulating the expression of proteins related to epithelialmesenchymal transition (EMT) in breast cancer stem cells (CSCs). ${ }^{64}$ MLT reduced the viability of MCF-7 and MDAMB-231 cells under hypoxic conditions by decreasing the expression of HIF-1 $\alpha$ and VEGF-A. Protein array data showed that MLT treatment during hypoxia reduced the expression of VEGF receptors, matrix metalloproteinase 9 (MMP9), and angiogenin in MCF-7 cells. In contrast, MDA-MB-231 cells treated with MLT showed a significant decrease in VEGFR2, epidermal growth factor receptor, and angiogenesis. Taken together, these results showed MLT has potential antiangiogenic activity under hypoxic conditions. ${ }^{65}$ MLT exhibited anticancer activity against breast cancer by targeting various receptors and kinases involved in angiogenesis (Figure 4). MLT inhibits the proliferation of breast cancer cells induced by bisphenol, which is an estrogen-like chemical that causes hormone-related cancers. MLT significantly eliminates BPA-elevated cell proliferation by downregulating the phosphorylation of ERK and AKT. MLT also inhibits the elevation of steroid receptor coactivator expression and estrogen response element activity triggered by BPA. ${ }^{66}$ MLT decreased ERK phosphorylation induced by nicotine in both normal MCF-10A and low-malignant breast cancer cells (MCF7), which in turn blocks motility and invasiveness. Furthermore, MLT significantly reduces fascin and calpain activation, thus restructuring the overall cytoskeleton architecture and abolishing invasive membrane 


\section{Anticancer Activity: Melatonin in Breast Cancer}

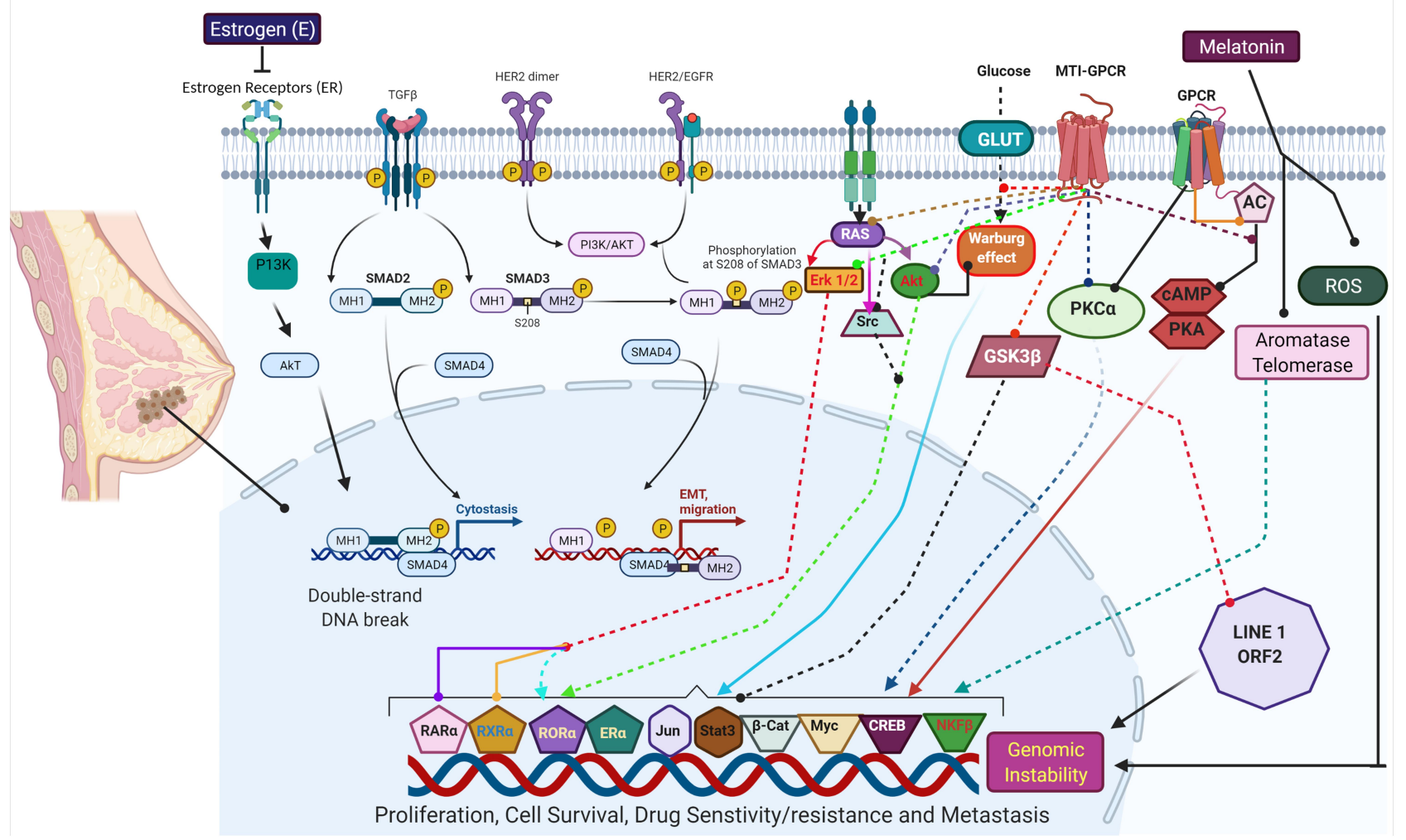

Figure 4 Molecular mechanism of anticancer activity of MLT in breast cancer cells.

protrusion. ${ }^{67}$ MLT differentially modulates NF-кB expression in breast and liver cancer cells. For instance, breast cancer xenograft nude mice treated with MLT showed reduced tumor size and decreased expression of NF-kB. Conversely, hepatocarcinoma treated with MLT showed an increased expression of NF-kB compared with control cells. ${ }^{68}$ MicroRNAs play a critical role in gene regulation, progression, and angiogenesis in breast cancer. MLT can modify the expression of innumerable genes and miRNAs related to cancer. MLT increased the level of gene expression of miR-148a-3p and decreased the gene and protein expression of IGF-1R and VEGF both in vitro and in vivo. Upregulation of miR-148a-3p inhibits cell survival, migration, and invasion of breast tumor cells and decreases angiogenic factors. ${ }^{69}$ The combined effects of zinc and MLT were evaluated in female rats by evaluating the level of IL-6 and lipid peroxidation. The results showed combination effect significantly decreased tumor growth due to disruption of metabolism, suppressed IL-6 levels, and reduced tissue damage. ${ }^{70}$ Palmer et $\mathrm{al}^{71}$ reported the effect of MLT in patients with breast cancer undergoing chemotherapy. Various parameters were evaluated, including cognition, depressive symptoms, and sleep quality. They also examined whether these effects are related to serum levels of brain-derived neurotrophic factor and its receptor, tropomyosin kinase B (TrkB). The findings from clinical studies revealed that MLT improved executive function on TMT scores, enhanced episodic memory and recognition on the Rey Auditory Verbal Learning test, and increased verbal fluency in orthographically controlled oral word association test. MLT induced apoptosis and autophagy in ELT3 cells by increasing the distribution of cells in the sub-G1 phase and increasing DNA condensation. MLT also exerted a highly selective effect on primary normal human uterine smooth muscle cells, such as upregulation of p21, p27, and PTEN protein expression, but not activation of apoptosis. ${ }^{72}$ The emergence of resistance to chemotherapeutic agents is a setback for the successful management and treatment of resistant tumors. The combination of a ketogenic diet and MLT inhibited cisplatinand vincristine-resistant breast cancer by inducing apoptosis, inhibiting angiogenesis, and downregulating resistance genes. ${ }^{73}$ Recently, review summarized the effect of MLT and regulation of miRNAs by MLT in different 
pathologies such as malignant and nonmalignant diseases. These miRNAs based strategy will be a novel and alternative targeted therapy for cancer ${ }^{74,75}$ discussed the role of circadian rhythm disorders in epithelial-mesenchymal transition (EMT) and tumor-immune interactions in endocrine-related cancers. Particularly, the review discussed the disorder of circadian rhythms causes alteration in numerous endocrine functions and homeostasis. As a result, it causes development of endocrine-related cancers, like breast, ovarian and prostate cancer and also it induces proinflammatory and immunosuppressive phenotype in the tumour microenvironment. MLT downregulates TRPC6, which is playing major role in impairing store-operated calcium entry (SOCE) in triple negative breast cancer cells (TNBC). SOCE is inevitable process for TNBC cells. Nanomolar range of MLT, significantly attenuates TNBC MDA-MB-231 cell viability, proliferation and migration in a time- and concentration-dependent manner. Pretreatment with different concentrations of melatonin significantly reduced SOCE in MDA-MB-231 cells without altering $\mathrm{Ca}^{2+}$ release from the intracellular stores. TRPC6 downregulation involved in melatonin's inhibitory effects on $\mathrm{Ca}^{2+}$ influx and the maintenance of cancer hallmarks, and point toward a novel antitumoral mechanism of melatonin in TNBC cells. ${ }^{76}$ Estrogens are significant player for the development of breast cancer. Estrogen synthesis is regulated by the enzyme aromatase, which is therapeutic option for breast cancer. MLT could suppressive aromatase activity, leading to reduced estrogen biosynthesis. Hence, MLT can act as inhibitor for aromatase action, which is playing important role as oncostatic molecule in breast cancer. $^{77}$ The level of MLT influences the concentration of estrogen receptor in hormone-dependent estrogenpositive breast cancer. The alteration of MLT levels by chemotherapy governing clinical and psychological symptoms of breast cancer, such as sleep quality and depression severity ${ }^{78}$ Chuffa et al $^{79}$ reported that the role of MLT in regulating the expression of 46 microRNAs (miRNAs) and their target genes in breast, oral, gastric, colorectal, and prostate cancers, and glioblastoma. The deregulated miRNA-associated target genes revealed their involvement in the regulation of cellular and developmental processes in breast, gastric, and oral cancers. The findings found that eight upregulated genes and 16 downregulated genes that were appositively correlated with MLT. MLT regulates various genes involved in circadian rhythm. BMAL1 was reduced in tumor hypoxiainduced acidosis, and recovered by selectively targeting acidic $\mathrm{pH}$ in breast cancer cell lines. MLT significantly prevented acidosis-mediated decrease of BMAL1 by inhibiting lactate dehydrogenase-A during hypoxia ${ }^{80}$ Cancer stem cells (CSCs) are resistant to chemotherapeutic drugs and cause recurrence of cancer and CSCs causes serious problems in the treatment of various cancers. MLT modulate various physiological process of CSCs and it would be alternative strategy for the treatment of cancer ${ }^{81}$ Menéndez-Menéndez et al found that MLT enhanced the anti-proliferative effect of doxorubicin in MCF-7. ${ }^{82}$ MLT downregulate TWIST1 (Twist-related protein 1) in estrogen-dependent breast cancer cells. Combined with doxorubicin, melatonin inhibited the activation of p70S6K and modulated the expression of breast cancer, angiogenesis and clock genes. Inhibition of TWIST1 by MLT could overcoming resistance and improving the oncostatic potential of doxorubicin in estrogen-dependent breast cancer cells. Goyal et $\mathrm{al}^{83}$ studied the correlation between MLT and expression patterns of MLT1 receptor with estrogen, progesterone, and HER2 receptors. ${ }^{83}$ The authors found that a positive correlation of the MT1 expression with ER, PR, and HER 2 receptor. Higher MT1 receptor expression was observed in the receptor-positive cases compared to triple-negative cases. The findings from these studies suggest that MLT receptor status can be used as an independent pathologic indicator to evaluate breast carcinoma tissue. Breast tumor xenografts of rats exposed to dLAN and circadian disruption increases the levels of phosphorylated and acetylated STAT3, increased DNMT1, but reduced sirtuin 1 (SIRT1) and ARHI. While administration of MLT and/or SIRT1 blocked/reversed interleukin 6 (IL6)-induced acetylation of STAT3 and its methylation of ARH1 in MCF-7 breast cancer cells ${ }^{84}$ MenéndezMenéndez and Carlos Martínez-Campa discussed MLT as an anti-tumor agent in hormone-dependent cancers by interfering with the estrogen signaling-mediated transcription, and also regulates the production of estradiol through the control of the enzymes involved in its synthesis, acting as a selective estrogen enzyme modulator (SEEM). ${ }^{85} \mathrm{MLT}$ alone potentially inhibits breast cancer metastasis through inhibiting DJ-1/KLF17/ID-1 signaling pathway. The combination of melatonin and taxol potentially inhibits metastasis in breast cancer. $^{86}$ MLT enhanced the antiproliferative and apoptotic responses to low doses of docetaxel in breast cancer cells. Combination effect of MLT and docetaxel induced changes in gene expression profiles. Docetaxel downregulated TP53, cyclin-dependent kinase inhibitor 1A (CDKN1A) and cadherin 13 (CDH13), and 
upregulated mucin 1 (MUC1), GATA binding protein 3 (GATA3) and c-MYC, whereas melatonin counteracted these effects. MLT stimulated the expression of the proapoptotic BAD and BAX genes, and enhanced the inhibition of the anti-apoptotic gene BCL-2 induced by docetaxel.

\section{Role and Therapeutic Potential of MLT on Prostate Cancer Cells}

Prostate cancer ranks as the second-most frequent cancer and the fifth leading cause of cancer death in men. ${ }^{2,87}$ One of the crucial factors for prostate cancer is obesity. ${ }^{88}$ However, the rate of death has been decreasing owing to early diagnosis and treatment. A case-cohort study reported that men with low first-morning urinary levels of 6-sulphatoxymelatonin (aMT6s) had a high risk of prostate cancer. ${ }^{89}$ Conversely, patients with high MLTsulfate levels or a high MLT-sulfate/cortisol ratio were less likely to have prostate cancer. ${ }^{90}$ Pharmacological concentrations of MLT can inhibit the growth of androgendependent and -independent prostate cancer. ${ }^{91}$

An in vivo study revealed that administration of MLT to rats through drinking water prevented the testosteronemediated regrowth of the prostate by modulating MLT binding sites in rats, whereas an in vitro study showed that MLT inhibits cell viability and cell growth. ${ }^{92,93}$ Furthermore, MLT inhibits androgen-induced prostate cell growth via disarticulation of androgen receptors from the nucleus to the cytoplasm in prostate epithelial cells. ${ }^{94}$ MLT inhibited the proliferation of hormone-independent LNCaP prostate cancer cells via MT1 receptor activation both in vitro and in nude mice xenograft models. A preclinical study involving patients with prostate cancer reveals that the oncostatic property of MLT can stabilize prostatespecific antigen levels. ${ }^{95}$ MLT is known to exert antitumor effect in various types of cancers. However, the mechanism and effect of dose have yet to be elucidated. Therefore, Paroni et $\mathrm{al}^{96}$ investigated the effect of MLT at nanomolar concentrations in a mouse model of human prostate cancer. To test this hypothesis, LNCaP human prostate cancer cells were xenografted into 7-week-old Foxn1nu/nu male mice treated with MLT (18 i.p. injections of $1 \mathrm{mg} / \mathrm{kg}$ in 41 days). The results revealed that MLT levels in plasma and xenografted tissue were $4 \times$ and $60 \times$ higher in MLT-treated mice, respectively, than in the control samples (saline-treated mice). Xenografted mice treated with MLT showed lower microvessel density than the control. MLT reduced angiogenesis by decreasing Ki67 expression and increasing HIF-1 $\alpha$ expression and Akt phosphorylation. Furthermore, MLT plays a major role in maintaining redox balance by increasing the expression of Nrf2. MLT plays critical role in modulating mitochondria mediated apoptosis in prostate cancer by activating ROS and subsequently various kinases such as p38, SAPK and JNK (Figure 5).

MLT potentially inhibits $5 \alpha$-dihydrotestosterone or $17 \beta$-estradiol (E2)-induced LNCaP cell proliferation at physiological and pharmacological concentrations. In contrast, high concentrations of MLT inhibit total prostate-specific antigen production by $\mathrm{LNCaP}$ cells. A study revealed that MLT inhibits the activation of $\mathrm{mt} 1$ receptor and attenuates sex steroid-induced calcium influx in LNCaP cells. ${ }^{97}$ MLT-mediated cGMP causes nuclear exclusion of the androgen receptor (AR), which increases intracellular calcium and protein kinase $\mathrm{C}$ (PKC) activation, which is a possible signaling pathway that regulates AR localization and androgen responses in target cells. ${ }^{98}$ MLT exhibits antiproliferative effects by activating $\mathrm{PKC}$ and protein kinase A (PKA) via upregulation of the MT(1) receptor and the p27(Kip1) gene and protein in hormone-refractory 22Rv1 human prostate cancer cells, thereby proving that MLT prevented prostate cancer by inhibiting NF- $\mathrm{KB}$ signaling activation via inhibition of DNA binding through MT1 receptor-induced PKA and PKC stimulation. These studies proved the involvement of MT1 receptor-mediated inhibition of NF- $\mathrm{KB}$ signaling activation in the mechanism of MLT. ${ }^{99,100}$ MLT inhibited RAhuman fibroblast-like synoviocytes (FLS) proliferation in a dose-dependent manner by upregulating P21 and P27 and inducing the phosphorylation of ERK, but it also affected the phosphorylation of P38 in RA-FLSs. ${ }^{101}$ The combination of MLT and docosahexaenoic acid decreases the proliferation of PNT1A prostate benign cells via the modulation of mitochondrial bioenergetics and ROS production. Cells treated with DHA showed increased ROS production and impaired mitochondrial function, which was probably related to AKT inactivation. In contrast, MLT improved OXPHOS and decreased ROS, which was related to AKT/mTOR dephosphorylation. Altogether, this study showed that the combination of DHA and MLT inhibits the proliferation of prostate cancer cells. ${ }^{102}$ In vitro and in vivo model suggest that MLT inhibits MMP-13 expression and the migratory and invasive capacities of prostate cancer cells via the $\mathrm{MT}_{1}$ receptor and the phospholipase 


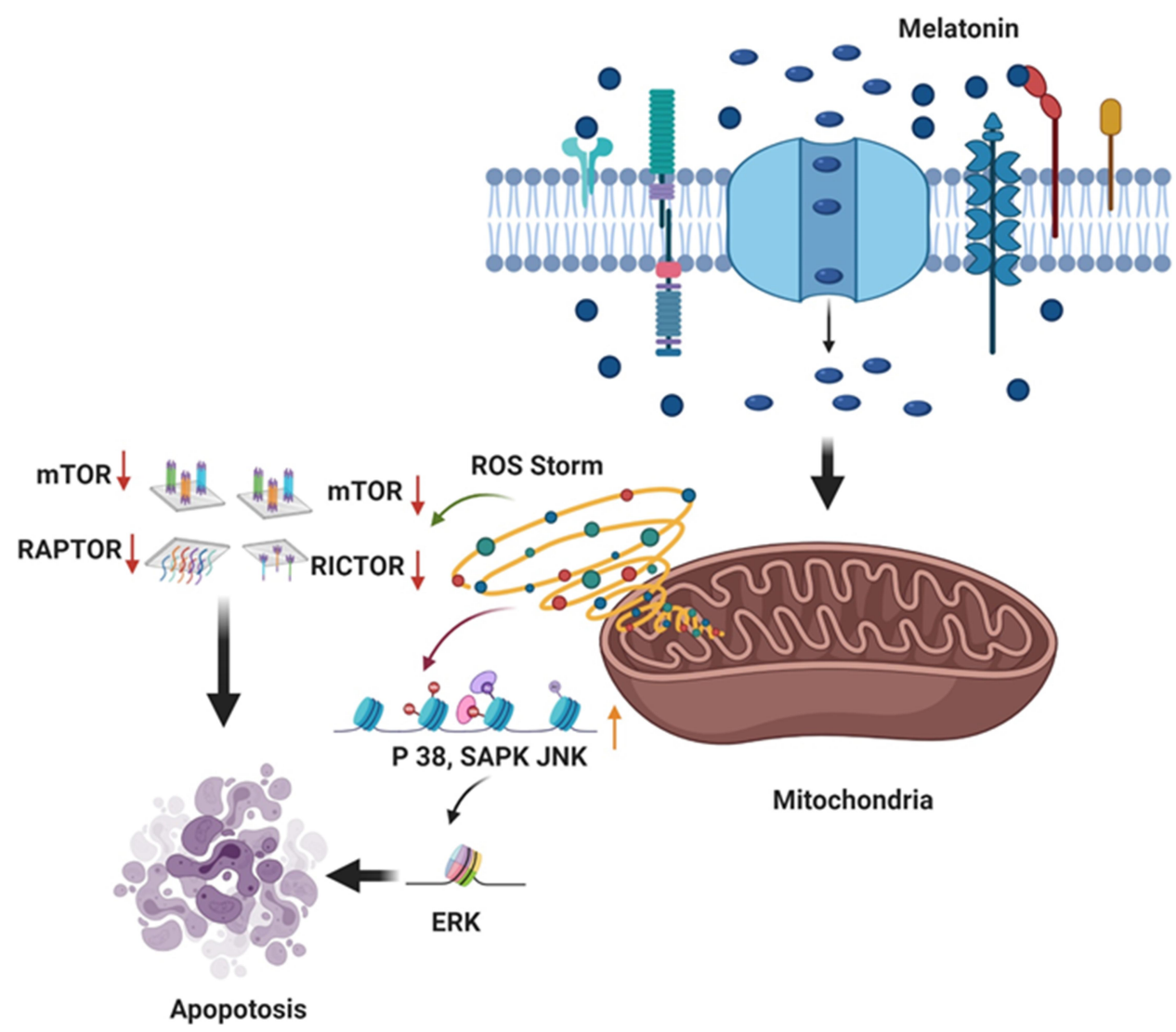

Figure 5 MLT targets mitochondria mediated apoptosis in prostate cancer cells.

C, p38, and c-Jun signaling cascades. ${ }^{103}$ Combination of MLT and radiation increases overall survival of prostate cancer patients with poor prognosis. ${ }^{104}$ Calastretti et al evaluated the effect of MLT analogue called UCM 1037 inhibits cell proliferation, cell cycle distribution, and cytotoxicity in LNCaP, PC3, DU145, and 22Rv1 prostate cancer cells dose- and time-dependent manner and UCM 1037 down-regulates androgen receptor levels and Akt activation in LNCaP and 22Rv1 cells. ${ }^{105}$ MLT limits glycolysis as well as the tricarboxylic acid cycle and pentose phosphate pathway in prostate cancer cells, suggesting that the reduction of glucose uptake is a major target of the indole in this tumor type. ${ }^{106}$

\section{Role and Therapeutic Potential of MLT in Colorectal Cancer}

Colorectal cancer incidence rates are approximately threefold higher in developed versus developing countries; however, as the average case fatality is higher in lower HDI settings, there is less variation in the mortality rates. ${ }^{2}$ The major causes of colorectal cancers are dietary patterns, obesity, lack of physical activity, and lifestyle factors, whereas the lower mortality observed in developed countries is due to good practices in cancer treatment and management. ${ }^{107}$ Prominent factors that increase the risk of colon cancer are obesity and consumption of processed or red meat and alcoholic drinks. ${ }^{108}$ Colorectal cancer begins as a polyp in the intestinal mucosa, and primary adenomatous lesions, which transform into a malignancy; in fact, $24 \%$ of untreated polyps progress to cancer. ${ }^{109}$ Moreover, normal epithelial cells can transform into hyperproliferative mucosa, which then leads to a benign adenoma, which subsequently develops into carcinoma. ${ }^{110}$ The common treatment modalities for colorectal cancer are surgery, chemotherapy, radiotherapy, immunotherapy, and targeted therapy. Recently, MLT has been proven to reduce the severity of colorectal cancer owing to its potent anticancer, anti-inflammatory, and antioxidant properties. The changes in MLT levels could be a major cause of the elevation of colorectal cancer incidence, indicating that MLT plays a crucial role in suppressing colorectal cancer development and progression. MLT level is disrupted in those who work day and night shifts. ${ }^{11-113}$ 
A study was conducted to investigate MLT as a predictor for cancer patients. MLT levels in blood were monitored before and at 28 days after each cycle of chemotherapy. The study included 42 men and women with breast cancer (10), lung cancer (13), colon cancer (11), soft tissue sarcoma (4), testicular cancer (1), Hodgkin's disease (1), and peritoneal mesothelioma. The results showed that, irrespective of the type of tumor and chemotherapeutic regimen, $12 / 16$ patients (75\%) whose MLT was markedly enhanced after chemotherapy had an objective regression. In contrast, 2/26 patients (8\%) whose MLT did not enhance after chemotherapy had a clinical response. The percentage of objective responses was significantly higher in patients with a chemotherapy-induced MLT increase than in those with no MLT increase. ${ }^{47} \mathrm{~A}$ study was conducted to potentiate the effect of IL-2 with MLT for the purpose of reducing the dose of IL-2 required to achieve effective host antitumor response. The study was performed with a combination of low-dose IL-2 administered subcutaneously once a day ( 3 million IU/day for 6 days/ week for 4 weeks) with MLT $(50 \mathrm{mg} /$ day orally) as second-line therapy in metastatic colorectal cancer patients pretreated with 5-FU. Among the 14 patients, 13 showed disseminated liver metastases. No objective tumor regression was observed. However, disease stabilization was achieved in 4/13 patients, whereas it progressed in the other nine patients. The mean number of lymphocytes and eosinophils significantly increased in patients with stable disease compared to those with progressive disease, whereas the eosinophil numbers remain unchanged. Moreover, serum levels of neopterin and TNF significantly increased during therapy, and TNF increase was correlated with side effects and not control of cancer development. Finally, this study concluded that the treatment with IL-2 and MLT facilitates host antitumor response rather than tumor regression. ${ }^{114}$ The inhibitory effect of MLT on the cell growth of CT-26 cells, a murine colon carcinomaderived cell line, was reported. This study showed that MLT inhibits cell growth in a dose-dependent manner; however, at doses below $1 \mathrm{mM}$, the effect was not significant. When the dose of MLT was 1,2, and $3 \mathrm{mM}$, the rate of cell growth inhibition was $22 \% 25 \%$, and $47 \%$, respectively. ${ }^{115}$

MLT-induced antitumor therapies was performed in 20 metastatic patients. MLT was administered orally at $20 \mathrm{mg} /$ day in the evening for at least 2 months. The results showed that VEGF mean levels decreased with the therapy, showing significant differences from the pre-treatment values. ${ }^{116}$
Lissoni ${ }^{34}$ conducted a study to evaluate the effect of concomitant MLT administration on the efficacy and toxicity of several chemotherapeutic combinations in patients with metastatic NSCLC or gastrointestinal tumors. The study consisted of 370 patients who were randomized to receive chemotherapy alone or chemotherapy plus MLT. Patients with colorectal cancer were treated with oxaliplatin plus 5-FU, or weekly CPT-11 or 5-FU and FA. Patients with NSCLC received cisplatin plus etoposide or cisplatin plus gemcitabine, whereas those with gastric cancer received cisplatin, epirubicin, 5-FU, and FA or weekly 5-FU plus FA. The results showed that tumor regression was significantly higher in patients concomitantly treated with MLT than in those treated with chemotherapy alone. The effect of MLT on cell viability was investigated in Colon 38 murine cancer cell line in the presence of 4P-PDOT or luzindole. The results showed that MLT significantly decreased the viability of cancer cells in the presence of a selective antagonist of MT2 membrane receptor. The antagonist alone did not have any effect on the growth of Colon 38 cells. The obtained data indicate that MLT receptors are not indispensable to the oncostatic action of MLT. ${ }^{117}$

The combination of MLT with the genotoxicity inducer irinotecan was studied in human lymphocytes, A549 lung cancer cells, and HT29 colorectal adenocarcinoma cells. Irinotecan was shown to induce DNA damage in all tested cells. The combination of MLT at concentrations of $50 \mu \mathrm{M}$ with increasing doses of irinotecan $(7.5,15,30$, and $60 \mu \mathrm{M})$ resulted in an increase in DNA damage in A549 and HT29 cancer cells, but was not effective in inducing DNA damage in healthy human lymphocytes. ${ }^{118}$ The combined effects of ursolic acid (UA) and MLT were evaluated in SW480 and LoVo cells. The results showed that combined treatment with UA and MLT significantly enhanced inhibition of cell viability and migration as well as promoted changes in cell morphology and spreading via modulation of cytochrome $\mathrm{c}$ release, activation of caspase, enhanced inhibition of MMP9/COX-, and translocation of $\mathrm{p} 300 / \mathrm{NF}-\mathrm{\kappa B}$ from the cell nuclei to the cytoplasm. These results, therefore, showed that MLT potentiated the antiproliferative and pro-apoptotic effects of UA in colon cancer cells. ${ }^{119}$ MLT inhibits edn-1 mRNA expression, ECE1 protein expression, and ET-1 release from colorectal cancer cells (Figure 6). Studies from both in and in vitro demonstrate that MLT inhibited proliferation and viability, and increases apoptosis in CRC cells via upregulating the expression of the miR-34a/449a cluster. ${ }^{120}$

MLT induces apoptosis by inhibiting the expression of endothelin-1 (ET-1), inhibits edn-1 mRNA expression, 


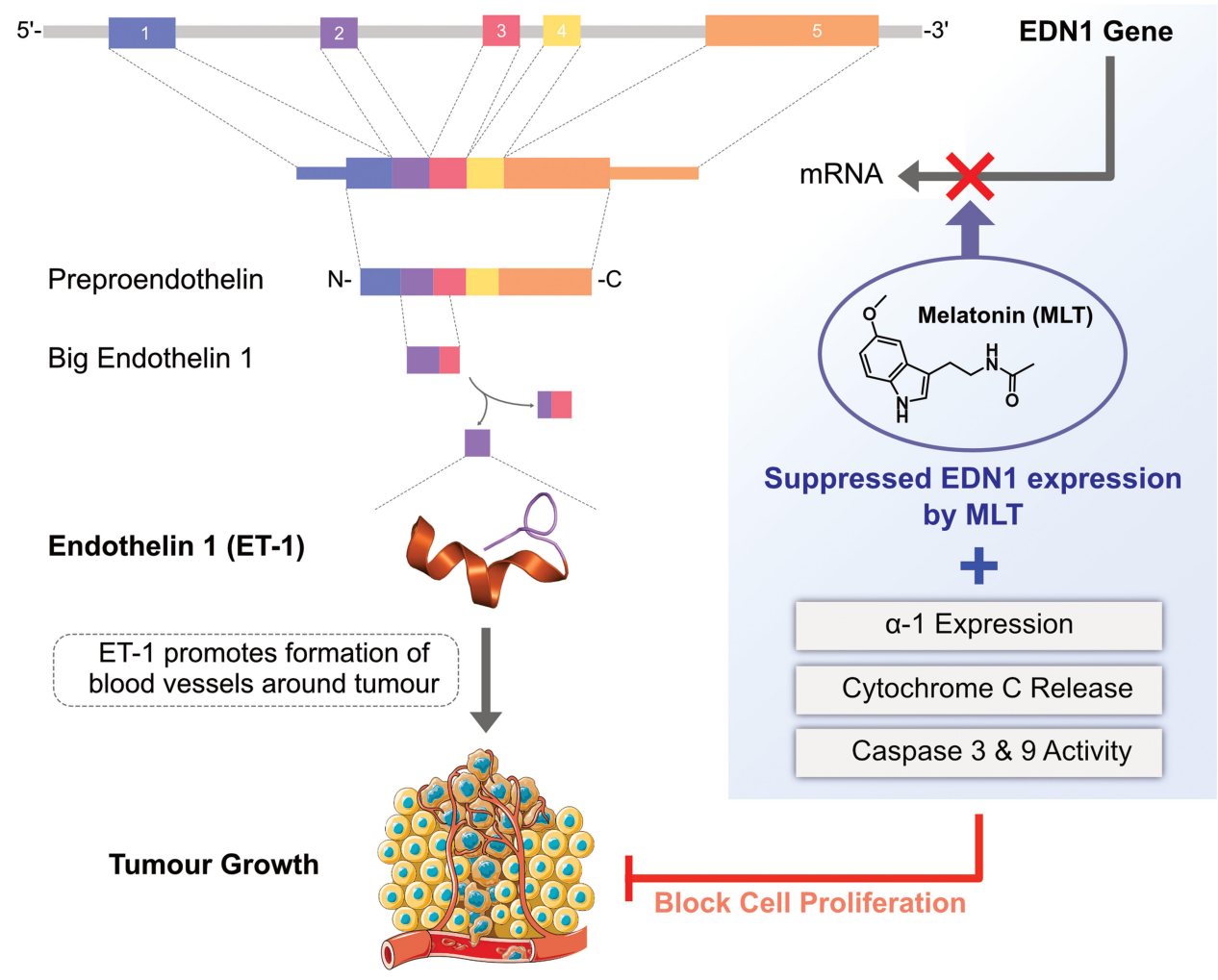

Figure 6 Inhibitory effects of MLT on endothelin.

ECE-1 protein expression, and ET-1 release from colorectal cancer cells. The inhibition of edn- 1 expression is due to the inactivation of FoxO1 and NF- $\kappa \beta$ transcription factors and the blocking of Akt and ERK phosphorylation. The inhibition of edn-1 expression is due to the inactivation of FoxO1 and NF- $\kappa \beta$ transcription factors and associated with increased Src phosphorylation, whereas NF- $\kappa \beta$ inactivation is associated with the blockade of Akt and ERK phosphorylation due to the inhibition of PKC activity after MLT treatment. ${ }^{121}$ HCT116 human colorectal adenocarcinoma cells treated with $10 \mu \mathrm{m}$ MLT showed increased levels of cell death- and cell cycle-related proteins. MLT significantly decreased MT1 in a dose-dependent manner. MLT upregulated Bax and downregulated Bcl-xL. MLT decreased the population of S-phase cells, increased the expression of p16 and p-p21, and further attenuated E- and A-type cyclins. ${ }^{122}$ Pharmacological concentrations of MLT significantly suppressed cell proliferation and enhanced apoptosis in a dose-dependent manner. The observed apoptosis was accompanied by MLT-induced dephosphorylation and nuclear import of histone deacetylase 4 (HDAC4). This was further confirmed by the use of HDAC4-specific siRNA, which potentially decreases MLT-induced apoptosis, indicating that nuclear localization of HDAC4 is required for MLT-induced apoptosis. Moreover, constitutively active $\mathrm{Ca}^{2+} /$ calmodulindependent protein kinase II alpha (CaMKII $\alpha$ ) abrogated MLT-induced HDAC4 nuclear import and apoptosis of LoVo cells. ${ }^{123}$ MLT potentially induces apoptosis in two different cancer cells, A2780 ovarian cancer cell line and the stable cell line DLD1 derived from colorectal carcinoma, compared with normal endothelial cells through the type 1 sodium/calcium exchanger and type 1 IP3 receptor. The data from this study suggested that the different targeting of calcium transport systems in tumor and normal (non-tumor) cells is suggested as a key mechanism underlying the anticancer effect of MLT. ${ }^{124}$ The effect of MLT on autophagy and Nrf2 signaling pathways in a mouse model of colitis-associated colon carcinogenesis (CACC) was reported. In this study, first, the authors induced CACC in male Swiss Albino mice via administration of a single i.p. injection of 1,2-dimethylhydrazine dihydrochloride (DMH) at $20 \mathrm{mg} / \mathrm{kg}$ body weight, followed by three cycles of 3\% w/v dextran sulfate sodium (DSS) in drinking water treatment initiated 1 week after DMH injection. MEL was supplied $(1 \mathrm{mg} / \mathrm{kg}$ body weight, p.o., for 8 and 18 weeks) after 1 week of DSS treatment. The results indicated that MEL treatment decreased the 
progression of CACC by downregulating various autophagy markers, such as Beclin-1, LC3B-II/LC3B-I ratio, and $\mathrm{p} 62$, which are associated with the increased expression of $\mathrm{Nrf} 2$ and the associated antioxidant enzymes. ${ }^{125}$ Another study investigated the effect of multi-targeted combinations (SN38/EF24; SN38/EF24/MLT) on the growth of colon cancer in experimental animals. The animals were treated with SN38/EF24 and SN38/EF24/MLT for 22 days. ROS, which are key molecules in the development of cancer, were measured using nitroxideenhanced magnetic resonance imaging and in isolated tissue specimens. Interestingly, the results showed that both combinations significantly suppressed tumor growth. Remarkable and more pronounced effects were observed in SN38/EF24/MLT-treated mice, which showed almost complete destruction of the tumor. The findings concluded that the anticancer effect of the triple combination EF24/ SN38/MLT was mediated by a decrease in "oncogenic" ROS and an increase in "onco-suppressive" ROS. ${ }^{126}$ The effects of MLT and H-1152, a selective inhibitor of Rhoassociated protein kinase (ROCK), on cell migration were reported in RKO cells. The RKO cells treated with MLT showed decreased expression of ROCK2, p-MYPT1, and p-MLC, and increased expression of ZO-1 and occludin. The phosphorylation levels of p38 were reduced in cells treated with either MLT or H-1152 alone. The possible action mechanism of MLT in inhibiting the migration of RKO colon cancer cells is the downregulation of ROCK expression via the $\mathrm{p} 38 /$ mitogen-activated protein kinase (MAPK) signaling pathway. ${ }^{127}$ The combination of MLT and 5-FU significantly inhibited cell proliferation, colony formation, cell migration, and cell invasion in colon cancer cells through the caspase/PARP-dependent apoptosis pathway as well as induced cell cycle arrest. MLT and 5-FU markedly suppressed the phosphorylation of PI3K, AKT, $\mathrm{IKK} \alpha, \mathrm{I} \kappa \mathrm{B} \alpha$, and $\mathrm{p} 65$ proteins; promoted the translocation of NF- $\mathrm{KB}$ p50/p65 from the nuclei to the cytoplasm; abrogated their binding to the iNOS promoter; and thereby enhanced the inhibition of iNOS signaling. A study in a xenograft mouse model also implied that MLT and 5-FU exerted synergistic antitumor effects by inhibiting the AKT and iNOS signaling pathways. ${ }^{128}$ Moloudizargari et al reported that MLT can potentially modulate anticancer drugs to reduce tumor progression via various intracellular signaling pathways such as mitogen-activated protein kinase (MAPK), extracellular signal-regulated kinase (ERK) and protein kinase $\mathrm{B}$ (AKT/PKB) signaling. ${ }^{129}$
Generally, the level of cellular prion protein $\left(\operatorname{PrP}^{\mathrm{C}}\right)$ in oxaliplatin-resistant colorectal cancer (SNU-C5/Oxal-R) was higher than that in normal cancer cells. The effect of MLT was assessed in both SNU-C5 cells and SNU-C5/Oxal-R cells; later, the cells showed high $\operatorname{PrP}^{\mathrm{C}}$ expression as well as superoxide dismutase and catalase activities. Treatment of SNU-C5/Oxal-R cells with oxaliplatin and MLT decreased $\operatorname{PrP}^{\mathrm{C}}$ expression and increased superoxide anion generation. In SNU-C5/Oxal-R cells, MLT and oxaliplatin induced endoplasmic reticulum stress. ${ }^{130}$ An investigation was performed to decipher the molecular mechanism of prion protein-Oct4 axis in colon CSCs. The study examined the expression of $\mathrm{PrP}^{\mathrm{C}}$ and Oct4 in specimens from patients with colorectal cancer, and found that the expression of $\operatorname{PrP}^{\mathrm{C}}$ and Oct4 was significantly correlated with metastasis and tumor stages. Surprisingly, co-treatment with 5-FU and MLT inhibited the stem cell markers Oct4, Nanog, Sox2, and ALDH1A1 by downregulating PrPC. ${ }^{131}$ The combined effect of MLT and radiotherapy was investigated in HCT 116human colorectal carcinoma cell line. The cells were treated with MLT in combination with ionizing radiation (IR). The results revealed that MLT effectively inhibited the proliferation, colony formation rate, and migration of HCT116 cells following IR. An in vivo study also supported that compared with MLT or IR alone, the combined treatment suppressed tumor cell growth, resulting in a much higher tumor inhibition rate. This study concluded that the combination of MLT and IR results in enhanced therapeutic effects in the patients. ${ }^{132}$ The apoptotic mechanism of co-treatment with MLT and pterostilbene (Ptero) was evaluated in colorectal cancer. MLT and Ptero co-treatment (MLT+Ptero) showed synergistic cytotoxicity compared with MLT or Ptero alone, decreasing the number of colonies and Ki67 expression as well as increasing apoptotic cells and ROS production in colorectal cancer, according to the caspase- 3 activity and PARP level. Interestingly, MLT+Ptero upregulated the expression of miRNAs, such as miR-25-5p, miR-542-5p, miR-711, miR-4725-3p, and miR-4484, and downregulated the expression of miR-4504, miR-668-3p, miR-3121-5p, miR-195-3p, and miR-5194 in HT29 cells. Collectively, these findings provide evidence that MLT+Ptero enhances apoptosis via miR-25-5p-mediated NEDD9 inhibition in colon cancer cells. ${ }^{133}$ Doxorubicin or MLT or combination of DOX and MLT significantly decreased the proliferation and viability, tumor spheroid formation, invasion, and migration of Caco-2 colorectal cancer cells in a concentration and time dependent manner. Combination treatment increase rate of apoptosis and significantly influences genes involved in 
apoptosis and cell motility. Combination treatment shows stronger effect compared either Dox or MLT. ${ }^{134}$ Hence, MLT will be an alternative and therapeutic agent for colorectal cancer. $^{135}$

\section{Role and Therapeutic Potential of MLT in Skin Cancer}

Skin cancer, particularly melanoma, is one of the most complex, aggressive, and heterogeneous cancers and is the leading cause of death worldwide. ${ }^{136,137}$ Melanoma cancer not only arises from cutaneous melanocytes but also originates from mucosal surfaces, such as the genital and gastrointestinal mucosa, oral cavity, and eye uveal tract. ${ }^{138}$ Skin cancer is divided into melanoma and nonmelanoma. Non-melanoma skin cancer is the fifth most common cancer in men and women. ${ }^{139}$ This cancer is caused by several etiological factors, such as skin phototype, hair color, multiple nevi, family history, and ultraviolet radiation (UVR). ${ }^{140}$ The conventional treatments for skin cancer are chemotherapy and radiotherapy; however, these treatments do not potentially increase the survival rate of patients. ${ }^{141}$ Moreover, during chemotherapy, patients become resistant to cytotoxic drugs, and undesired side effects may occur. Therefore, it is necessary to explore biocompatible, effective, novel therapies, or complementary therapies. MLT, the main product of the pineal gland, has been shown to play a critical role in skin cancer as an oncostatic and anticancer agent.

The anti-mutagenic and oncostatic actions of MLT on benzo(a)pyrene-induced two-stage skin carcinogenesis in mice have been reported. MLT-treated mice decreased not only the number of animals bearing papilloma but also the number of papilloma per animal both in the initiation and promotion stages of skin carcinogenesis. Furthermore, MLT reduces lipid peroxides and can prevent the binding of BP or its metabolites to DNA. ${ }^{142}$ The radioprotective effect of MLT against organ damage induced by wholebody IR in rats was investigated. A total of 32 male Sprague-Dawley rats were exposed to irradiation at a single whole-body dose of $800 \mathrm{cGy}$ at different time points, such as $12 \mathrm{~h}$ and $72 \mathrm{~h}$. The rats were then administered either saline or MLT (20 mg/kg or $10 \mathrm{mg} / \mathrm{kg}$, i.p.) before and after IR. Several oxidative and antioxidative parameters were then analyzed. The results showed that at both 12 and $72 \mathrm{~h}$ following IR, the tissue levels of MDA were elevated significantly and GSH levels were reduced. On the contrary, MLT-treated mice showed significantly decreased levels of MDA and increased GSH levels. MLT inhibits the high levels of myeloperoxidase activity in the colonic tissue at both 12 and $72 \mathrm{~h}$, and in the hepatic tissue at $72 \mathrm{~h}$ following IR. MLT decreased the oxidative stress induced by IR through free radical-scavenging and antioxidant properties. ${ }^{143}$ Furthermore, the authors investigated the radioprotective properties of MLT on the corpus cavernosum and bladder tissues of rats exposed to whole-body IR. The same parameters were analyzed in IR- and MLTtreated rats. Similarly, IR elevated MDA levels and reduced GSH levels. MLT administration reversed the oxidative organ injury. ${ }^{144}$ To determine the inhibitory effect of MLT on malignancies of mesenchymal origin in 3-month-old Swiss mice, carcinogenesis was induced by subcutaneous injection of $2 \mathrm{mg}$ of benzo[a]pyrene (BP) dissolved in $0.1 \mathrm{~mL}$ of olive oil. One group of mice was treated with MLT at doses of $2 \mathrm{mg} / \mathrm{L}$ or $20 \mathrm{mg} / \mathrm{L}$ at night via drinking water, whereas one group of mice was not treated with MLT and served as a PB-control. The results showed that MLT treatment inhibited BP-induced carcinogenesis, decreased the incidence of subcutaneous sarcomas, and increased the latency and survival of mice. BP increased the levels of MDA and catalase. In contrast, the MLTtreated mice showed a significant decrease in MDA and catalase levels both in the serum and tumor tissue compared with animals treated with BP. In particular, a lower dose of MLT is more effective than a higher dose. ${ }^{145}$ Mice treated with MLT, metformin, and a combination of both showed significantly reduced number and size of skin tumors, along with reduced LPO levels. ${ }^{146}$ In another study, the endogenous production levels of MLT metabolites, including 6-hydroxyMLT (6(OH)M), N(1)-acetyl-N(2)-formyl -5-methoxykynuramine (AFMK), and 5-methoxytryptamine (5MT), were estimated in various ethnic groups, such as African-Americans (30-50 years old), Caucasians (60-90 years old), and Caucasian women. The highest levels of MLT and AFMK were observed in AfricanAmericans, particularly in the younger population, whereas $6(\mathrm{OH}) \mathrm{M}$ and 5MT levels were similar in all groups. The effects of $6(\mathrm{OH}) \mathrm{M}, \mathrm{AFMK}$, and 5MT were also investigated in normal human melanocytes. The results showed that MLT and its metabolites $\left(10^{-5} \mathrm{M}\right)$ inhibited tyrosinase activity, cell growth, and DNA synthesis in a dosedependent manner. ${ }^{147}$ Another study showed that MLT effectively acts against UVR-induced epidermal damage, skin cancer, inflammation, and DNA photodamage by silencing Hsp70 in human keratinocytes, providing cellular resistance to such stressors. Furthermore, MLT inhibits the 
pro-inflammatory and pro-apoptotic effects of UVR in normal human epidermal keratinocytes. ${ }^{148}$ MLT and its derivatives protect against the UV-induced production ROS, 6-4-photoproducts, and cyclobutane pyrimidine dimers in the skin, which further causes skin cell damage by stimulating the expression of nuclear factor erythroid 2-related factor 2 and its target enzymes and proteins, which play an important role in cell protection from different damaging factors, including ultraviolet B (UVB). MLT and its metabolites enhance DNA repair and p53 expression in melanocytes exposed to UVB. ${ }^{149}$ However, MLT exhibited cytotoxic, genotoxic, apoptotic, and ROS generationpromoting effects in human epidermoid carcinoma cells (A-431) and human normal skin fibroblastic cells (CCD1079Sk). The anticancer activity of MLT was significantly higher in cancer cells than in normal cells. ${ }^{150}$ The possible beneficial effects of MLT and its active derivatives against UVB was investigated via topical application of MLT, AFMK, or NAS in human and porcine skin ex vivo and in cultured HaCaT cells. Topical application of MLT and AFMK protected epidermal cells against UVB-induced oxidative DNA damage and apoptosis, and increased the expression of $\mathrm{p} 53^{\mathrm{ser} 15}$; however, no effect was observed with NAS. MLT and its derivatives upregulated the expression of antioxidative enzymes after UVB radiation in HaCaT cells. ${ }^{151}$ In another study, to determine the combinatorial effect of MLT and vemurafenib on antitumor activities in patients with V600 BRAF mutant melanomas was investigated. The results showed that in mice with melanoma xenografts, MLT significantly and synergistically enhanced the vemurafenib-mediated inhibition of angiogenic parameters and stemness weakening in melanoma cells. Mechanistic studies revealed that MLT enhanced the antitumor effect of vemurafenib by abrogating the nuclear translocation of NF- $\mathrm{B}$ p50/p65 and their binding to iNOS and hTERT promoters, thereby suppressing the expression of iNOS and hTERT. ${ }^{152}$

\section{Role and Therapeutic Potential of MLT in Liver Cancer}

Liver cancer is the fourth leading cause of cancer death and the incidence and mortality rates of liver cancer are two to three times higher among men than among women in most world regions. ${ }^{2}$ The incidence rate is two-fold greater among men in developed countries. The main risk factors for $\mathrm{HCC}$ are chronic infection with hepatitis $\mathrm{B}$ virus or hepatitis $\mathrm{C}$ virus, aflatoxin-contaminated foodstuffs, heavy alcohol intake, obesity, smoking, and type 2 diabetes. ${ }^{153}$ Vaccine therapy against hepatitis $B$ virus is one of the primary prevention therapies for liver cancer. To confirm the enhancement of the antitumor effect of IL-2 in the presence of MLT, concomitant administration of MLT and low-dose IL-2 was carried out in patients with cancer who had progressed during previous immunotherapy with IL-2 alone, including 14 patients with advanced solid tumors, 6 with lung cancer, 4 with kidney cancer, 2 with stomach cancer, 1 with liver cancer, and 1 with melanoma. IL-2 was administered at a daily dose of 3 million IU s.c. for 6 days/week for 4 weeks. MLT was administered orally at a daily dose of $40 \mathrm{mg}$ every day, starting at 7 days prior to IL-2 administration. Tumor regression, as represented by partial remission, was achieved in $3 / 14(21 \%)$ patients. $^{154}$ Lissoni et al $^{155}$ designed a study to evaluate the efficacy of immunotherapy with low-dose IL-2 plus MLT versus chemotherapy in patients with advanced NSCLC. The study included 60 patients with locally advanced or metastatic NSCLC, who were randomized to receive immunotherapy IL-2 (3 million IU/day subcutaneously for 6 days/week for 4 weeks) or chemotherapy (cisplatin $20 \mathrm{mg} / \mathrm{m}^{2}$ and etoposide $100 \mathrm{mg} / \mathrm{m}^{2}$ intravenously each day for 3 days; the cycles of chemotherapy were repeated every 21 days until progression) and MLT (40 mg/day orally every day, starting at 7 days before IL-2 administration). The results showed that there was no response achieved with chemotherapy, whereas immunotherapy with low-dose IL-2 plus MLT showed a better response and was better tolerated. Co-incubation of MLT at doses of $640 \mu \mathrm{M}$ to $3 \mathrm{mM}$ with ethanol and tamoxifen showed dose-dependent inhibition of HEPA 1-6 mouse hepatoma cells, showing a significantly higher degree of inhibition than ethanol alone. ${ }^{156}$ In another study, HepG2 human hepatocarcinoma cells were treated with various concentrations of MLT (1000-10,000 $\mu \mathrm{M}$ ) for 2, 4, 6, 8, and 10 days. MLT treatment induced apoptosis with increased caspase-3 activity and poly(ADP-ribose) polymerase proteolysis, cytochrome c release, Bax upregulation, increased caspase-9 activity, and concomitant activation of JNK, 1,-2 and -3 ; moreover, the expression of $\mathrm{p} 38$, a member of the MAPK family, was upregulated by MLT treatment. The reduced cell proliferation and alterations in cell cycle were coincident with a significant increase in the expression of p53 and p21 proteins. $^{157}$ MLT protects against organ damage induced by whole-body IR in Sprague-Dawley rats. The tissue levels of MDA in irradiated rats were 
elevated, whereas GSH levels were reduced in all organs. On the contrary, MLT-treated rats showed decreased levels of MDA and myeloperoxidase activity, as well as increased levels of GSH. In conclusion, the antioxidative and free radical-scavenging properties of MLT reduced the oxidative stress induced by IR. Thus, supplementation of adjuvant therapy with MLT may have some benefit for successful radiotherapy in patients with liver cancer. ${ }^{143}$ In vivo studies reported that $N$-nitrosodiethylamine (NDEA)injected Wistar male rats showed decreased bodyweight, macroscopic and microscopically detectable liver tumors, as well as increased levels of plasma aspartate transaminase, alanine transaminase, and alpha-fetoprotein. NDEA treatment decreased the levels of liver thiobarbituric acid reactive substances and the activity of catalase and superoxide dismutase, as well as increased the reduced levels of glutathione, glutathione peroxidase, and glutathione S-transferase in the liver. MLT-treated rats showed significantly reduced tumor development and improvements in all the biochemical changes induced by NDEA. ${ }^{158}$ MLT inhibited the mTOR/Akt pathway in liver cancer and induced autophagy, protecting mouse hepatoma $\mathrm{H} 22$ cells against apoptosis. ${ }^{159}$ In another study, HepG2 cells and primary human hepatocytes were treated with MLT, and MLT showed pro-apoptotic effects via increased expression of the BH3-only protein Bim, increased transcriptional activity of the forkhead-responsive element, decreased phosphorylation of FOXO3a at $\operatorname{Thr}(32)$ and Ser(253), and increased nuclear localization of FOXO3a. ${ }^{160}$ In HepG2 and SMMC-7721 cells, MLT promoted apoptosis and downregulated survivin and XIAP expression, but had no effect on the expression of cIAP1 and cIAP-2. These data suggest that the inhibition of survivin and XIAP is involved in reversing apoptosis resistance. Furthermore, MLT reduced the expression of COX-2 and inhibited AKT activation in HepG2 and SMMC-7721 cells. ${ }^{161}$ Cancer cell growth is dependent on the release of VEGF, and the level of VEGF is particularly higher in hypoxic conditions than in normoxic conditions. To investigate the antiangiogenic effect of MLT on HepG2 cells, the cells were treated with MLT under normoxic or $\mathrm{CoCl}_{2}$-induced hypoxic conditions. MLT at a pharmacological concentration $(1 \mathrm{mM})$ decreases cellular and secreted VEGF levels and prevents HUVEC tube formation under hypoxia, which is associated with a reduction in Hifl $\alpha$ protein expression, nuclear localization, and transcriptional activity. MLT exerts an antiangiogenic effect in HepG2 cells by interfering with the transcriptional activation of VEGF via Hifl $\alpha$ and STAT3. ${ }^{162}$ In another study, the susceptibility of HCC cell lines, such as HepG2, HuH7, and Hep3B cells, to sorafenib was investigated. Sorafenib at $1 \mu \mathrm{mol} / \mathrm{L}$ inhibited the cell viability of $\mathrm{HepG} 2$ or $\mathrm{HuH} 7$ cells, and sorafenib $2.5 \mu \mathrm{mol} / \mathrm{L}$ inhibited the cell viability of Hep3B cells. However, co-administration of MLT and sorafenib led to a synergistic cytotoxic effect on HepG2 and $\mathrm{HuH} 7$ cells, and Hep3B cells showed susceptibility to doses of sorafenib that had no effect when administered alone. The combinatorial effect of MLT and sorafenib increased ROS production and mitochondrial membrane depolarization, which is the major factor responsible for mitophagy induction. ${ }^{163}$ Subsequently, another study suggested that co-treatment with MLT and sorafenib significantly decreased the clonogenicity of HuH-7 cells compared with treatment with a single agent. Furthermore, MLT synergistically augmented sorafenib-induced apoptosis, which is associated with the activation of caspase-3 and the JNK/c-Jun pathway. ${ }^{164}$ MLT strongly inhibited the proliferation, migration, and invasion capacities of Huh7 and HepG2 cells, and noticeably induced the expression of let7i-3p miRNA in the cells. Transfection of cells with let7i-3p significantly reduced RAF1 expression and activated the MAPK signaling downstream from RAF1. These findings revealed that MLT inhibits HCC progression by modulating let7i-3p-mediated RAF1 suppression. ${ }^{165}$ A recent study suggested that MLT supplementation reduced the disrupted structure and function of the liver and mitochondria in nonalcoholic fatty liver disease by ceasing the fission and activation of mitophagy via inhibition of the NR4A1/DNA-PKcs/p53 pathway, resulting in improved mitochondrial and liver function in nonalcoholic fatty liver disease. ${ }^{166}$ Lung cancer metastasis was potentially inhibited by MLT via blocking of EMT. This effect of EMT is mediated by the MT1 receptor, PLC, p38/ERK, and $\beta$-catenin signaling cascades. ${ }^{39}$ MLT is able to prevent carcinogenesis and as a promising treatment option for the primary liver tumors hepatocellular carcinoma (HCC) and cholangiocarcinoma (CCA), either alone or in combination with other compounds. ${ }^{167}$ Several studies reported that MLT plays significant role in various functions such as endocrine, neural, immune and antioxidant functions both receptor dependent and independent manner. ${ }^{168}$ MLT inhibits HepG2 and Hep3B proliferation and cell cycle progression via affecting the cell cycle-associated proteins. MLT potentiates cisplatin-induced apoptosis associated with upregulated caspase-3 and poly ADP-ribose 
polymerase (PARP) cleavage, as well as Bcl-2 expression. Furthermore, MLT inhibits glucose uptake and ATP production via downregulation of Glucose transporter 3 (GLUT3). ${ }^{169}$ Impairment of circadian rhythms associated with various liver diseases, and disruption of rhythms or clock gene expression may promote liver steatosis, inflammation, or cancer development. Due to antioxidative properties of MLT protects oxidative stress-induced liver damage and improves liver conditions and also it restored circadian rhythms. Hence, MLT could be promising therapeutic strategies for liver diseases. ${ }^{170}$

\section{Role and Therapeutic Potential of MLT in Cervical Cancer}

Among women, breast cancer is the most commonly diagnosed cancer and the leading cause of cancer death, and cervical cancer ranks fourth in terms of incidence and mortality. Cervical cancer leading in most 28 of 31 countries and is the leading cause of cancer death in 42 countries. ${ }^{2}$ There were estimated to be 570,000 cases of cervical cancer and 311,000 deaths due to cervical cancer worldwide in 2018. This disease ranks as the fourth-most frequently diagnosed cancer and the fourth leading cause of cancer death in women. Cervical cancer ranks second after breast cancer in terms of incidence and mortality in lower HDI settings. ${ }^{2}$ However, the mortality rate is significantly decreased in developed countries owing to early diagnosis and prevention. The main cause of cervical cancer is infection by the human papillomavirus (HPV), with other external factors, various biochemical alterations, as well as genetic and epigenetic changes also contributing to the initiation and development of cervical cancer. $^{171,172}$ Current treatment options for cervical cancer include chemotherapy, surgical ablation, and radiotherapy. In a multicenter study of endometrial cancer in Austria, 138 women were evaluated for anamnestic, serologic, and cytologic risk factors. Among the 138 patients, 68 were diagnosed with endometrial cancer, and 70 patients had abnormal bleeding, irrespective of age and menopausal status. Further studies showed a correlation between the concentration of MLT and endometrial cancer. The mean plasma MLT value was $6.1 \mathrm{pg} / \mathrm{mL}$ in the cancer-positive group and $33.2 \mathrm{pg} / \mathrm{mL}$ in the cancer-negative control group, showing a six-fold difference between the two groups. The study concluded that decreasing MLT plasma levels may be an indicator of endometrial cancer. ${ }^{173}$ Another study was conducted to determine the correlation between serum MLT level and women suffering from genital tract cancers, in which 46 women were divided into three groups. The first group consisted of 23 patients with malignant tumors of the genital tract. The second group consisted of 16 healthy volunteers who served as the first control group, whereas the third group consisted of 7 subjects who had a myomatous uterus and served as the second control group without malignancy. The results from this study showed that there were no significant differences in circadian MLT profiles among the three groups studied. However, the level of MLT was significantly lower in patients with endometrial cancer of the genital tract compared with tumor-free control groups, and there were no significant differences in MLT secretion between tumor-free control groups and patients with invasive ovarian cancer and squamous cervical cancer. However, significant differences were observed between endometrial cancer and invasive ovarian cancer. ${ }^{174}$ After 5 years, the same research group reported serum MLT circadian profiles in women suffering from cervical cancer. The first group consisted of 31 patients with cervical cancer in various stages of the disease. The second group consisted of 14 healthy volunteers who served as the control group. MLT levels were significantly lower in patients with cancer than in healthy individuals. Moreover, nocturnal MLT concentrations and the area under the curve were significantly lower in patients with advanced-stage cancer than in those with preinvasive cancer. The findings from this study indicate that the presence of cervical cancer affects MLT levels in women. Furthermore, MLT level depends on the stage of cancer. ${ }^{175}$

A study was conducted to determine the inhibitory effect of MLT on 7.12-dimethylbenz[a]anthracene (DMBA)-induced carcinogenesis in the uterine cervix and vagina of mice and in vitro. Forty female CBA mice were exposed to intravaginal polyurethane sponges incorporating $0.1 \%$ solution of DMBA for 2 months at an interval of twice per week. Starting from the day of the first DMBA application, a part of the mice was exposed to MLT in tap water $(20 \mathrm{mg} / \mathrm{L})$ at night five times a week for 4 months. The results revealed that DMBA-treated mice developed malignancies in the vagina and cervix uteri, and two mice developed benign cervical tumors. There were no malignancies in the vagina and uterine cervix of mice exposed to both DMBA and MLT. Thus, this study concluded that MLT inhibits cervical and vaginal carcinogenesis induced by DMBA in mice. ${ }^{176}$ In addition, an in vitro study was performed to examine the effects of MLT on 
ME-180 human cervical cancer cells. The cells were treated with various concentrations of MLT, and cell viability and proliferation were examined. MLT at $2 \mathrm{mM}$ inhibited cell growth after $48 \mathrm{~h}$ of treatment, decreasing the levels of glutathione up to $95 \%$, but exhibited no effect at concentrations of $2 \mu \mathrm{M}$ and $0.1 \mathrm{mM} .{ }^{177}$ Another study reported the combined effect of MLT with various chemotherapeutic agents, including cisplatin, 5-FU, and DOX. MLT significantly induced cytotoxic effects in cervical cancer cells with all the chemotherapeutic agents tested. Furthermore, MLT increased caspase- 3 activation, particularly in cisplatin- and 5-FU-challenged cells. Likewise, co-treatment with MLT and cisplatin significantly induced ROS generation and mitochondrial apoptosis, and markedly increased DNA fragmentation compared with treatment with cisplatin alone. ${ }^{178}$ MLT or combination of MLT and zinc ameliorated DMBA induced brain cortex tissue damage in DMBA-induced breast cancer. ${ }^{70}$

The potential anticancer activity of a combination of MLT with either cisplatin or 5-FU, as well as the involvement of MT1, -2 , and -3 receptors were investigated in HT-29 human colorectal cancer cells and HeLa cervical cancer cells. The results showed that co-treatment with MLT and either cisplatin or 5-FU significantly reduced cell viability in both HT-29 and HeLa cells. Furthermore, MLT significantly increased the cytotoxic effect of 5-FU through the activation of caspase-3. Blockade of MT1 and/or MT2 receptors with luzindole was unable to reverse the enhanced apoptotic effects of chemotherapeutic agent in combination with MTL. In contrast, when MT3 receptors were blocked with prazosin, the synergistic effect of MLT with chemotherapeutic effect was reversed. The findings from this study revealed that MLT potentiates the cytotoxic and proapoptotic effect of chemotherapeutic agents in both cell lines, and this effect is mediated by MT3 receptor stimulation. ${ }^{179}$ To determine the effect of TNF- $\alpha$ mediated cell death in the presence of MLT, HeLa cells were incubated with TNF $\alpha$, and cell death was then determined. MLT induced cancer cell death in the presence of TNF- $\alpha$ via the activation of caspase-9, reduction of mitochondrial potential, elevated ROS production, reduction of ATP production, and elevation of cyt-c expression in the nucleus. In addition, MLT increased the response of $\mathrm{HeLa}$ cells to TNF- $\alpha$ mediated cancer death by repressing mitophagy. ${ }^{180}$ Wang et al reported that SGK1 is an anti-oxidative factor that promotes survival of cervical cancer cells. ${ }^{181}$ Further a strong inverse association between SGK1 and oxidative phosphorylation. Inhibition of SGK1 confers susceptibility to MLT as a pro-oxidant, resulting increased level of ROS and eventually increased cell cytotoxicity. Chen et $\mathrm{al}^{182}$ studied the effect and mechanism of MLT on HeLa cells apoptosis under cisplatin (CIS) treatment. ${ }^{182}$ Co-treatment of MLT and CIS increases apoptosis through caspase-9-related apoptosis and decreasing level of lower mitochondria membrane potential, higher mitochondria ROS, and expression of higher level of pro-apoptotic proteins compared to the treatment with CIS alone.

\section{Role and Therapeutic Potential of MLT in Ovarian Cancer}

Ovarian cancer begins as abnormal, out-of-control multiplication of cells in the ovary, leading to tumor formation. Ovarian cancer is one of the most common causes of morbidity related to gynecologic malignancies. Possible risk factors include hereditary ovarian cancer, obesity, diabetes mellitus, alcohol consumption, aging, and smoking. Current treatments for ovarian cancer include surgery, chemotherapy, and combination therapy. ${ }^{183}$ Ovarian cancer is the seventh most common cancer, and the eighth most common cause of death due to cancer in women worldwide. Among gynecological cancers, cervical cancer and endometrial cancer represent the greatest burden in developing and developed countries, respectively. However, the rate of death due to ovarian cancer is almost twice higher in developed countries than in developing countries. The population with the highest rate of diagnosis per year is China $(34,575)$, followed by India $(26,834)$ and the USA $(20,874)$ (World Ovarian Cancer Coalition 2018; http://www.cancer.org.au). To measure the steadystate level of MLT, epidemiological studies of prostate, lung, colorectal, and ovarian cancer were carried out by measuring the serum level of MLT in 97 individuals. The Pearson correlation coefficients between the two measures separated by 1 year and 5 years were 0.87 and 0.70 , respectively. Further, the environmental effect of MLT levels was measured in 130 individuals during winter and summer. The results showed that the level of MLT was slightly higher in winter $(6.36 \pm 0.59 \mathrm{pg} / \mathrm{mL})$ than in summer $(4.83 \pm 0.62 \mathrm{pg} / \mathrm{mL}) .{ }^{184}$ Clinical trials suggested that the use of MLT as an adjuvant with chemotherapy decreased 1-year mortality and reduced chemotherapyinduced symptoms, such as asthenia, leucopenia, nausea, 
vomiting, and hypotension, whereas a nested case-control study showed no obvious association between urinary MLT level and ovarian cancer risk. ${ }^{185,186}$

IL-2 immunotherapy is a beneficial therapy for the treatment of recurrent advanced ovarian cancer. Interestingly, MLT can amplify IL-2 efficacy by counteracting macrophage-mediated immunosuppression. A pilot Phase II study investigated the efficacy of treatment with low-dose IL-2 plus MLT in patients with advanced ovarian cancer. Patients were injected with IL-2 subcutaneously at 3 million IU/day at 6 days/week for 4 weeks, and MLT was administered orally at $40 \mathrm{mg} /$ day. Using this protocol, a partial response was achieved. This study suggests that immunotherapy with low-dose IL-2 plus MLT may be a well-tolerated and promising therapy for advanced ovarian cancer progressing on standard medical treatments. ${ }^{187}$ In another phase II study, the same author investigated the efficacy of combination therapy with tamoxifen (TMX) plus MLT in patients with metastatic solid tumors. The results showed that oral supplementation with these two drugs increased the performance and survival of patients. This study suggested that the combination of TMX plus MLT has a beneficial effect on untreatable metastatic solid tumors. ${ }^{188}$ In another study, primary cells from seven ovarian and six mammary tumors were incubated with YC05R pineal extract and chemotherapeutic drugs. YC05R pineal extract inhibited the growth of all tumors in a dose-dependent manner. Both MLT and pineal extract inhibited cell growth depending on the cell types derived from individual cases. None of the primary cells responded in a similar manner. The study concluded that MLT is an inhibitor of human mammary and ovarian carcinoma in individual cases, and that the pineal gland contains active antitumor substances that inhibit both mammary and ovarian tumors. ${ }^{22}$ A clinical study showed that MLT secretion was lower in patients with endometrial cancer compared with that in tumor-free control groups; however, significant differences in MLT secretion were observed between endometrial cancer and invasive ovarian cancer. ${ }^{174} \mathrm{Kim}$ et al ${ }^{189}$ investigated the combined effect of MLT and cisplatin in human ovarian cancer cells. The results showed that MLT alone had no significant inhibitory effect on cell viability, proliferation, and death. However, its combination with cisplatin synergistically inhibited the viability of SK-OV-3 cells by increasing the sub-G1 DNA content, TUNEL-positive cells, and caspase 3 levels, as well as inhibited the phosphorylation of ERK and the dephosphorylation of 90-kDa ribosomal S6 kinase
(p90RSK) and heat shock protein 27 (HSP27) induced by cisplatin. Furthermore, MLT in a combination with cisplatin remarkably blocked the expression and colocalization of p90RSK and HSP27. MLT protects against cisplatininduced cytotoxicity in OSEN normal ovarian epithelial cells. Collectively, these findings suggest that MLT enhances cisplatin-induced apoptosis via the inactivation of the ERK/p90RSK/HSP27 cascade in SK-OV-3 cells as a potent synergist to cisplatin treatment. MLT suppresses the TLR4-mediated inflammatory response through MyD88- and TRIF-dependent signaling pathways in an in vivo model of ovarian cancer. Furthermore, it suppresses the expression level of various proteins, including nuclear factor kappa B (NF-kB p65), inhibitor of NF-kB alpha (IkB $\alpha)$, IkB kinase alpha (IKK- $\alpha)$, TNF receptorassociated factor 6 (TRAF6), TRIF, interferon regulatory factor 3 (IRF3), interferon $\beta$ (IFN- $\beta$ ), TNF- $\alpha$, and IL- $6 .{ }^{190}$ The effect of MLT on follicle development and oocyte maturation was investigated by exposing in vitro cultured mouse vitrified-warmed ovarian follicles to 10 pmol MLT. The results showed significant increases in follicle survival and diameter compared with those in the control group. ${ }^{191}$ MLT regulates anticancer activity through receptor mediated and activation of various signaling cascades in ovarian cancer cells (Figure 7). The levels of IL-6 in saliva, serum, and bronchoalveolar lavage fluid (BALF) and its family members playing significant role in diagnosis, prognosis of relapse-free survival and recurrence and IL-6 serving as biomarker of cancer. ${ }^{192}$ The apoptotic effect of MLT in ovarian cancer was studied by analyzing the expression of several pro-apoptotic and anti-apoptotic proteins in an ethanol-preferring rat model. To induce ovarian cancer, the left ovary was injected directly with a single dose of $100 \mu \mathrm{g}$ DMBA dissolved in $10 \mu \mathrm{L}$ of sesame oil under the bursa, and the right ovaries were used as sham-surgery controls. The rats that developed ovarian cancer showed no significant change in body weight gain, ethanol consumption, and energy intake. Interestingly, the absolute and relative masses of ovarian cancer were reduced after exposure to MLT, regardless of ethanol consumption. In addition, MLT therapy and ethanol intake promoted apoptosis, upregulation of $\mathrm{p} 53$, Bax, and cleaved caspase-3, and DNA fragmentation. ${ }^{193}$ MLT inhibits the growth of human ovarian cancer cells, such as OVCAR429 and PA-1 cells, via accumulation of cells in the G1 phase, which is associated with the downregulation of CDK 2 and 4. ${ }^{194}$ After chemotherapy, the ovaries became pre-matured, and follicle loss occurred. To elucidate the 


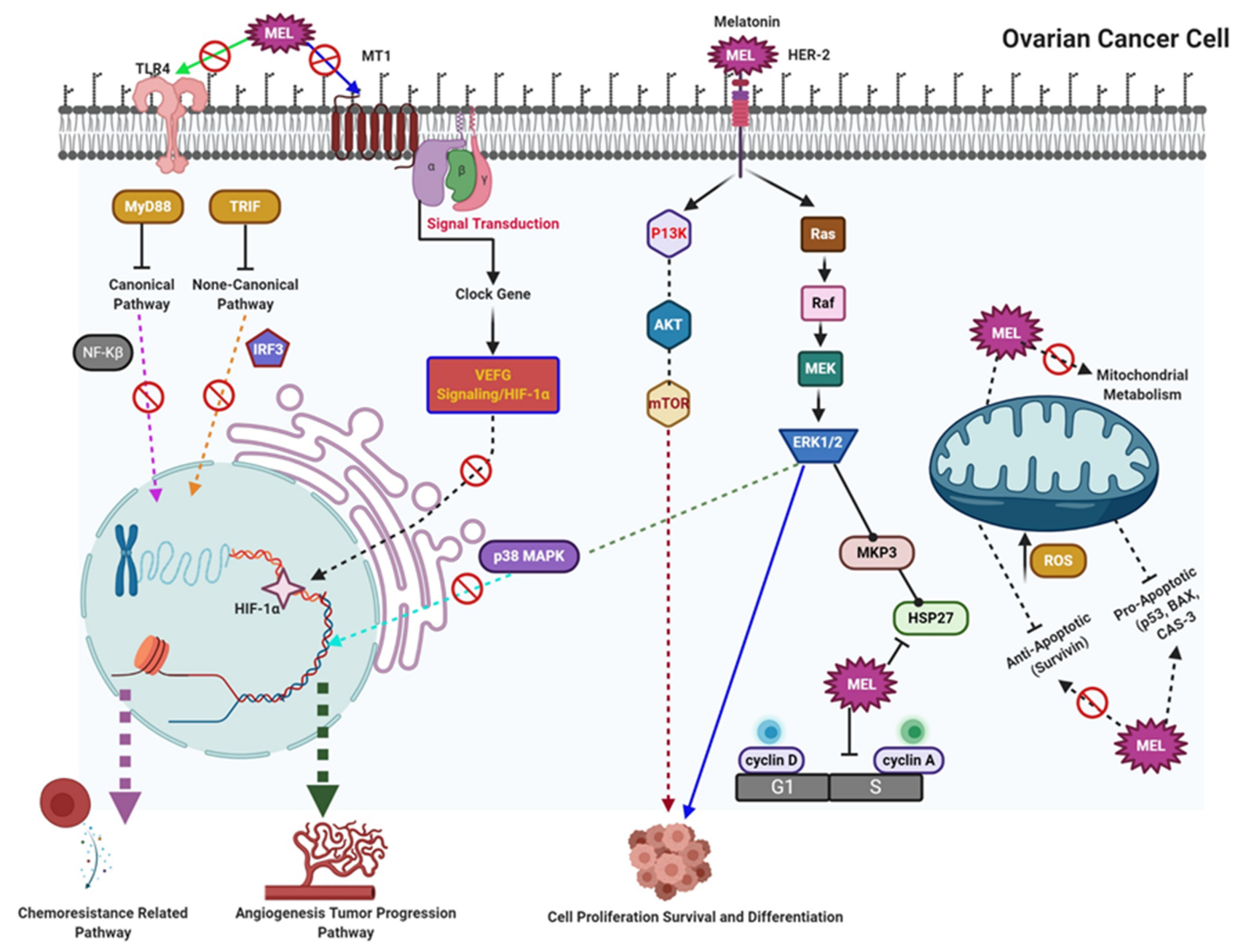

Figure 7 Molecular mechanism of anticancer activity of MLT on ovarian cancer.

mechanism, Jang et $\mathrm{al}^{195}$ revealed that MLT prevented cisplatin-induced disruption of the follicle reserve by decreasing the cisplatin-mediated inhibitory phosphorylation of PTEN and cisplatin-induced phosphorylation of AKT, GSK3 $\beta$, and FOXO3a, all of which trigger follicle activation. In addition, MLT inhibited the inhibitory effect of cisplatin on the phosphorylation and nuclear export of FOXO3a, which is required in the nucleus to maintain the dormancy of primordial follicles. These studies provide evidence that MLT exerted a protective effect against cisplatin-induced follicle loss by preventing the phosphorylation of PTEN/AKT/FOXO3a pathway members. Therefore, the authors concluded that MLT is a potential therapeutic agent that could protect the ovary and help preserve fertility during chemotherapy in women with cancer.

Circadian rhythms play an important role in ovarian cancer, and night shift workers are more prone to developing gynecological cancers. Therefore, a study was conducted to elucidate the effect of MLT on the seasonal distribution of birth. MLT was measured in 96 women with ovarian cancer and 40 healthy women. In addition, 277 women with ovarian cancer and 1076 controls were retrospectively enrolled for the analysis of seasonal distribution of birth over a 7-year period. The analysis revealed that MLT levels in the serum of women with ovarian cancer were significantly lower than those in healthy women, but there was no significant difference in seasonal distribution of birth between patients with ovarian cancer and the control group. The findings of the study reveal that MLT levels are not associated with the seasonal distribution of birth. Interestingly, a lower level of MLT is a major factor in the pathogenesis of ovarian cancer. ${ }^{14}$ To provide evidence of the antiangiogenic effect of MLT on ovarian cancer, rats were induced with serous papillary ovarian cancer, and half of the animals received 
intraperitoneal injections of MLT $(200 \mu \mathrm{g} / 100 \mathrm{~g}$ body weight/day) for 60 days. MLT-treated animals showed a significant reduction in ovarian cancer size and microvessel density. Serum MLT level was significantly higher, and the expression of its receptor MT1 was significantly increased in ovarian cancer-bearing rats, regardless of ethanol intake. After exposure to MLT, the expression of TGF $\beta 1$, VEGFR1, and VEGFR2. ${ }^{196}$ Co-administration of MLT and ghrelin inhibits cisplatin-induced follicle disruption by restoring the number of primordial follicles and corpus luteum in cisplatin-treated ovaries, compared with single administration. MLT and ghrelin co-administration inhibited cisplatin-induced phosphorylation of PTEN and FOXO3a, which induces cytoplasmic translocation of FOXO3a. ${ }^{197}$ CSCs play a critical role in resistance to chemotherapy. Therefore, the effect of MLT was investigated in CSCs isolated from SKOV3 ovarian cancer cells. MLT inhibited the invasiveness and migration of CSCs compared with those of SKOV3 cells and inhibited the proliferation of CSCs by $23 \%$, which was confirmed by a marked decrease in the protein expression of Ki67 and decreased expression of EMT-related genes, including ZEB1, ZEB2, Snail, and vimentin. ${ }^{198}$ A study from mouse model demonstrated that chronic restraint stress (CRS) stimulated the abdominal implantation metastasis of epithelial ovarian cancer (EOC) cells and the expression of epithelial-mesenchymal transition-related markers. MLT effectively reduced the abdominal tumor burden of ovarian cancer induced by CRS. ${ }^{199}$

\section{Mechanisms of the Anticancer Activity of MLT}

MLT is a naturally produced hormone that can be used as an adjuvant in cancer treatments. In particular, MLT is associated with sexual hormones steroidogenesis in breast, ovarian, and prostate cancers. MLT, an antiestrogenic agent, regulates the levels and modulates the transcriptional activity of the ER and AR, depending on exposure to light at night. MLT potentially synergizes with chemotherapeutic agents, thus facilitating the use of lower doses of chemotherapeutic agents and leading to the prevention of the undesirable detrimental side effects of chemo- and radiotherapy. Clinical trials have proved the ability of MLT to enhance the therapeutic effect of various anticancer drugs and to improve the sleep and life quality of patients with cancer. MLT potentially acts as a metastasis inhibitor by inhibiting the proliferation and autonomous growth of tumor cells; moreover, MLT selectively blocks the signal transduction pathways of tumor cells. ${ }^{99,200}$

The anticancer and anti-angiogenic activity of MLT in cancer is mediated by various mechanisms, including membrane receptor-dependent and -independent mechanisms (Figure 8). Angiogenesis is an important event in cancer progression and development. Generally, tumor cells stimulate angiogenesis by activating angiogenic factors and inhibiting antiangiogenic factors. ${ }^{201,202}$ VEGF is one of the critical factors for angiogenesis. In fact, mice treated with MLT showed disrupted tumor blood vessel formation and decreased serum levels of VEGF. ${ }^{203-205}$ Administration of MLT reduced serum VEGF levels in patients with cancer metastasis, and the protein and mRNA levels of VEGF were decreased in pancreatic carcinoma cells. ${ }^{116,206}$ Via its direct anticancer mechanism, MLT can inhibit the proliferation and growth of tumor cells, prevent healthy cells from becoming neoplastic, and induce cellular turnover and replacement of tumor cells with healthy cells through activation of caspasedependent apoptosis. ${ }^{207,208}$ MLT exhibited an oncostatic mechanism through the activation and upregulation of p21/WAF1 and p53 suppressor genes, which halt the reproduction cycle of tumor cells, and physiological concentrations of MLT reduced the number and vitality of the tumor cells via pro-apoptotic pathways. ${ }^{58,209}$ MLT exhibited not only receptor-mediated antitumor activity but also complex antitumor mechanisms, including activation of apoptosis as well as inhibition of proliferation and cell differentiation, all of which depend on the physiological concentrations of MLT and the intracellular redox state. ${ }^{210}$ Tumor death depends on the ability to induce either an antioxidant environment, which facilitates an antiproliferative effect, or a pro-oxidant environment related to the cytotoxic effect. ${ }^{210}$ The antiproliferative action of MLT is associated with decreased levels of intracellular ROS and increased sub-cellular antioxidant enzymes, and the occurrence of programmed cell death is induced by increased levels of ROS and decreased levels of antioxidant defenses. ${ }^{211}$

The oncostatic action of MLT plays a critical role in metastasis, which is a major cause of death in various cancers and is correlated with the regulation of cell-cell and cell-matrix interactions, extracellular matrix remodeling by matrix metalloproteinases, cytoskeleton reorganization, EMT, and angiogenesis. ${ }^{10}$ The combination of MLT and arsenic trioxide synergistically killed cancer cells 
THE TUMOR MICROENVIRONMENT

Melatonin and its ubiquitous anticancer effects

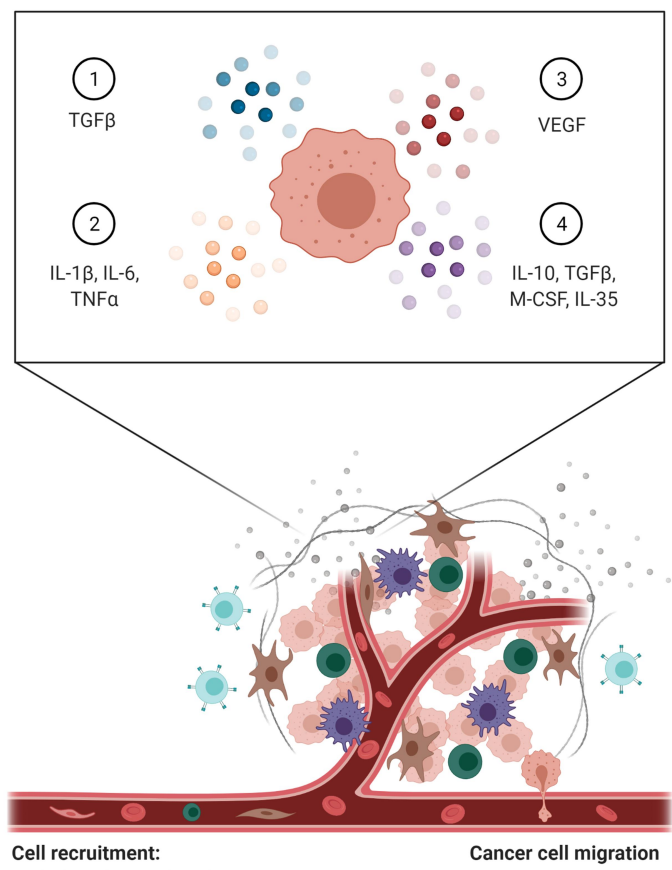

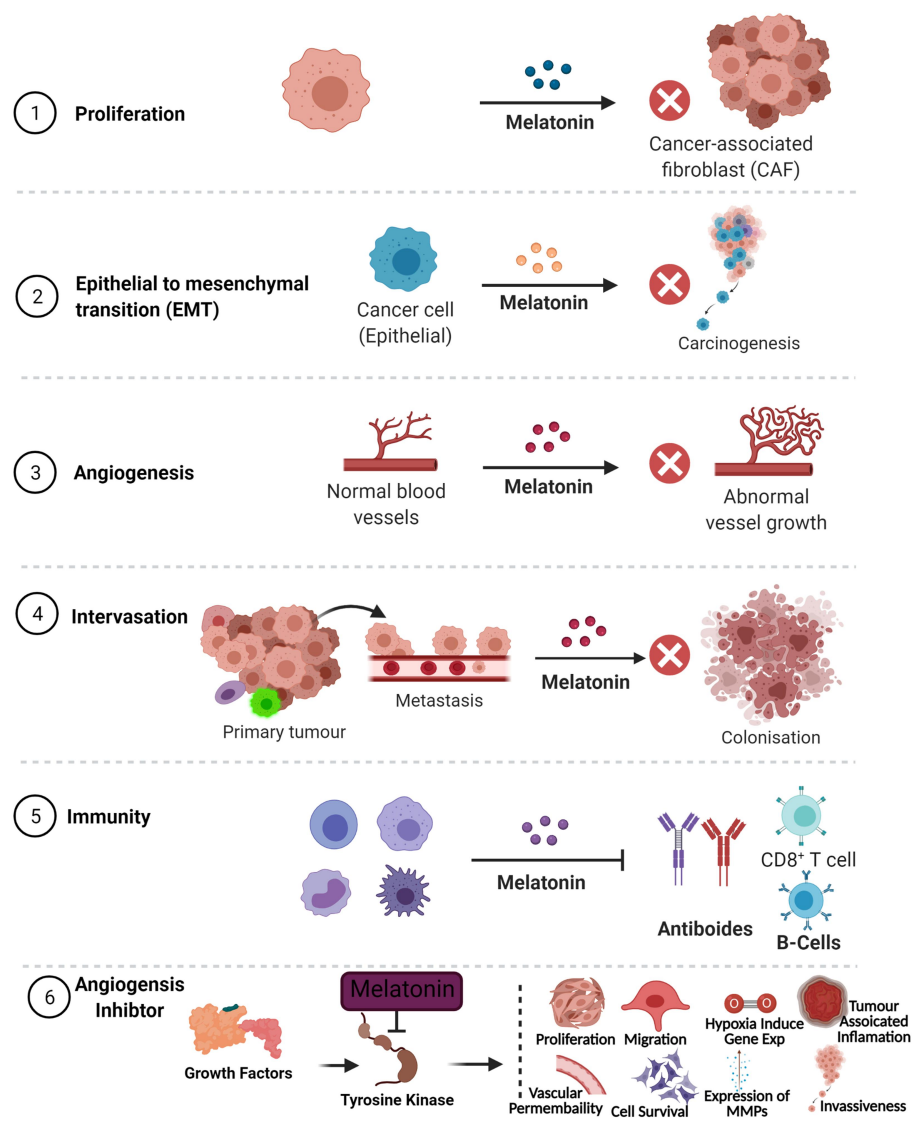

Figure 8 Ubiquitous anticancer and antiangiogenic effect of MLT.

through activation of the apoptotic pathway, increased production of intracellular ROS, upregulation of Redd1 expression, and activation of the p38/JNK (c-JUN$\mathrm{N}$-terminal kinase) pathway in human breast cancer cells. ${ }^{212}$ Similarly, the combination of MLT and puromycin synergistically increased cell death in MDA-MB 231 breast cancer cells via the reduction of $45 \mathrm{~S}$ pre-rRNA and downregulation of the upstream binding factors XPO1 and IPO7, procaspase 3, and Bcl-xL. ${ }^{213}$ The anticancer activity of MLT depends on activation of signal transduction processes of the MT1 and MT2 membrane receptors and antioxidant activities, inhibition of enzymes involved in carcinogenesis, reversal of the Warburg effect, telomerase-inhibitory action, induction of epigenetic processes, and anti-inflammatory effect. ${ }^{11}$ The in vitro and in vivo effects of melatonin on various type of cancers were shown in Table 1.

\section{Conclusion and Future Perspectives}

Cancer is a group of diseases characterized by uncontrolled growth and spread of abnormal cells. The incidence and mortality rates of cancer have increased immensely. MLT is a multifunctional pineal hormone produced by the pineal gland that not only regulates the circadian rhythm but also has multiple functions, including antioxidant, anti-inflammatory, antiaging, immunomodulatory, anti-estrogenic, anti-proliferative, anti-metastatic, pro-apoptotic, antiangiogenic, prodifferentiation, and anti-carcinogenic, anti-tumor, and anticancer effects. There is a large body of evidence from experimental and clinical studies suggesting that MLT has the potential to exhibit anticancer activities, such as apoptotic, oncostatic, anti-proliferative, and antiangiogenic effects, against all solid and liquid tumors. MLT mitigates cancer at the initiation, progression, and metastasis phases. The involvement of MLT in activating various anticancer mechanisms in various types of cancers makes it an important physiological anticancer agent. In this review, we comprehensively presented the most important and significant data on the history, epidemiology, risk factors, therapeutic efficacy, clinical significance, and anticancer mechanism of MLT. Further, we discussed the anticancer mechanism of MLT in cancers. However, to date, the molecular mechanism of the anticancer activity of MLT 
Table I The in vitro and in vivo Effects of Melatonin on Various Type of Cancers

\begin{tabular}{|c|c|c|c|c|}
\hline $\begin{array}{l}\text { Type of } \\
\text { Cancer }\end{array}$ & $\begin{array}{l}\text { Type of Experiments } \\
\text { Performed }\end{array}$ & Objective of the Study & Significance of the Study & Reference \\
\hline Lung & $\begin{array}{l}\text { Tumor inoculation and melatonin } \\
\text { treatment }(1.25 \mathrm{mg} / \mathrm{kg} / \mathrm{night}) \text { were } \\
\text { performed } 2 \text { months after } \\
\text { pinealectomy }\end{array}$ & $\begin{array}{l}\text { Female BD2FI mice with subcutaneous } \\
\text { propagation of Lewis lung carcinoma }\end{array}$ & $\begin{array}{l}\text { Melatonin treatment decreased metastasis with } \\
\text { consequent restoration of thymic efficiency }\end{array}$ & {$[214]$} \\
\hline Lung & $\begin{array}{l}30 \text { NSCLC patients before and after } \\
\text { treatment with standard } \\
\text { chemotherapy (cisplatin plus } \\
\text { vinorelbine) and } 63 \text { healthy } \\
\text { volunteers }\end{array}$ & $\begin{array}{l}\text { Melatonin levels were measured in blood and } \\
\text { urine samples }\end{array}$ & $\begin{array}{l}\text { Melatonin, its precursor tryptophan, and its } \\
\text { major metabolite, 6-sulfatoxymelatonin } \\
\text { concentrations were significantly lower in } \\
\text { cancer patients, in comparison with healthy } \\
\text { subjects }\end{array}$ & [215] \\
\hline Lung & $\begin{array}{l}\text { I7 patients with stages I and II of } \\
\text { untreated NSCLC, } 17 \text { patients with } \\
\text { stages III and IV of untreated } \\
\text { NSCLC, and I7 controls }\end{array}$ & $\begin{array}{l}\text { Melatonin level was measured in blood } \\
\text { samples }\end{array}$ & $\begin{array}{l}\text { Melatonin levels were lower in the patients } \\
\text { with NSCLC than in normal subjects }\end{array}$ & {$[216]$} \\
\hline Lung & SK-LU-I NSCLC cell line & $\begin{array}{l}\text { Cells were treated with Melatonin }(1,2 \mathrm{mM})+ \\
\text { cisplatin }(10-200 \mu \mathrm{M})(48 \mathrm{~h} \text { in culture })\end{array}$ & $\begin{array}{l}\text { Melatonin potentiate the effect of cisplatin and } \\
\text { reduce the IC50 concentration of cisplatin }\end{array}$ & [38] \\
\hline Lung & $\begin{array}{l}\text { A549 cells and healthy human } \\
\text { lymphocytes }\end{array}$ & $\begin{array}{l}\text { Combination of melatonin }(50 \mu \mathrm{M}) \text { and } \\
\text { various concentrations of irinotecan }(7.5,15 \text {, } \\
30 \text {, and } 60 \mu \mathrm{M})\end{array}$ & $\begin{array}{l}\text { The combination treatment specific to cancer } \\
\text { cells not healthy lymphocytes }\end{array}$ & [118] \\
\hline Lung & A549 cells & $\begin{array}{l}\text { Melatonin }(0.1,1 \mathrm{mM})+\text { doxorubicin }(0.1, \mathrm{I} \\
\mathrm{microg} / \mathrm{mL})\end{array}$ & $\begin{array}{l}\text { Melatonin increases cytotoxicity and apoptosis } \\
\text { with doxorubicin }\end{array}$ & [217] \\
\hline Lung & $\begin{array}{l}\text { Female C57B/6 mice with } \\
\text { subcutaneous propagation of Lewis } \\
\text { lung carcinoma HI } 299 \text { and A549 } \\
\text { cells }\end{array}$ & $\begin{array}{l}\text { Melatonin }(1 \mathrm{mg} / \mathrm{kg})+\text { cyclophosphamide }(40 \\
160 \mathrm{mg} / \mathrm{kg})+ \text { etoposide }(20,40 \mathrm{mg} / \mathrm{kg})\end{array}$ & $\begin{array}{l}\text { Melatonin can rescue myeloid progenitor cells } \\
\text { from chemotherapy-induced apoptosis }\end{array}$ & {$[218]$} \\
\hline Lung & HI 299 and A549 cells & $\begin{array}{l}\text { Melatonin }(\mathrm{I} \mathrm{mM})+\text { berberine }(20 \mu \mathrm{M} \text { to } 200 \\
\mu \mathrm{M})\end{array}$ & $\begin{array}{l}\text { Melatonin sensitized NSCLC cells to berberine } \\
\text { and enhanced apoptosis }\end{array}$ & [219] \\
\hline Lung & $\begin{array}{l}\text { Untreatable metastatic NSCLC or } \\
\text { Gl cancers (No of patients 846) }\end{array}$ & $\begin{array}{l}\text { Melatonin }(20 \mathrm{mg} / \text { day })+\mathrm{IL}-2 \text { ( } 3 \text { million IU/day, } \\
5 \text { days/week, } 4 \text { weeks })+ \text { supportive care }\end{array}$ & $\begin{array}{l}\text { The combination treatment reduces tumor } \\
\text { regressions }\end{array}$ & [220] \\
\hline Lung & $\begin{array}{l}\text { Advanced lung adenocarcinoma } \\
\text { No of patients } 23\end{array}$ & $\begin{array}{l}\text { Melatonin }(20 \mathrm{mg} / \text { day })+\text { somatostatin } \\
(1-3 \mathrm{mg} / \text { day })+\text { Retinoids }(5 \mathrm{~mL})+\text { Vitamin } \\
\mathrm{D}(0.3 \mathrm{mg} / \text { day })+\text { bromocriptine }(2.5 \mathrm{mg} / \text { day })+ \\
\text { cyclophosphamide }(150 \mathrm{mg} / \text { day })\end{array}$ & $\begin{array}{l}\text { Combination treatments increases } 95 \text { days of } \\
\text { survival of patients }\end{array}$ & [221] \\
\hline Lung & $\begin{array}{l}\text { Untreated metastatic NSCLC (No } \\
\text { of patients 147) }\end{array}$ & $\begin{array}{l}\text { Melatonin }(20 \mathrm{mg} / \mathrm{day})+\text { cisplatin plus } \\
\text { etoposide or gemcitabine }\end{array}$ & $\begin{array}{l}\text { Combination treatment increases over all } \\
\text { survival of patients for } 2 \text { years and also tumor } \\
\text { regression was observed }\end{array}$ & [34] \\
\hline Lung & $\begin{array}{l}\text { Untreated metastatic NSCLC (No } \\
\text { of patients } 100 \text { ) }\end{array}$ & $\begin{array}{l}\text { Melatonin }(20 \mathrm{mg} / \text { day })+\text { cisplatin }(20 \mathrm{mg} / \mathrm{m} 2 / \\
\text { day }+ \text { etoposide }(100 \mathrm{mg} / \mathrm{m} 2 / \text { day })\end{array}$ & $\begin{array}{l}\text { Overall survival of patients was increased and } \\
\text { also tumor regression rate was observed } \\
\text { The percent of I-year survival was significantly } \\
\text { higher in patients treated with melatonin plus } \\
\text { chemotherapy }\end{array}$ & [32] \\
\hline Lung & Advanced NSCLC & $\begin{array}{l}\text { Melatonin }(20 \mathrm{mg} / \text { day })+\text { cisplatin }(20 \mathrm{mg} / \mathrm{m} 2 / \\
\text { day })+ \text { etoposide }(100 \mathrm{mg} / \mathrm{m} 2 / \text { day })\end{array}$ & $\begin{array}{l}\text { The inhibitory action of melatonin on } \\
\text { mammary cancer estrogen-positive cell lines is } \\
\text { depends on its ability to regulate either the } \\
\text { synthesis of estrogens or estrogen signaling } \\
\text { pathways }\end{array}$ & [222] \\
\hline
\end{tabular}


Table I (Continued).

\begin{tabular}{|c|c|c|c|c|}
\hline $\begin{array}{l}\text { Type of } \\
\text { Cancer }\end{array}$ & $\begin{array}{l}\text { Type of Experiments } \\
\text { Performed }\end{array}$ & Objective of the Study & Significance of the Study & Reference \\
\hline Breast & In vitro & $\begin{array}{l}\text { Cancer estrogen-positive cell lines treated } \\
\text { with InM melatonin } \\
\text { InM melatonin }\end{array}$ & $\begin{array}{l}\text { Decreases the levels of ER } \alpha \text { in in vitro } \\
\text { experiments in MCF-7 cells }\end{array}$ & [223] \\
\hline Breast & In vitro & MCF-7 cells treated with (I nM) & $\begin{array}{l}\text { Combination of melatonin and troglitazone } \\
\text { induces apoptosis in MDA-MB-23I }\end{array}$ & [224] \\
\hline Breast & In vitro & Melatonin (ImM) and troglitazone & $\begin{array}{l}\text { Combination of melatonin and DMBA reduced } \\
\text { tumor incidence and decreased the quantity of } \\
\text { invasive and in situ carcinomas in a rat model }\end{array}$ & [225] \\
\hline Breast & In vivo & $\begin{array}{l}\text { Melatonin ( } 500 \mathrm{mg} / \mathrm{day}, 2 \text { weeks prior to } \\
\text { DMBA during } 20 \text { weeks, injected at late } \\
\text { afternoon) and resveratrol }\end{array}$ & $\begin{array}{l}\text { Combined with doxorubicin, and melatonin } \\
\text { enhanced cancer cells apoptosis in vivo in rats } \\
\text { bearing breast tumors and also increases } \\
\text { survival rate. }\end{array}$ & [226] \\
\hline Breast & In vivo & $\begin{array}{l}\text { The animals treated with both doxorubicin } \\
\text { plus melatonin ( } 10 \mathrm{mg} / \mathrm{kg} \text { of body weight, daily } \\
\text { injected during } 15 \text { days) }\end{array}$ & Increases survival rate and reduce tumor level & [227] \\
\hline Breast & In vitro & $\begin{array}{l}\text { MCF-7 cells treated with doxorubicin and } \\
\text { melatonin }\end{array}$ & $\begin{array}{l}\text { Combination of doxorubicin and melatonin had } \\
\text { a synergic effect on apoptosis and } \\
\text { mitochondrial oxidative stress. }\end{array}$ & [228] \\
\hline Prostate & In vivo & $\begin{array}{l}\text { Rats were treated with melatonin (dose of } \\
150 \mathrm{mg} / 100 \mathrm{~g} \text { of body weight, administered for } \\
4 \text { weeks) }\end{array}$ & $\begin{array}{l}\text { Melatonin treated rats showed significant } \\
\text { decrease in the ventral prostate weight in } \\
\text { castrated and castrated-testosterone-treated } \\
\text { rats }\end{array}$ & [229] \\
\hline Prostate & In vitro & $\begin{array}{l}\text { Prostate cancer cells treated with, } \\
\text { a physiological dose of melatonin ( } \mathrm{nM})\end{array}$ & $\begin{array}{l}\text { Melatonin treatment attenuated the growth of } \\
\text { the human androgen-sensitive prostatic tumor } \\
\text { cell line LNCaP in vitro }\end{array}$ & [230] \\
\hline Breast & In vitro & $\begin{array}{l}\text { Breast cancer cell lines CMT-U229 and MCF-7 } \\
\text { treated with ImM melatonin }\end{array}$ & Inhibits metastasis & [64] \\
\hline Breast & In vitro & $\begin{array}{l}\text { MCF-7/6, MCF-7/Her2.I, and MCF-7/CXCR4 } \\
\text { cells treated with 10-9 M of melatonin }\end{array}$ & $\begin{array}{l}\text { Inhibiting cancer cell invasion by down- } \\
\text { regulation of the p } 38 \text { pathway and suppression } \\
\text { of MMP- } 2 \text { and }-9 \text { expression and activity }\end{array}$ & [227] \\
\hline Breast & In vivo & $\begin{array}{l}\text { Athymic nude mice treated with melatonin at } \\
\text { concentration of } 40 \mathrm{mg} / \mathrm{kg}\end{array}$ & $\begin{array}{l}\text { Melatonin inhibits angiogenesis by reducing cell } \\
\text { proliferation and tumor size }\end{array}$ & {$[231]$} \\
\hline Breast & In vivo & $\begin{array}{l}\text { BALB/C mice were treated with melatonin } \\
33 \mathrm{mg} / \mathrm{L}\end{array}$ & $\begin{array}{l}\text { Melatonin decreases tumor size by the } \\
\text { mechanism regulation global DNA methylation }\end{array}$ & [232] \\
\hline Prostate & In vivo & Mice were treated with $4 \mathrm{nM}$ of melatonin & $\begin{array}{l}\text { Melatonin inhibits angiogenesis and inhibits } \\
\text { growth }\end{array}$ & [96] \\
\hline Prostate & In vivo & Mice were treated with 10 and $20 \mathrm{mg} / \mathrm{L}$ & $\begin{array}{l}\text { Melatonin inhibits tumorigenesis by } \\
\text { suppressing SIRTI activity }\end{array}$ & [233] \\
\hline $\begin{array}{l}\text { Ovarian } \\
\text { cancer }\end{array}$ & In vitro & $\begin{array}{l}\text { Ovarian cancer cell lines such as OVCAR-429 } \\
\text { and PA-I cells treated with various } \\
\text { concentrations of } 400,600 \text {, and } 800 \mu \mathrm{M} \\
\text { melatonin }\end{array}$ & $\begin{array}{l}\text { Inhibiting angiogenesis by delay of } \mathrm{GI} / \mathrm{S} \text { via } \\
\text { down-regulation of CDK2 and } 4\end{array}$ & [194] \\
\hline
\end{tabular}

(Continued) 
Table I (Continued).

\begin{tabular}{|l|l|l|l|l|}
\hline $\begin{array}{l}\text { Type of } \\
\text { Cancer }\end{array}$ & $\begin{array}{l}\text { Type of Experiments } \\
\text { Performed }\end{array}$ & Objective of the Study & Significance of the Study \\
\hline $\begin{array}{l}\text { Ovarian } \\
\text { cancer }\end{array}$ & In vivo & $\begin{array}{l}\text { Rats were treated with } 200 \mu \mathrm{g} / 100 \\
\mathrm{~g} \text { melatonin }\end{array}$ & $\begin{array}{l}\text { Reducing tumor size and apoptosis by various } \\
\text { mechanisms such as upregulation of } \mathrm{p} 53, \mathrm{BAX}, \\
\text { and cleaved caspase-3, and enhancement of } \\
\text { DNA fragmentation; attenuating the TLR4- } \\
\text { induced MyD88- and TRIF-dependent signaling } \\
\text { pathways; attenuating Her-2, p38 MAPK, } \\
\text { p-AKT, and mTOR Levels }\end{array}$ \\
\hline $\begin{array}{l}\text { Cervical } \\
\text { cancer }\end{array}$ & In vivo & $\begin{array}{l}\text { Nude rats were treated with } 500 \mathrm{pM} \\
\text { melatonin }\end{array}$ & $\begin{array}{l}\text { Melatonin inhibiting tumor growth suppressing } \\
\text { tumor metabolism and proliferation through } \\
\text { inhibiting aerobic glycolysis and fatty acid } \\
\text { metabolic signaling }\end{array}$ \\
\hline
\end{tabular}

against different types of cancer is unclear, and the fundamental action mechanism of MLT remains to be elucidated. MLT regulates cancer in a receptor-dependent and -independent manner. The unique feature of MLT is that it inhibits the entry of cancer cells into the vascular system and prevents them from metastasizing to distant sites. Considering the wide range of the pleiotropic beneficial effects of MLT both in vitro and in vivo, MLT is a good candidate for further research to determine its role in various types of cancer.

Although several studies have reported that MLT has several beneficial anticancer activities, still it has some minor side effects such as drowsiness, dizziness, headaches, as well as nausea and apathy combined with weight gain. Long term administration of MLT decreases semen quality and motility. Increased level of MLT causes damage to retinal photoreceptors. Hence, future research is still needed to fully elucidate its anticancer mechanisms and safety measurement of usage. Several studies have reported that MLT has several beneficial anticancer activities, future research is still needed to fully elucidate its anticancer mechanisms. It is well known that MLT has dual actions, namely pre-apoptotic and anti-apoptotic actions. For example, the antiapoptotic effect is observed in not only cancer cells but also normal cells; therefore, the differential mechanism needs to be addressed between normal and cancer cells, and the elusive function of MLT in cancer treatment needs to be further studied. Moreover, studies are required to achieve consistent and uniform responses and to eliminate ambiguity. At this juncture, researchers from different institutes at similar times can use various parameters including different types of cell lines, doses (physiological, pharmacological, and toxicological dose of MLT), incubation conditions, treatment duration, and passage number of treated cells for specific functions with specific targets. Further clinical studies are required to focus on enhancing the capacity of MLT in reducing the undesired detrimental effects of anticancer drugs. Another important and vital aspect, future studies are required to solve the inconsistency of the results derived from epidemiological studies. This might be caused by the use of different kinds of samples, sample collection times, and assessment methods of MLT. Therefore, different assessment methods for MLT need to be compared, and the most reliable one should be adopted in future studies. Furthermore, the most appropriate sample collection time must be determined based on the quantity of MLT in human samples. Experimental studies can be designed to explore the link between anticancer activity of MLT with autophagy and mitochondrial dysfunctions. Further investigations are essential to evaluate methods of MLT assessment to avoid discrepancies in various clinical studies or ethnic groups, with a focus on longterm analysis. This study is necessary to address the link between circadian dynamics of MLT secretion and cancer prevalence. Clinical trials are warranted to determine the ability of MLT in enhancing the efficacy of anticancer drugs. Most importantly, studies need to address the oncostatic effect of MLT via direct administration of MLT to patients with cancer to determine the dosage and long-term safety of MLT and the precise role of MLT in human physiology, especially in relation to cancer. Furthermore, more studies are required to completely elucidate the oncogenic and anticancer effects of MLT 
against various types of cancers and to enhance its clinical applications.

\section{Acknowledgments}

This paper was supported by Konkuk University in 2018.

\section{Funding}

This paper was funded by Konkuk University in 2018.

\section{Disclosure}

The authors declare no conflicts of interest for this work.

\section{References}

1. Ferlay J, Soerjomataram I, Dikshit R, et al. Cancer incidence and mortality worldwide: sources, methods and major patterns in GLOBOCAN 2012. Int $J$ Cancer. 2015;136(5):E359-386. doi:10.1002/ijc. 29210

2. Bray F, Ferlay J, Soerjomataram I, Siegel RL, Torre LA, Jemal A. Global cancer statistics 2018: GLOBOCAN estimates of incidence and mortality worldwide for 36 cancers in 185 countries. CA Cancer J Clin. 2018;68(6):394-424. doi:10.3322/caac.21492

3. Siegel RL, Miller KD, Jemal A. Cancer statistics, 2019. $C A$ Cancer J Clin. 2019;69(1):7-34. doi:10.3322/caac.21551

4. Zhou Y, Li Y, Zhou T, Zheng J, Li S, Li HB. Dietary natural products for prevention and treatment of liver cancer. Nutrients. 2016;8(3):156. doi:10.3390/nu8030156

5. Hanahan D, Weinberg RA. The hallmarks of cancer. Cell. 2000;100(1):57-70. doi:10.1016/s0092-8674(00)81683-9

6. Hahn WC, Weinberg RA. Modelling the molecular circuitry of cancer. Nat Rev Cancer. 2002;2(5):331-341. doi:10.1038/nrc795

7. Pardal R, Clarke MF, Morrison SJ. Applying the principles of stem-cell biology to cancer. Nat Rev Cancer. 2003;3 (12):895-902. doi:10.1038/nrc1232

8. Van Raamsdonk CD, Bezrookove V, Green G, et al. Frequent somatic mutations of GNAQ in uveal melanoma and blue naevi. Nature. 2009;457(7229):599-602. doi:10.1038/nature07586

9. Waldum HL, Sandvik AK, Brenna E, Fossmark R, Qvigstad G, Soga J. Classification of tumours. J Exp Clin Cancer Res. 2008;27(1):70. doi:10.1186/1756-9966-27-70

10. Su SC, Hsieh MJ, Yang WE, Chung WH, Reiter RJ, Yang SF. Cancer metastasis: mechanisms of inhibition by melatonin J Pineal Res. 2017;62(1):e12370. doi:10.1111/jpi.12370

11. Reiter RJ, Rosales-Corral SA, Tan DX, et al. Melatonin, a full service anti-cancer agent: inhibition of initiation, progression and metastasis Int J Mol Sci. 2017;18(4):843. doi:10.3390/ijms18040843

12. Innominato PF, Lim AS, Palesh O, et al. The effect of melatonin on sleep and quality of life in patients with advanced breast cancer. Support Care Cancer. 2016;24(3):1097-1105. doi:10.1007/s00520-015-2883-6

13. Acuña-Castroviejo $\mathrm{D}$, Rahim $\mathrm{I}$, Acuña-Fernández $\mathrm{C}$, et al. Melatonin, clock genes and mitochondria in sepsis. Cell Mol Life Sci. 2017;74(21):3965-3987. doi:10.1007/s00018-017-2610-1

14. Zhao M, Wan J, Zeng K, et al. The reduction in circulating melatonin level may contribute to the pathogenesis of ovarian cancer: a retrospective study. $J$ Cancer. 2016;7(7):831-836. doi: $10.7150 /$ jca. 14573

15. Vijayalaxmi V, Thomas CR, Reiter RJ, Herman,TS. Melatonin: from basic research to cancer treatment clinics. $J$ Clin Oncol. 2002;20(10):2575-2601. doi:10.1200/jco.2002.11.004
16. Luchetti F, Canonico B, Betti M, et al. Melatonin signaling and cell protection function. FASEB j. 2010;24(10):3603-3624. doi:10.1096/fj.10-154450

17. Cutando A, López-Valverde A, Arias-Santiago S, et al. Role of melatonin in cancer treatment. Anticancer Res. 2012;32 (7):2747-2753.

18. Srinivasan V, Spence DW, Pandi-Perumal SR, Trakht I, Cardinali DP. Therapeutic actions of melatonin in cancer: possible mechanisms. Integr Cancer Ther. 2008;7(3):189-203. doi:10.1177/1534735408322846

19. Sainz RM, Mayo JC, Rodriguez C, Tan DX, Lopez-Burillo S, Reiter RJ. Melatonin and cell death: differential actions on apoptosis in normal and cancer cells. Cell Mol Life Sci. 2003;60 (7):1407-1426. doi:10.1007/s00018-003-2319-1

20. Hill SM, Belancio VP, Dauchy RT, et al. Melatonin: an inhibitor of breast cancer. Endocr Relat Cancer. 2015;22(3):R183-R204. doi:10.1530/ERC-15-0030

21. Khoory R, Stemme D. Plasma melatonin levels in patients suffering from colorectal carcinoma. J Pineal Res. 1988;5(3):251-258. doi:10.1111/j.1600-079x.1988.tb00651.x

22. Bartsch H, Buchberger A, Franz H, et al. Effect of melatonin and pineal extracts on human ovarian and mammary tumor cells in a chemosensitivity assay. Life Sci. 2000;67(24):2953-2960. doi:10.1016/s0024-3205(00)00882-1

23. Karasek M, Fraschini F. Is there a role for the pineal gland in neoplastic growth? In: Fraschini F, Reiter RJ, editors. Role of Melatonin and Pineal Peptides in Neuroimmunomodulation. Boston, MA:Springer; 1991:243-251.

24. Nooshinfar E, Safaroghli-Azar A, Bashash D, Akbari ME. Melatonin, an inhibitory agent in breast cancer. Breast Cancer. 2017;24(1):42-51. doi:10.1007/s12282-016-0690-7

25. Li Y, Li S, Zhou Y, et al. Melatonin for the prevention and treatment of cancer. Oncotarget. 2017;8(24):39896-39921. doi:10.18632/oncotarget.16379

26. Lissoni P, Barni S, Crispino S, Tancini G, Fraschini F. Endocrine and immune effects of melatonin therapy in metastatic cancer patients. Eur $J$ Cancer Clin Oncol. 1989;25(5):789-795. doi:10.1016/0277-5379(89)90122-3

27. Lissoni P, Barni S, Tancini G, et al. A study of the mechanisms involved in the immunostimulatory action of the pineal hormone in cancer patients. Oncology. 1993;50(6):399-402. doi:10.1159/000227218

28. Lissoni P, Tancini G, Barni S, et al. Treatment of cancer chemotherapy-induced toxicity with the pineal hormone melatonin. Support Care Cancer. 1997;5(2):126-129. doi:10.1007/bf01262569

29. Lissoni P, Rovelli F, Brivio F, Brivio O, Fumagalli L. Circadian secretions of IL-2, IL-12, IL-6 and IL-10 in relation to the light/ dark rhythm of the pineal hormone melatonin in healthy humans. Nat Immun. 1998;16(1):1-5. doi:10.1159/000069464

30. Lissoni P, Rovelli F, Giani L, et al. Dehydroepiandrosterone sulfate (DHEAS) secretion in early and advanced solid neoplasms: selective deficiency in metastatic disease. Int J Biol Markers. 1998;13 (3):154-157. doi:10.1177/172460089801300306

31. Lissoni P, Malugani F, Bukovec R, et al. Reduction of cisplatin-induced anemia by the pineal indole 5 -methoxytryptamine in metastatic lung cancer patients. Neuro Endocrinol Lett. 2003;24(1-2):83-85.

32. Lissoni P, Chilelli M, Villa S, Cerizza L, Tancini G. Five years survival in metastatic non-small cell lung cancer patients treated with chemotherapy alone or chemotherapy and melatonin: a randomized trial. $J$ Pineal Res. 2003;35(1):12-15. doi:10.1034/j.1600-079x.2003.00032.x

33. Anisimov VN, Alimova IN, Baturin DA, et al. The effect of melatonin treatment regimen on mammary adenocarcinoma development in HER-2/neu transgenic mice. Int $J$ Cancer. 2003;103(3):300-305. doi:10.1002/ijc.10827 
34. Lissoni P. Biochemotherapy with standard chemotherapies plus the pineal hormone melatonin in the treatment of advanced solid neoplasms. Pathol Biol. 2007;55(3-4):201-204. doi:10.1016/j. patbio.2006.12.025

35. Lissoni P. Biochemotherapy with immunomodulating pineal hormones other than melatonin: 5-methoxytryptamine as a new oncostatic pineal agent. Pathol Biol. 2007;55(3-4):198-200. doi:10.1016/j.patbio.2006.12.008

36. Song N, Kim AJ, Kim HJ, et al. Melatonin suppresses doxorubicin-induced premature senescence of A549 lung cancer cells by ameliorating mitochondrial dysfunction. J Pineal Res. 2012;53(4):335-343. doi:10.1111/j.1600-079X.2012.01003.x

37. Zhou Q, Gui S, Zhou Q, Wang Y. Melatonin inhibits the migration of human lung adenocarcinoma A549 cell lines involving JNK/MAPK pathway. PLoS One. 2014;9(7):e101132. doi:10.1371/journal.pone.0101132

38. Plaimee P, Weerapreeyakul N, Barusrux S, Johns NP. Melatonin potentiates cisplatin-induced apoptosis and cell cycle arrest in human lung adenocarcinoma cells. Cell Prolif. 2015;48 (1):67-77. doi:10.1111/cpr.12158

39. Chao CC, Chen PC, Chiou PC, et al. Melatonin suppresses lung cancer metastasis by inhibition of epithelial-mesenchymal transition through targeting to Twist. Clin Sci. 2019;133(5):709-722. doi:10.1042/cs20180945

40. Jablonska K, Nowinska K, Piotrowska A, et al. Prognostic impact of melatonin receptors MT1 and MT2 in non-small cell lung cancer (NSCLC). Cancers. 2019;11(7):1001. doi:10.3390/ cancers 11071001

41. Ma Z, Liu D, Di S, et al. Histone deacetylase 9 downregulation decreases tumor growth and promotes apoptosis in non-small cell lung cancer after melatonin treatment. J Pineal Res. 2019;67(2): e12587. doi:10.1111/jpi.12587

42. Gurunathan S, Jeyaraj M, Kang MH, Kim JH. Melatonin enhances palladium-nanoparticle-induced cytotoxicity and apoptosis in human lung epithelial adenocarcinoma cells A549 and H1229. Antioxidants (Basel). 2020;9(4). doi:10.3390/antiox9040357

43. Alvarez-Artime A, Cernuda-Cernuda R, Francisco Artime N, et al. Melatonin-induced cytoskeleton reorganization leads to inhibition of melanoma cancer cell proliferation. Int J Mol Sci. 2020;21(2):548. doi:10.3390/ijms21020548

44. Pourhanifeh MH, Sharifi M, Reiter RJ, Davoodabadi A, Asemi Z. Melatonin and non-small cell lung cancer: new insights into signaling pathways. Cancer Cell Int. 2019;19:131. doi:10.1186/ s12935-019-0853-7

45. Kahkesh MH, Salehi Z, Najafi M, Ghobadi A, Izad M, Shirazi A. The inhibitory effect of melatonin on the proliferation of irradiated A549 cell line. J Cancer Res Ther. 2020;16(6):1500-1505. doi:10.4103/jcrt.JCRT_682_19

46. Liu PI, Chang AC, Lai JL, et al. Melatonin interrupts osteoclast functioning and suppresses tumor-secreted RANKL expression: implications for bone metastases. Oncogene. 2021;40:1503-1515. doi:10.1038/s41388-020-01613-4

47. Lissoni P, Tancini G, Barni S, et al. Melatonin increase as predictor for tumor objective response to chemotherapy in advanced cancer patients. Tumori Journal. 1988;74(3):339-345. doi:10.1177/030089168807400317

48. Bartsch C, Bartsch H, Jain AK, Laumas KR, Wetterberg L. Urinary melatonin levels in human breast cancer patients. J Neural Transm. 1981;52(4):281-294. doi:10.1007/bf01256753

49. Tamarkin L, Danforth D, Lichter A, et al. Decreased nocturnal plasma melatonin peak in patients with estrogen receptor positive breast cancer. Science. 1982;216(4549):1003-1005. doi:10.1126/ science. 7079745

50. Blask DE, Hill SM. Effects of melatonin on cancer: studies on MCF-7 human breast cancer cells in culture. J Neural Transm Suppl. 1986;21:433-449.
51. Hill SM, Blask DE. Effects of the pineal hormone melatonin on the proliferation and morphological characteristics of human breast cancer cells (MCF-7) in culture. Cancer Res. 1988;48(21):6121-6126.

52. Crespo D, Fernández-Viadero $\mathrm{C}$, Verduga R, Ovejero V, Cos S. Interaction between melatonin and estradiol on morphological and morphometric features of MCF-7 human breast cancer cells. J Pineal Res. 1994;16(4):215-222. doi:10.1111/j.1600-079x.1994.tb00105.x

53. Lemus-Wilson A, Kelly PA, Blask DE. Melatonin blocks the stimulatory effects of prolactin on human breast cancer cell growth in culture. $\mathrm{Br} J$ Cancer. 1995;72(6):1435-1440. doi:10.1038/bjc. 1995.526

54. Eck KM, Yuan L, Duffy L, et al. A sequential treatment regimen with melatonin and all-trans retinoic acid induces apoptosis in MCF-7 tumour cells. Br J Cancer. 1998;77(12):2129-2137. doi:10.1038/bjc.1998.357

55. Cos S, Fernández R, Güézmes A, Sánchez-Barceló EJ. Influence of melatonin on invasive and metastatic properties of $\mathrm{MCF}-7$ human breast cancer cells. Cancer Res. 1998;58(19):4383-4390.

56. Cini G, Neri B, Pacini A, et al. Antiproliferative activity of melatonin by transcriptional inhibition of cyclin D1 expression: a molecular basis for melatonin-induced oncostatic effects. $J \quad$ Pineal Res. 2005;39(1):12-20. doi:10.1111/j.1600079X.2004.00206.x

57. Cos S, Blask DE, Lemus-Wilson A, Hill AB. Effects of melatonin on the cell cycle kinetics and "estrogen-rescue" of MCF-7 human breast cancer cells in culture. J Pineal Res. 1991;10(1):36-42. doi:10.1111/j.1600-079x.1991.tb00007.x

58. Mediavilla MD, Cos S, Sánchez-Barceló EJ. Melatonin increases p53 and p21WAF1 expression in MCF-7 human breast cancer cells in vitro. Life Sci. 1999;65(4):415-420. doi:10.1016/s00243205(99)00262-3

59. Yuan L, Collins AR, Dai J, Dubocovich ML, Hill SM. MT(1) melatonin receptor overexpression enhances the growth suppressive effect of melatonin in human breast cancer cells. Mol Cell Endocrinol. 2002;192 (1-2):147-156. doi:10.1016/s0303-7207(02)00029-1

60. Cucina A, Proietti S, D'Anselmi F, et al. Evidence for a biphasic apoptotic pathway induced by melatonin in MCF-7 breast cancer cells. J Pineal Res. 2009;46(2):172-180. doi:10.1111/j.1600079X.2008.00645.x

61. Lee SE, Kim SJ, Youn JP, Hwang SY, Park CS, Park YS. MicroRNA and gene expression analysis of melatonin-exposed human breast cancer cell lines indicating involvement of the anticancer effect. J Pineal Res. 2011;51(3):345-352. doi:10.1111/j.1600-079X.2011.00896.x

62. Margheri M, Pacini N, Tani A, et al. Combined effects of melatonin and all-trans retinoic acid and somatostatin on breast cancer cell proliferation and death: molecular basis for the anticancer effect of these molecules. Eur J Pharmacol. 2012;681(1-3):3443. doi:10.1016/j.ejphar.2012.02.011

63. Alvarez-García V, González A, Alonso-González C, MartínezCampa C, Cos S. Regulation of vascular endothelial growth factor by melatonin in human breast cancer cells. J Pineal Res. 2013;54 (4):373-380. doi:10.1111/jpi.12007

64. Gonçalves Ndo N, Colombo J, Lopes JR, et al. Effect of melatonin in epithelial mesenchymal transition markers and invasive properties of breast cancer stem cells of canine and human cell lines. PLoS One. 2016;11(3):e0150407. doi:10.1371/journal. pone. 0150407

65. Jardim-Perassi BV, Lourenço MR, Doho GM, et al. Melatonin regulates angiogenic factors under hypoxia in breast cancer cell lines. Anticancer Agents Med Chem. 2016;16(3):347-358. doi:10.2174/1871520615666150511094201

66. Wang T, Liu B, Guan Y, et al. Melatonin inhibits the proliferation of breast cancer cells induced by bisphenol A via targeting estrogen receptor-related pathways. Thorac Cancer. 2018;9 (3):368-375. doi:10.1111/1759-7714.12587 
67. Proietti S, Catizone A, Masiello MG, et al. Increase in motility and invasiveness of MCF7 cancer cells induced by nicotine is abolished by melatonin through inhibition of ERK phosphorylation. J Pineal Res. 2018;64(4):e12467. doi:10.1111/ jpi.12467

68. Colombo J, Jardim-Perassi BV, Ferreira JPS, et al. Melatonin differentially modulates $\mathrm{NF}-\mathrm{\kappa B}$ expression in breast and liver cancer cells. Anticancer Agents Med Chem. 2018;18 (12):1688-1694. doi:10.2174/1871520618666180131112304

69. Lacerda JZ, Ferreira LC, Lopes BC, et al. Therapeutic potential of melatonin in the regulation of $\mathrm{miR}-148 \mathrm{a}-3 \mathrm{p}$ and angiogenic factors in breast cancer. Microrna. 2019;8(3):237-247. doi:10.2174/ 2211536608666190219095426

70. Gulbahce-Mutlu E, Baltaci SB, Menevse E, Mogulkoc R, Baltaci AK. The effect of zinc and melatonin administration on lipid peroxidation, IL-6 levels, and element metabolism in DMBA-induced breast cancer in rats. Biol Trace Elem Res. 2020;199(3):1044-1051. doi:10.1007/s12011-020-02238-0

71. Palmer ACS, Zortea M, Souza A, et al. Clinical impact of melatonin on breast cancer patients undergoing chemotherapy; effects on cognition, sleep and depressive symptoms: a randomized, double-blind, placebo-controlled trial. PLoS One. 2020;15(4): e0231379. doi:10.1371/journal.pone.0231379

72. Lin PH, Tung YT, Chen HY, et al. Melatonin activates cell death programs for the suppression of uterine leiomyoma cell proliferation. J Pineal Res. 2020;68(1):e12620. doi:10.1111/ jpi. 12620

73. Talib WH. A ketogenic diet combined with melatonin overcomes cisplatin and vincristine drug resistance in breast carcinoma syngraft. Nutrition. 2020;72:110659. doi:10.1016/j. nut.2019.110659

74. Pourhanifeh MH, Mehrzadi S, Hosseinzadeh A. Melatonin and regulation of miRNAs: novel targeted therapy for cancerous and noncancerous disease. Epigenomics. 2021;13(1):65-81. doi:10.2217/epi-2020-0241

75. Hadadi E, Acloque H. Role of circadian rhythm disorders in EMT and tumor-immune interactions in endocrine-related cancers. Endocr Relat Cancer. 2021;28:R67-R80. doi:10.1530/erc-200390

76. Jardin I, Diez-Bello R, Falcon D, et al. Melatonin downregulates TRPC6, impairing store-operated calcium entry in triple negative breast cancer cells. J Biol Chem. 2020. doi:10.1074/jbc. RA120.015769

77. Jin Y, Choi YJ, Heo K, Park SJ. Melatonin as an oncostatic molecule based on its anti-aromatase role in breast cancer. Int J Mol Sci. 2021;22(1):438. doi:10.3390/ijms22010438

78. Ahabrach H, El Mlili N, Errami M, Cauli O. Circadian rhythm and concentration of melatonin in breast cancer patients. Endocr Metab Immune Disord Drug Targets. 2020;20. doi:10.2174/ 1871530320666201201110807

79. Chuffa LGA, Lupi LA, Cucielo MS, Silveira HS, Reiter RJ, Seiva FRF. Melatonin promotes uterine and placental health: potential molecular mechanisms. Int J Mol Sci. 2019;21(1). doi:10.3390/ijms21010300

80. Kwon YJ, Seo EB, Kwon SH, et al. Extracellular acidosis promotes metastatic potency via decrease of the BMAL1 circadian clock gene in breast cancer. Cells. 2020;9(4):989. doi:10.3390/cells9040989

81. Maroufi NF, Vahedian V, Hemati S, et al. Targeting cancer stem cells by melatonin: effective therapy for cancer treatment. Pathol Res Pract. 2020;216(5):152919. doi:10.1016/j.prp.2020.152919

82. Menéndez-Menéndez J, Hermida-Prado F, Granda-Díaz R, et al. Deciphering the molecular basis of melatonin protective effects on breast cells treated with Doxorubicin: TWIST1 a transcription factor involved in EMT and metastasis, a novel target of melatonin. Cancers (Basel). 2019;11(7):1011. doi:10.3390/ cancers 11071011
83. Goyal R, Gupta T, Bal A, Sahni D, Singh G. Role of melatonin in breast carcinoma: correlation of expression patterns of melatonin-1 receptor with estrogen, progesterone, and HER2 receptors. Appl Immunohistochem Mol Morphol. 2020;28 (7):518-523. doi:10.1097/pai.0000000000000788

84. Xiang S, Dauchy RT, Hoffman AE, et al. Epigenetic inhibition of the tumor suppressor ARHI by light at night-induced circadian melatonin disruption mediates STAT3-driven paclitaxel resistance in breast cancer. J Pineal Res. 2019;67(2):e12586. doi:10.1111/jpi.12586

85. Menéndez-Menéndez J, Martínez-Campa C. Melatonin: an anti-tumor agent in hormone-dependent cancers. Int J Endocrinol. 2018;2018:3271948. doi:10.1155/2018/3271948

86. El-Sokkary GH, Ismail IA, Saber SH. Melatonin inhibits breast cancer cell invasion through modulating DJ-1/KLF17/ID-1 signaling pathway. $J$ Cell Biochem. 2019;120(3):3945-3957. doi:10.1002/jcb. 27678

87. Wong MC, Goggins WB, Wang HH, et al. Global incidence and mortality for prostate cancer: analysis of temporal patterns and trends in 36 countries. Eur Urol. 2016;70(5):862-874. doi:10.1016/j.eururo.2016.05.043

88. Bray F, Kiemeney LA. Epidemiology of prostate cancer in Europe: patterns, trends and determinants. In: Management of Prostate Cancer. Cham:Springer; 2017:1-27.

89. Sigurdardottir LG, Markt SC, Rider JR, et al. Urinary melatonin levels, sleep disruption, and risk of prostate cancer in elderly men. Eur Urol. 2015;67(2):191-194. doi:10.1016/j.eururo.2014.07.008

90. Tai SY, Huang SP, Bao BY, Wu MT. Urinary melatonin-sulfate/ cortisol ratio and the presence of prostate cancer: a case-control study. Sci Rep. 2016;6:29606. doi:10.1038/srep29606

91. Sainz RM, Mayo JC, Tan DX, León J, Manchester L, Reiter RJ. Melatonin reduces prostate cancer cell growth leading to neuroendocrine differentiation via a receptor and PKA independent mechanism. Prostate. 2005;63(1):29-43. doi:10.1002/pros.20155

92. Laudon M, Gilad E, Matzkin H, Braf Z, Zisapel N. Putative melatonin receptors in benign human prostate tissue. J Clin Endocrinol Metab. 1996;81(4):1336-1342. doi:10.1210/jcem.81.4.8636329

93. Gilad E, Laudon M, Matzkin H, et al. Functional melatonin receptors in human prostate epithelial cells. Endocrinology. 1996;137(4):1412-1417. doi:10.1210/endo.137.4.8625918

94. Rimler A, Culig Z, Levy-Rimler G, et al. Melatonin elicits nuclear exclusion of the human androgen receptor and attenuates its activity. Prostate. 2001;49(2):145-154. doi:10.1002/pros.1129

95. Shiu SY, Law IC, Lau KW, Tam PC, Yip AW, Ng WT. Melatonin slowed the early biochemical progression of hormone-refractory prostate cancer in a patient whose prostate tumor tissue expressed MT1 receptor subtype. J Pineal Res. 2003;35(3):177-182. doi:10.1034/j.1600-079x.2003.00074.x

96. Paroni R, Terraneo L, Bonomini F, et al. Antitumour activity of melatonin in a mouse model of human prostate cancer: relationship with hypoxia signalling. J Pineal Res. 2014;57(1):43-52. doi:10.1111/jpi.12142

97. Xi SC, Tam PC, Brown GM, Pang SF, Shiu SY. Potential involvement of $\mathrm{mt} 1$ receptor and attenuated sex steroid-induced calcium influx in the direct anti-proliferative action of melatonin on androgen-responsive LNCaP human prostate cancer cells. $J$ Pineal Res. 2000;29(3):172-183. doi:10.1034/j.1600079x.2000.d01-64.x

98. Lupowitz Z, Rimler A, Zisapel N. Evaluation of signal transduction pathways mediating the nuclear exclusion of the androgen receptor by melatonin. Cell Mol Life Sci. 2001;58 (14):2129-2135. doi:10.1007/p100000842

99. Tam CW, Mo CW, Yao KM, Shiu SY. Signaling mechanisms of melatonin in antiproliferation of hormone-refractory 22Rv1 human prostate cancer cells: implications for prostate cancer chemoprevention. J Pineal Res. 2007;42(2):191-202. doi:10.1111/j.1600-079X.2006.00406.x 
100. Shiu SY, Leung WY, Tam CW, Liu VW, Yao KM. Melatonin MT1 receptor-induced transcriptional up-regulation of p27(Kip1) in prostate cancer antiproliferation is mediated via inhibition of constitutively active nuclear factor kappa B (NF- $\mathrm{kB})$ : potential implications on prostate cancer chemoprevention and therapy. $J \quad$ Pineal Res. 2013;54(1):69-79. doi:10.1111/j.1600079X.2012.01026.x

101. Nah SS, Won HJ, Park HJ, et al. Melatonin inhibits human fibroblast-like synoviocyte proliferation via extracellular signal-regulated protein kinase/P21(CIP1)/P27(KIP1) pathways. $J \quad$ Pineal Res. 2009;47(1):70-74. doi:10.1111/j.1600079X.2009.00689.x

102. Tamarindo GH, Ribeiro DL, Gobbo MG, et al. Melatonin and docosahexaenoic acid decrease proliferation of PNT1A prostate benign cells via modulation of mitochondrial bioenergetics and ROS production. Oxid Med Cell Longev. 2019;2019:5080798. doi:10.1155/2019/5080798

103. Wang SW, Tai HC, Tang $\mathrm{CH}$, et al. Melatonin impedes prostate cancer metastasis by suppressing MMP-13 expression. $J$ Cell Physiol. 2020;236(5):3979-3990. doi:10.1002/jcp.30150

104. Zharinov GM, Bogomolov OA, Chepurnaya IV, Neklasova NY, Anisimov VN. Melatonin increases overall survival of prostate cancer patients with poor prognosis after combined hormone radiation treatment. Oncotarget. 2020;11(41):3723-3729. doi:10.18632/oncotarget. 27757

105. Calastretti A, Gatti G, Lucini V, et al. Melatonin analogue antiproliferative and cytotoxic effects on human prostate cancer cells. Int J Mol Sci. 2018;19(5):1505. doi:10.3390/ijms19051505

106. Hevia D, Gonzalez-Menendez P, Fernandez-Fernandez M, et al. Melatonin decreases glucose metabolism in prostate cancer cells: a (13)C stable isotope-resolved metabolomic study. Int J Mol Sci. 2017;18(8):1620. doi:10.3390/ijms18081620

107. Arnold M, Sierra MS, Laversanne M, Soerjomataram I, Jemal A, Bray F. Global patterns and trends in colorectal cancer incidence and mortality. Gut. 2017;66(4):683-691. doi:10.1136/gutjnl-2015-310912

108. Magalhães B, Peleteiro B, Lunet N. Dietary patterns and colorectal cancer: systematic review and meta-analysis. Eur J Cancer Prev. 2012;21(1):15-23. doi:10.1097/CEJ.0b013e3283472241

109. Kuipers EJ, Grady WM, Lieberman D, et al. Colorectal cancer. Nat Rev Dis Primers. 2015;1:15065. doi:10.1038/nrdp.2015.65

110. Vogelstein B, Fearon ER, Hamilton SR, et al. Genetic alterations during colorectal-tumor development. $N$ Engl J Med. 1988;319 (9):525-532. doi:10.1056/nejm198809013190901

111. Papantoniou K, Castaño-Vinyals G, Espinosa A, et al. Night shift work, chronotype and prostate cancer risk in the MCC-Spain case-control study. Int $J$ Cancer. 2015;137(5):1147-1157. doi:10.1002/ijc. 29400

112. Parent M, El-Zein M, Rousseau MC, Pintos J, Siemiatycki J. Night work and the risk of cancer among men. Am J Epidemiol. 2012;176(9):751-759. doi:10.1093/aje/kws318

113. Lin CL, Liu TC, Wang YN, Chung CH, Chien WC. The association between sleep disorders and the risk of colorectal cancer in patients: a population-based nested case-control study. In Vivo. 2019;33(2):573-579. doi:10.21873/invivo.11513

114. Barni S, Lissoni P, Cazzaniga M, et al. Neuroimmunotherapy with subcutaneous low-dose interleukin-2 and the pineal hormone melatonin as a second-line treatment in metastatic colorectal carcinoma. Tumori J. 1992;78(6):383-387. doi:10.1177/ 030089169207800608

115. Farriol M, Venereo Y, Orta X, Castellanos JM, Segovia-Silvestre T. In vitro effects of melatonin on cell proliferation in a colon adenocarcinoma line. J Appl Toxicol. 2000;20(1):21-24. doi:10.1002/(sici)10991263(200001/02)20:1<21::aid-jat623>3.0.co;2-m
116. Lissoni P, Rovelli F, Malugani F, Bucovec R, Conti A, Maestroni GJ. Anti-angiogenic activity of melatonin in advanced cancer patients. Neuro Endocrinol Lett. 2001;22(1):45-47.

117. Winczyk K, Pawlikowski M, Guerrero JM, Karasek M. Possible involvement of the nuclear RZR/ROR-alpha receptor in the antitumor action of melatonin on murine Colon 38 cancer. Tumour Biol. 2002;23(5):298-302. doi:10.1159/000068569

118. Kontek R, Nowicka H. The modulatory effect of melatonin on genotoxicity of irinotecan in healthy human lymphocytes and cancer cells. Drug Chem Toxicol. 2013;36(3):335-342. doi: $10.3109 / 01480545.2012 .737805$

119. Wang J, Guo W, Chen W, et al. Melatonin potentiates the antiproliferative and pro-apoptotic effects of ursolic acid in colon cancer cells by modulating multiple signaling pathways. J Pineal Res. 2013;54(4):406-416. doi:10.1111/jpi.12035

120. Ji G, Zhou W, Li X, Du J, Li X, Hao H. Melatonin inhibits proliferation and viability and promotes apoptosis in colorectal cancer cells via upregulation of the microRNA-34a/449a cluster. Mol Med Rep. 2021;23(3). doi:10.3892/mmr.2021.11826

121. León J, Casado J, Jiménez Ruiz SM, et al. Melatonin reduces endothelin-1 expression and secretion in colon cancer cells through the inactivation of FoxO-1 and NF- $\kappa \beta$. J Pineal Res. 2014;56(4):415-426. doi:10.1111/jpi.12131

122. Hong Y, Won J, Lee Y, et al. Melatonin treatment induces interplay of apoptosis, autophagy, and senescence in human colorectal cancer cells. J Pineal Res. 2014;56(3):264-274. doi:10.1111/jpi.12119

123. Wei JY, Li WM, Zhou LL, Lu QN, He W. Melatonin induces apoptosis of colorectal cancer cells through HDAC4 nuclear import mediated by CaMKII inactivation. J Pineal Res. 2015;58 (4):429-438. doi:10.1111/jpi.12226

124. Chovancova B, Hudecova S, Lencesova L, et al. Melatonininduced changes in cytosolic calcium might be responsible for apoptosis induction in tumour cells. Cell Physiol Biochem. 2017;44(2):763-777. doi:10.1159/000485290

125. Trivedi PP, Jena GB, Tikoo KB, Kumar V. Melatonin modulated autophagy and Nrf2 signaling pathways in mice with colitis-associated colon carcinogenesis. Mol Carcinog. 2016;55 (3):255-267. doi:10.1002/mc.22274

126. Bakalova R, Zhelev Z, Shibata S, Nikolova B, Aoki I, Higashi T. Impressive suppression of colon cancer growth by triple combination SN38/EF24/Melatonin: "Oncogenic" versus "OncoSuppressive" reactive oxygen species. Anticancer Res. 2017;37 (10):5449-5458. doi:10.21873/anticanres.11973

127. Liu Z, Zou D, Yang X, et al. Melatonin inhibits colon cancer RKO cell migration by downregulating Rho-associated protein kinase expression via the p38/MAPK signaling pathway. Mol Med Rep. 2017;16(6):9383-9392. doi:10.3892/mmr.2017.7836

128. Gao Y, Xiao X, Zhang C, et al. Melatonin synergizes the chemotherapeutic effect of 5-fluorouracil in colon cancer by suppressing $\mathrm{PI} 3 \mathrm{~K} / \mathrm{AKT}$ and $\mathrm{NF}-\mathrm{\kappa B} / \mathrm{iNOS}$ signaling pathways. $J$ Pineal Res. 2017;62(2):e12380. doi:10.1111/jpi.12380

129. Moloudizargari M, Moradkhani F, Hekmatirad S, Fallah M, Asghari MH, Reiter RJ. Therapeutic targets of cancer drugs: modulation by melatonin. Life Sci. 2021;267:118934. doi:10.1016/j.lfs.2020.118934

130. Lee JH, Yoon YM, Han YS, Yun CW, Lee SH. Melatonin promotes apoptosis of oxaliplatin-resistant colorectal cancer cells through inhibition of cellular prion protein. Anticancer Res. 2018;38(4):1993-2000. doi:10.21873/anticanres.12437

131. Lee JH, Yun CW, Han YS, et al. Melatonin and 5-fluorouracil co-suppress colon cancer stem cells by regulating cellular prion protein-Oct4 axis. J Pineal Res. 2018;65(4):e12519. doi:10.1111/ jpi.12519 
132. Wang Q, Sun Z, Du L, et al. Melatonin sensitizes human colorectal cancer cells to $\gamma$-ray ionizing radiation in vitro and in vivo. Int J Mol Sci. 2018;19(12):3974. doi:10.3390/ijms19123974

133. Jung JH, Shin EA, Kim JH, et al. NEDD9 inhibition by miR-25$5 p$ activation is critically involved in co-treatment of melatoninand pterostilbene-induced apoptosis in colorectal cancer cells. Cancers. 2019;11(11):1684. doi:10.3390/cancers11111684

134. Jadid MFS, Aghaei E, Taheri E, et al. Melatonin increases the anticancer potential of doxorubicin in Caco-2 colorectal cancer cells. Environ Toxicol. 2021. doi:10.1002/tox.23105

135. Gil-Martín E, López-Muñoz F, Reiter RJ, Romero A. Understanding the oncostatic actions displayed by melatonin in colorectal cancer therapy. Future Med Chem. 2020;12 (13):1201-1204. doi:10.4155/fmc-2020-0086

136. Andor N, Graham TA, Jansen M, et al. Pan-cancer analysis of the extent and consequences of intratumor heterogeneity. Nat Med. 2016;22(1):105-113. doi:10.1038/nm.3984

137. Pourhanifeh $\mathrm{MH}$, Mohammadi R, Noruzi S, et al. The role of fibromodulin in cancer pathogenesis: implications for diagnosis and therapy. Cancer Cell Int. 2019;19:157. doi:10.1186/s12935019-0870-6

138. Fu S, Wu H, Zhang H, Lian CG, Lu Q. DNA methylation/hydroxymethylation in melanoma. Oncotarget. 2017;8(44):78163-78173. doi:10.18632/oncotarget.18293

139. Abdul-Karim RM, Cowey CL. Challenging the standard of care in advanced melanoma: focus on pembrolizumab. Cancer Manag Res. 2017;9:433-442. doi:10.2147/cmar.S92546

140. Hernando B, Ibarrola-Villava M, Fernandez LP, et al. Sex-specific genetic effects associated with pigmentation, sensitivity to sunlight, and melanoma in a population of Spanish origin. Biol Sex Differ. 2016;7:17. doi:10.1186/s13293-016-0070-1

141. Grzywa TM, Paskal W, Włodarski PK. Intratumor and intertumor heterogeneity in melanoma. Transl Oncol. 2017;10(6):956-975. doi:10.1016/j.tranon.2017.09.007

142. Kumar CA, Das UN. Effect of melatonin on two stage skin carcinogenesis in Swiss mice. Med Sci Monit. 2000;6(3):471-475.

143. Sener G, Jahovic N, Tosun O, Atasoy BM, Yeğen BC. Melatonin ameliorates ionizing radiation-induced oxidative organ damage in rats. Life Sci. 2003;74(5):563-572. doi:10.1016/j.lfs.2003.05.011

144. Sener G, Paskaloglu K, Toklu H, et al. Melatonin ameliorates chronic renal failure-induced oxidative organ damage in rats. $J$ Pineal Res. 2004;36(4):232-241. doi:10.1111/j.1600-079X.2004.00113.x

145. Vesnushkin GM, Plotnikova NA, Semenchenko AI, Anisimov VN. Dose-dependent inhibitory effect of melatonin on carcinogenesis induced by benzo[a]pyrene in mice. J Exp Clin Cancer Res. 2006;25(4):507-513.

146. Man'cheva TA, Demidov DV, Plotnikova NA, Kharitonova TV, Pashkevich IV, Anisimov VN. Melatonin and metformin inhibit skin carcinogenesis and lipid peroxidation induced by benz(a) pyrene in female mice. Bull Exp Biol Med. 2011;151 (3):363-365. doi:10.1007/s10517-011-1331-y

147. Kim TK, Lin Z, Tidwell WJ, Li W, Slominski AT. Melatonin and its metabolites accumulate in the human epidermis in vivo and inhibit proliferation and tyrosinase activity in epidermal melanocytes in vitro. Mol Cell Endocrinol. 2015;404:1-8. doi:10.1016/j. mce.2014.07.024

148. Kleszczyński K, Zwicker S, Tukaj S, et al. Melatonin compensates silencing of heat shock protein 70 and suppresses ultraviolet radiation-induced inflammation in human skin ex vivo and cultured keratinocytes. J Pineal Res. 2015;58(1):117-126. doi:10.1111/jpi.12197

149. Janjetovic Z, Jarrett SG, Lee EF, Duprey C, Reiter RJ, Slominski AT. Melatonin and its metabolites protect human melanocytes against UVB-induced damage: involvement of NRF2-mediated pathways. Sci Rep. 2017;7(1):1274. doi:10.1038/s41598-017-01305-2
150. Kocyigit A, Guler EM, Karatas E, Caglar H, Bulut H. Dosedependent proliferative and cytotoxic effects of melatonin on human epidermoid carcinoma and normal skin fibroblast cells. Mutat Res Genet Toxicol Environ Mutagen. 2018;829-830:50-60. doi:10.1016/j.mrgentox.2018.04.002

151. Skobowiat C, Brożyna AA, Janjetovic Z, et al. Melatonin and its derivatives counteract the ultraviolet $B$ radiation-induced damage in human and porcine skin ex vivo. J Pineal Res. 2018;65(2): e12501. doi:10.1111/jpi.12501

152. Hao J, Fan W, Li Y, et al. Melatonin synergizes BRAF-targeting agent vemurafenib in melanoma treatment by inhibiting iNOS/ hTERT signaling and cancer-stem cell traits. J Exp Clin Cancer Res. 2019;38(1):48. doi:10.1186/s13046-019-1036-z

153. London WT, Petrick J, McGlynn KA. Liver cancer. In: Cancer Epidemiology and Prevention. 4th ed. Oxford University Press; 2017:635-660.

154. Lissoni P, Barni S, Cazzaniga M, et al. Efficacy of the concomitant administration of the pineal hormone melatonin in cancer immunotherapy with low-dose IL-2 in patients with advanced solid tumors who had progressed on IL-2 alone. Oncology. 1994;51(4):344-347. doi:10.1159/000227362

155. Lissoni P, Meregalli S, Fossati V, et al. A randomized study of immunotherapy with low-dose subcutaneous interleukin-2 plus melatonin vs chemotherapy with cisplatin and etoposide as first-line therapy for advanced non-small cell lung cancer. Tumori. 1994;80(6):464-467. doi:10.1177/030089169408000611

156. Hermann R, Podhajsky S, Jungnickel S, Lerchl A. Potentiation of antiproliferative effects of tamoxifen and ethanol on mouse hepatoma cells by melatonin: possible involvement of mitogen-activated protein kinase and induction of apoptosis. J Pineal Res. 2002;33(1):8-13. doi:10.1034/j.1600-079x.2002.01846.x

157. Martín-Renedo J, Mauriz JL, Jorquera F, Ruiz-Andrés O, González P, González-Gallego J. Melatonin induces cell cycle arrest and apoptosis in hepatocarcinoma HepG2 cell line. J Pineal Res. 2008;45 (4):532-540. doi:10.1111/j.1600-079X.2008.00641.x

158. Subramanian P, Mirunalini S, Dakshayani KB, Pandi-Perumal SR, Trakht I, Cardinali DP. Prevention by melatonin of hepatocarcinogenesis in rats injected with $\mathrm{N}$-nitrosodiethylamine. $J$ Pineal Res. 2007;43(3):305-312. doi:10.1111/j.1600079X.2007.00478.x

159. Liu C, Jia Z, Zhang $X$, et al. Involvement of melatonin in autophagy-mediated mouse hepatoma H22 cell survival. Int Immunopharmacol. 2012;12(2):394-401. doi:10.1016/j. intimp.2011.12.012

160. Carbajo-Pescador S, Steinmetz C, Kashyap A, et al. Melatonin induces transcriptional regulation of Bim by FoxO3a in HepG2 cells. $B r \quad J$ Cancer. 2013;108(2):442-449. doi:10.1038/ bjc. 2012.563

161. Fan L, Sun G, Ma T, Zhong F, Wei W. Melatonin overcomes apoptosis resistance in human hepatocellular carcinoma by targeting survivin and XIAP. J Pineal Res. 2013;55(2):174-183. doi:10.1111/jpi.12060

162. Carbajo-Pescador S, Ordoñez R, Benet $M$, et al. Inhibition of VEGF expression through blockade of Hif1 $\alpha$ and STAT3 signalling mediates the anti-angiogenic effect of melatonin in HepG2 liver cancer cells. Br J Cancer. 2013;109(1):83-91. doi:10.1038/ bjc. 2013.285

163. Prieto-Domínguez N, Ordóñez R, Fernández A, et al. Melatonininduced increase in sensitivity of human hepatocellular carcinoma cells to sorafenib is associated with reactive oxygen species production and mitophagy. J Pineal Res. 2016;61(3):396-407. doi:10.1111/jpi.12358

164. Lin S, Hoffmann K, Gao C, Petrulionis M, Herr I, Schemmer P. Melatonin promotes sorafenib-induced apoptosis through synergistic activation of $\mathrm{JNK} / \mathrm{c}$-jun pathway in human hepatocellular carcinoma. J Pineal Res. 2017;62(3):e12398. doi:10.1111/jpi.12398 
165. Wang TH, Hsueh C, Chen CC, et al. Melatonin inhibits the progression of hepatocellular carcinoma through microRNA let7i-3p mediated RAF1 reduction. Int J Mol Sci. 2018;19(9). doi:10.3390/ijms19092687

166. Zhou H, Du W, Li Y, et al. Effects of melatonin on fatty liver disease: the role of NR4A1/DNA-PKcs/p53 pathway, mitochondrial fission, and mitophagy. J Pineal Res. 2018;64(1):e12450. doi:10.1111/jpi.12450

167. Fernández-Palanca $\mathrm{P}$, Méndez-Blanco $\mathrm{C}$, Fondevila $\mathrm{F}$, et al. Melatonin as an antitumor agent against liver cancer: an updated systematic review. Antioxidants (Basel). 2021;10(1):103. doi:10.3390/antiox10010103

168. Elmahallawy EK, Mohamed Y, Abdo W, Yanai T. Melatonin and mesenchymal stem cells as a key for functional integrity for liver cancer treatment. Int J Mol Sci. 2020;21(12):4521. doi:10.3390/ ijms 21124521

169. Mi L, Kuang H. Melatonin regulates cisplatin resistance and glucose metabolism through Hippo signaling in hepatocellular carcinoma cells. Cancer Manag Res. 2020;12:1863-1874. doi:10.2147/cmar.S230466

170. Sato K, Meng F, Francis H, et al. Melatonin and circadian rhythms in liver diseases: functional roles and potential therapies. J Pineal Res. 2020;68(3):e12639. doi:10.1111/ jpi.12639

171. Muñoz N, Castellsagué X, de González AB, Gissmann L. Chapter 1: HPV in the etiology of human cancer. Vaccine. 2006;24(Suppl 3):S3/1-10. doi:10.1016/j.vaccine.2006.05.115

172. Saavedra KP, Brebi PM, Roa JC. Epigenetic alterations in preneoplastic and neoplastic lesions of the cervix. Clin Epigenetics. 2012;4(1):13. doi:10.1186/1868-7083-4-13

173. Grin W, Grünberger W. A significant correlation between melatonin deficiency and endometrial cancer. Gynecol Obstet Invest. 1998;45(1):62-65. doi:10.1159/000009926

174. Karasek M, Kowalski AJ, Zylinska K. Serum melatonin circadian profile in women suffering from the genital tract cancers. Neuro Endocrinol Lett. 2000;21(2):109-113.

175. Karasek M, Szuflet A, Chrzanowski W, Zylinska K, Swietoslawski J. Decreased melatonin nocturnal concentrations in hemodialyzed patients. Neuro Endocrinol Lett. 2005;26 (6):653-656.

176. Anisimov VN, Zabezhinski MA, Popovich IG, et al. Inhibitory effect of melatonin on 7, 12-dimethylbenz[a] anthracene-induced carcinogenesis of the uterine cervix and vagina in mice and mutagenesis in vitro. Cancer Lett. 2000;156(2):199-205. doi:10.1016/s0304-3835(00)00463-8

177. Chen LD, Leal BZ, Reiter RJ, et al. Melatonin's inhibitory effect on growth of ME-180 human cervical cancer cells is not related to intracellular glutathione concentrations. Cancer Lett. 1995;91 (2):153-159. doi:10.1016/0304-3835(95)03745-i

178. Pariente R, Pariente JA, Rodríguez AB, Espino J. Melatonin sensitizes human cervical cancer HeLa cells to cisplatin-induced cytotoxicity and apoptosis: effects on oxidative stress and DNA fragmentation. J Pineal Res. 2016;60(1):55-64. doi:10.1111/ jpi. 12288

179. Pariente R, Bejarano I, Espino J, Rodríguez AB, Pariente JA. Participation of MT3 melatonin receptors in the synergistic effect of melatonin on cytotoxic and apoptotic actions evoked by chemotherapeutics. Cancer Chemother Pharmacol. 2017;80 (5):985-998. doi:10.1007/s00280-017-3441-3

180. Zhao Q, Wang W, Cui J. Melatonin enhances TNF- $\alpha$-mediated cervical cancer HeLa cells death via suppressing CaMKII/Parkin/ mitophagy axis. Cancer Cell Int. 2019;19:58. doi:10.1186/ s12935-019-0777-2

181. Wang M, Xue Y, Shen L, et al. Inhibition of SGK1 confers vulnerability to redox dysregulation in cervical cancer. Redox Biol. 2019;24:101225. doi:10.1016/j.redox.2019.101225
182. Chen L, Liu L, Li Y, Gao J. Melatonin increases human cervical cancer HeLa cells apoptosis induced by cisplatin via inhibition of JNK/Parkin/mitophagy axis. In Vitro Cell Dev Biol Anim. 2018;54 (1):1-10. doi:10.1007/s11626-017-0200-z

183. Zare H, Shafabakhsh R, Reiter RJ, Asemi Z. Melatonin is a potential inhibitor of ovarian cancer: molecular aspects. $J$ Ovarian Res. 2019;12(1):26. doi:10.1186/s13048-019-05028

184. Nogueira LM, Sampson JN, Chu LW, et al. Individual variations in serum melatonin levels through time: implications for epidemiologic studies. PLoS One. 2013;8(12):e83208. doi:10.1371/ journal.pone.0083208

185. Seely D, Wu P, Fritz H, et al. Melatonin as adjuvant cancer care with and without chemotherapy: a systematic review and meta-analysis of randomized trials. Integr Cancer Ther. 2012;11 (4):293-303. doi:10.1177/1534735411425484

186. Poole EM, Schernhammer E, Mills L, Hankinson SE, Tworoger SS. Urinary melatonin and risk of ovarian cancer. Cancer Causes Control. 2015;26(10):1501-1506. doi:10.1007/ s10552-015-0640-2

187. Lissoni P, Ardizzoia A, Barni S, Tancini G, Muttini M. Immunotherapy with subcutaneous low dose interleukin-2 plus melatonin as salvage therapy of heavily chemotherapy-pretreated ovarian cancer. Oncol Rep. 1996;3(5):947-949. doi:10.3892/or.3.5.947

188. Lissoni P, Paolorossi F, Tancini G, et al. A phase II study of tamoxifen plus melatonin in metastatic solid tumour patients. Br J Cancer. 1996;74(9):1466-1468. doi:10.1038/ bjc. 1996.566

189. Kim JH, Jeong SJ, Kim B, Yun SM, Choi DY, Kim SH. Melatonin synergistically enhances cisplatin-induced apoptosis via the dephosphorylation of ERK/p90 ribosomal S6 kinase/heat shock protein 27 in SK-OV-3 cells. J Pineal Res. 2012;52 (2):244-252. doi:10.1111/j.1600-079X.2011.00935.x

190. Chuffa LG, Fioruci-Fontanelli BA, Mendes LO, et al. Melatonin attenuates the TLR4-mediated inflammatory response through MyD88- and TRIF-dependent signaling pathways in an in vivo model of ovarian cancer. BMC Cancer. 2015;15:34. doi:10.1186/ s12885-015-1032-4

191. Ganji R, Nabiuni M, Faraji R. Development of mouse preantral follicle after in vitro culture in a medium containing melatonin. Cell J. 2015;16(4):546-553. doi:10.22074/cellj.2015.499

192. Unver N, McAllister F. IL-6 family cytokines: key inflammatory mediators as biomarkers and potential therapeutic targets. Cytokine Growth Factor Rev. 2018;41:10-17. doi:10.1016/j. cytogfr.2018.04.004

193. Chuffa LG, Alves MS, Martinez M, et al. Apoptosis is triggered by melatonin in an in vivo model of ovarian carcinoma. Endocr Relat Cancer. 2016;23(2):65-76. doi:10.1530/erc-15-0463

194. Shen CJ, Chang CC, Chen YT, Lai CS, Hsu YC. Melatonin suppresses the growth of ovarian cancer cell lines (OVCAR-429 and PA-1) and potentiates the effect of G1 arrest by targeting CDKs. Int J Mol Sci. 2016;17(2):176. doi:10.3390/ ijms 17020176

195. Jang H, Lee $\mathrm{OH}$, Lee $\mathrm{Y}$, et al. Melatonin prevents cisplatin-induced primordial follicle loss via suppression of PTEN/AKT/FOXO3a pathway activation in the mouse ovary. $J$ Pineal Res. 2016;60(3):336-347. doi:10.1111/jpi.12316

196. Zonta YR, Martinez M, Camargo IC, et al. Melatonin reduces angiogenesis in serous papillary ovarian carcinoma of ethanol-preferring rats. Int $J$ Mol Sci. 2017;18(4):763. doi:10.3390/ijms 18040763

197. Jang H, Na Y, Hong K, et al. Synergistic effect of melatonin and ghrelin in preventing cisplatin-induced ovarian damage via regulation of FOXO3a phosphorylation and binding to the p27Kip1 promoter in primordial follicles. J Pineal Res. 2017;63(3): e12432. doi:10.1111/jpi.12432 
198. Akbarzadeh M, Movassaghpour AA, Ghanbari H, et al. The potential therapeutic effect of melatonin on human ovarian cancer by inhibition of invasion and migration of cancer stem cells. $\mathrm{Sci}$ Rep. 2017;7(1):17062. doi:10.1038/s41598-017-16940-y

199. Bu S, Wang Q, Sun J, Li X, Gu T, Lai D. Melatonin suppresses chronic restraint stress-mediated metastasis of epithelial ovarian cancer via NE/AKT/ $\beta$-catenin/SLUG axis. Cell Death Dis. 2020;11(8):644. doi:10.1038/s41419-020-02906-y

200. García-Navarro A, González-Puga C, Escames G, et al. Cellular mechanisms involved in the melatonin inhibition of HT-29 human colon cancer cell proliferation in culture. J Pineal Res. 2007;43 (2):195-205. doi:10.1111/j.1600-079X.2007.00463.x

201. Folkman J. Tumor angiogenesis. In: The Molecular Basis of Cancer. 1995:76.

202. Cao Y. Tumor angiogenesis and therapy. Biomed Pharmacother. 2005;59:S340-S343. doi:10.1016/S0753-3322(05)80070-8

203. Colombo J, Maciel JM, Ferreira LC, Da Silva RF, Zuccari DA. Effects of melatonin on HIF- $1 \alpha$ and VEGF expression and on the invasive properties of hepatocarcinoma cells. Oncol Lett. 2016;12 (1):231-237. doi:10.3892/ol.2016.4605

204. Cerezo AB, Hornedo-Ortega R, Álvarez-fernández MA, Troncoso AM, García-Parrilla MC. Inhibition of VEGF-induced VEGFR-2 activation and HUVEC migration by melatonin and other bioactive indolic compounds. Nutrients. 2017;9(3):249. doi:10.3390/nu9030249

205. Kim M, Park HJ, Seol JW, et al. VEGF-A regulated by progesterone governs uterine angiogenesis and vascular remodelling during pregnancy. EMBO Mol Med. 2013;5(9):1415-1430. doi:10.1002/emmm.201302618

206. Lv D, Cui PL, Yao SW, Xu YQ, Yang ZX. Melatonin inhibits the expression of vascular endothelial growth factor in pancreatic cancer cells. Chin J Cancer Res. 2012;24(4):310-316. doi:10.3978/j.issn.1000-9604.2012.09.03

207. Fischer TW, Zmijewski MA, Wortsman J, Slominski A. Melatonin maintains mitochondrial membrane potential and attenuates activation of initiator (casp-9) and effector caspases (casp-3/casp-7) and PARP in UVR-exposed HaCaT keratinocytes. $J$ Pineal Res. 2008;44(4):397-407. doi:10.1111/j.1600079X.2007.00542.x

208. Sánchez-Hidalgo M, Lee M, de la Lastra CA, Guerrero JM, Packham G. Melatonin inhibits cell proliferation and induces caspase activation and apoptosis in human malignant lymphoid cell lines. J Pineal Res. 2012;53(4):366-373. doi:10.1111/j.1600079X.2012.01006.x

209. Mełen-Mucha G, Winczyk K, Pawlikowski M. Somatostatin analogue octreotide and melatonin inhibit bromodeoxyuridine incorporation into cell nuclei and enhance apoptosis in the transplantable murine colon 38 cancer. Anticancer Res. 1998;18 (5a):3615-3619.

210. Di Bella G, Mascia F, Gualano L, Di Bella L. Melatonin anticancer effects: review. Int J Mol Sci. 2013;14(2):2410-2430. doi:10.3390/ijms14022410

211. Sánchez-Sánchez AM, Martín V, García-Santos G, et al. Intracellular redox state as determinant for melatonin antiproliferative vs cytotoxic effects in cancer cells. Free Radic Res. 2011;45(11-12):1333-1341. doi:10.3109/10715762.2011.623700

212. Yun SM, Woo SH, Oh ST, et al. Melatonin enhances arsenic trioxide-induced cell death via sustained upregulation of Redd1 expression in breast cancer cells. Mol Cell Endocrinol. 2016;422:64-73. doi:10.1016/j.mce.2015.11.016

213. Jung JH, Sohn EJ, Shin EA, et al. Melatonin suppresses the expression of $45 \mathrm{~S}$ preribosomal RNA and upstream binding factor and enhances the antitumor activity of puromycin in MDA-MB-231 breast cancer cells. Evid Based Complement Alternat Med. 2013;2013:879746. doi:10.1155/2013/879746
214. Mocchegiani E, Perissin L, Santarelli L, et al. Melatonin administration in tumor-bearing mice (intact and pinealectomized) in relation to stress, zinc, thymulin and IL-2. Int J Immunopharmacol. 1999;21(1):27-46. doi:10.1016/s01920561(98)00067-8

215. Hu S, Shen G, Yin S, Xu W, Hu B. Melatonin and tryptophan circadian profiles in patients with advanced non-small cell lung cancer. $A d v$ Ther. 2009;26(9):886-892. doi:10.1007/s12325-009-0068-8

216. Mazzoccoli G, Carughi S, De Cata A, La Viola M, Vendemiale G. Melatonin and cortisol serum levels in lung cancer patients at different stages of disease. Med Sci Monit. 2005;11(6):Cr284288.

217. Fic M, Podhorska-Okolow M, Dziegiel P, et al. Effect of melatonin on cytotoxicity of doxorubicin toward selected cell lines (human keratinocytes, lung cancer cell line A-549, laryngeal cancer cell line Hep-2). In Vivo. 2007;21(3):513-518.

218. Maestroni GJ, Covacci V, Conti A. Hematopoietic rescue via T-cell-dependent, endogenous granulocyte-macrophage colony-stimulating factor induced by the pineal neurohormone melatonin in tumor-bearing mice. Cancer Res. 1994;54 (9):2429-2432

219. Lu JJ, Fu L, Tang Z, et al. Melatonin inhibits AP-2 $\beta /$ hTERT, NF$\kappa \mathrm{B} / \mathrm{COX}-2$ and $\mathrm{Akt} / \mathrm{ERK}$ and activates caspase/Cyto $\mathrm{C}$ signaling to enhance the antitumor activity of berberine in lung cancer cells. Oncotarget. 2016;7(3):2985-3001. doi:10.18632/oncotarget.6407

220. Lissoni P, Brivio F, Fumagalli L, et al. Neuroimmunomodulation in medical oncology: application of psychoneuroimmunology with subcutaneous low-dose IL-2 and the pineal hormone melatonin in patients with untreatable metastatic solid tumors. Anticancer Res. 2008;28(2b):1377-1381.

221. Norsa A, Martino V. Somatostatin, retinoids, melatonin, vitamin $\mathrm{D}$, bromocriptine, and cyclophosphamide in chemotherapy-pretreated patients with advanced lung adenocarcinoma and low performance status. Cancer Biother Radiopharm. 2007;22(1):50-55. doi:10.1089/cbr.2006.365

222. Lissoni P, Paolorossi F, Ardizzoia A, et al. A randomized study of chemotherapy with cisplatin plus etoposide versus chemoendocrine therapy with cisplatin, etoposide and the pineal hormone melatonin as a first-line treatment of advanced non-small cell lung cancer patients in a poor clinical state. J Pineal Res. 1997;23 (1):15-19. doi:10.1111/j.1600-079x.1997.tb00329.x

223. Cos S, González A, Martínez-Campa C, Mediavilla MD, AlonsoGonzález C, Sánchez-Barceló EJ. Estrogen-signaling pathway: a link between breast cancer and melatonin oncostatic actions. Cancer Detect Prev. 2006;30(2):118-128. doi:10.1016/j. cdp.2006.03.002

224. Molis TM, Spriggs LL, Hill SM. Modulation of estrogen receptor mRNA expression by melatonin in MCF-7 human breast cancer cells. Mol Endocrinol. 1994;8(12):1681-1690. doi:10.1210/ mend.8.12.7708056

225. Korkmaz A, Tamura H, Manchester LC, Ogden GB, Tan D-X, Reiter RJ. Combination of melatonin and a peroxisome proliferator-activated receptor- $\gamma$ agonist induces apoptosis in a breast cancer cell line. J Pineal Res. 2009;46(1):115-116. doi:10.1111/ j.1600-079X.2008.00635.x

226. Kisková T, Ekmekcioglu C, Garajová M, et al. A combination of resveratrol and melatonin exerts chemopreventive effects in $\mathrm{N}$-methyl-N-nitrosourea-induced rat mammary carcinogenesis. Eur J Cancer Prev. 2012;21(2):163-170. doi:10.1097/ CEJ.0b013e32834c9c0f

227. Mao L, Yuan L, Slakey LM, Jones FE, Burow ME, Hill SM. Inhibition of breast cancer cell invasion by melatonin is mediated through regulation of the p38 mitogen-activated protein kinase signaling pathway. Breast Cancer Res. 2010;12(6):R107. doi:10.1186/bcr2794 
228. Koşar PA, Nazıroğlu M, Övey İS, Çiğ B. Synergic effects of doxorubicin and melatonin on apoptosis and mitochondrial oxidative stress in MCF-7 breast cancer cells: involvement of TRPV1 channels. J Membr Biol. 2016;249(1-2):129-140. doi:10.1007/s00232-015-9855-0

229. Debeljuk L, Feder VM, Paulucci OA. Effects of melatonin on changes induced by castration and testosterone in sexual structures of male rats. Endocrinology. 1970;87(6):1358-1360. doi:10.1210/endo-87-6-1358

230. Lupowitz Z, Zisapel N. Hormonal interactions in human prostate tumor LNCaP cells. J Steroid Biochem Mol Biol. 1999;68(1-2):83-88. doi:10.1016/s0960-0760(98)00164-2

231. Jardim-Perassi BV, Arbab AS, Ferreira LC, et al. Effect of melatonin on tumor growth and angiogenesis in xenograft model of breast cancer. PLoS One. 2014;9(1):e85311. doi:10.1371/journal. pone. 0085311

232. Schwimmer H, Metzer A, Pilosof $\mathrm{Y}$, et al. Light at night and melatonin have opposite effects on breast cancer tumors in mice assessed by growth rates and global DNA methylation. Chronobiol Int. 2014;31(1):144-150. doi:10.3109/ 07420528.2013 .842925
233. Jung-Hynes B, Schmit TL, Reagan-Shaw SR, Siddiqui IA, Mukhtar H, Ahmad N. Melatonin, a novel Sirt1 inhibitor, imparts antiproliferative effects against prostate cancer in vitro in culture and in vivo in TRAMP model. J Pineal Res. 2011;50(2):140-149. doi:10.1111/j.1600-079X.2010.00823.x

234. Ferreira SG, Peliciari-Garcia RA, Takahashi-Hyodo SA, et al. Effects of melatonin on DNA damage induced by cyclophosphamide in rats. Braz J Med Biol Res. 2013;46(3):278-286. doi:10.1590/1414-431x20122230

235. Dauchy RT, Dauchy EM, Hanifin JP, et al. Effects of spectral transmittance through standard laboratory cages on circadian metabolism and physiology in nude rats. $J$ Am Assoc Lab Anim Sci. 2013;52(2):146-156.

236. Dauchy RT, Dauchy EM, Mao L, Belancio VP, Hill SM, Blask DE. A new apparatus and surgical technique for the dual perfusion of human tumor xenografts in situ in nude rats. Comp Med. 2012;62(2):99-108.

\section{Publish your work in this journal}

OncoTargets and Therapy is an international, peer-reviewed, open access journal focusing on the pathological basis of all cancers, potential targets for therapy and treatment protocols employed to improve the management of cancer patients. The journal also focuses on the impact of management programs and new therapeutic agents and protocols on patient perspectives such as quality of life, adherence and satisfaction. The manuscript management system is completely online and includes a very quick and fair peer-review system, which is all easy to use. Visit http://www.dovepress.com/ testimonials.php to read real quotes from published authors. 